\title{
Chemotherapy and radiotherapy for inoperable advanced pancreatic cancer (Review)
}

\author{
Yip D, Karapetis C, Strickland A, Steer CB, Goldstein D
}
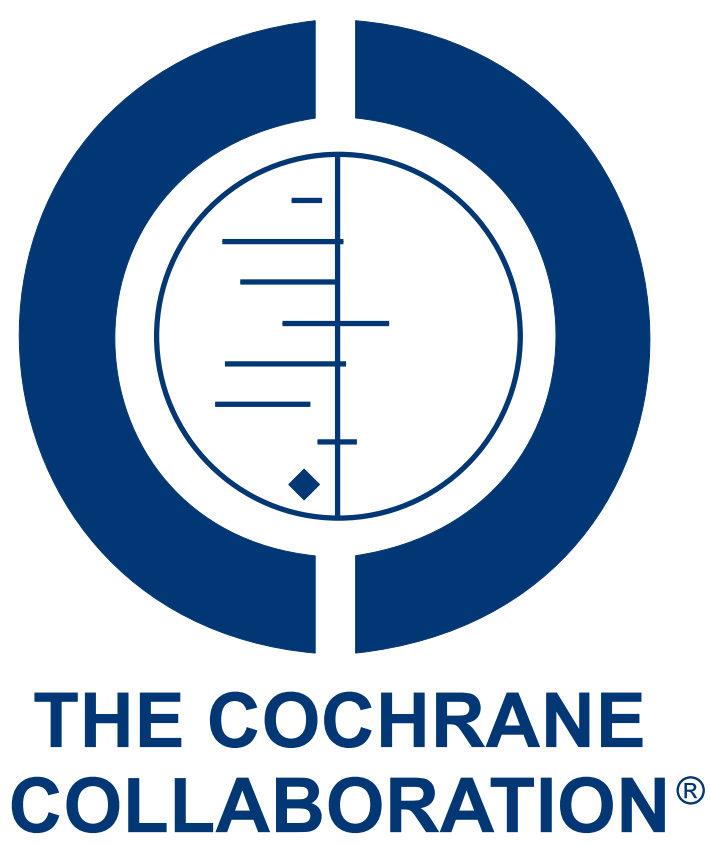

This is a reprint of a Cochrane review, prepared and maintained by The Cochrane Collaboration and published in The Cochrane Library 2007, Issue 1

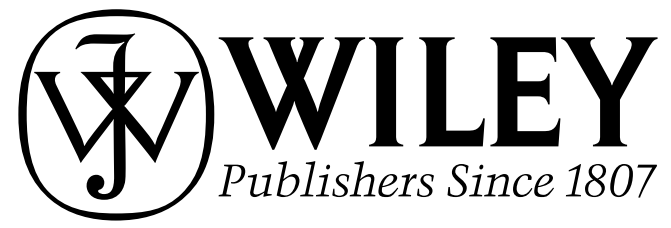

Chemotherapy and radiotherapy for inoperable advanced pancreatic cancer (Review)

Copyright $\odot 2007$ The Cochrane Collaboration. Published by John Wiley \& Sons, Ltd 
TABLE OF CONTENTS

ABSTRACT . . . . . . . . . . . . . . . . . . . . . . . . . . . . . . .

PLAIN LANGUAGE SUMMARY . . . . . . . . . . . . . . . . . . . . . . . . . . . . . . . . . . . . . . . . . . .

BACKGROUND . . . . . . . . . . . . . . . . . . . . . . . . . . . . . . . . . . . . . 2

OBJECTIVES . . . . . . . . . . . . . . . . . . . . . . . . . . . . . . . . . . . . . . . . . . . . . 2

CRITERIA FOR CONSIDERING STUDIES FOR THIS REVIEW . . . . . . . . . . . . . . . . . . . . . . . . . . .

SEARCH METHODS FOR IDENTIFICATION OF STUDIES . . . . . . . . . . . . . . . . . . . . . . . . . . . . 3

METHODS OF THE REVIEW . . . . . . . . . . . . . . . . . . . . . . . . . . . . . . . . . . . . . . . . . . . . . . c c 4

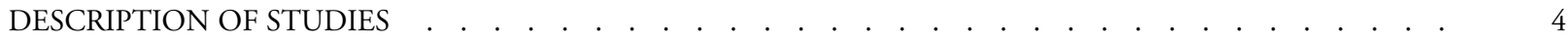

METHODOLOGICAL QUALITY . . . . . . . . . . . . . . . . . . . . . . . . . . . . . . . . . . . . . . .

RESUlTS . . . . . . . . . . . . . . . . . . . . . . . . . . . . . . . . . . . . . . . . 6

DISCUSSION . . . . . . . . . . . . . . . . . . . . . . . . . . . . . . . . . . . . . . . . 10

AUTHORS' CONCLUSIONS . . . . . . . . . . . . . . . . . . . . . . . . . . . . . . . . . . . . . . . . . . 11

POTENTIAL CONFLICT OF INTEREST . . . . . . . . . . . . . . . . . . . . . . . . . . . . . . . . . . . . . . . .

ACKNOWLEDGEMENTS . . . . . . . . . . . . . . . . . . . . . . . . . . . . . . . . . . . . . . . . 12

SOURCES OF SUPPORT . . . . . . . . . . . . . . . . . . . . . . . . . . . . . . . . . . . . . 12

REFERENCES . . . . . . . . . . . . . . . . . . . . . . . . . . . . . . . . . . . . . . . . 12

TABLES . . . . . . . . . . . . . . . . . . . . . . . . . . . . . . . . . . . . . . . . . . 20

Characteristics of included studies . . . . . . . . . . . . . . . . . . . . . . . . . . . . . . .

Characteristics of excluded studies . . . . . . . . . . . . . . . . . . . . . . . . . . . . . . . . . . . . . 4046

Characteristics of ongoing studies . . . . . . . . . . . . . . . . . . . . . . . . . . . . . . . . . . . . . . . . 48

ADDITIONAL TABLES . . . . . . . . . . . . . . . . . . . . . . . . . . . . . . . . . . . . . . . . . . . . . . . $\quad . \quad 56$

Table 01. Best supportive care versus chemotherapy trials for advanced pancreatic cancer . . . . . . . . . . . . . 56

Table 02. 5FU versus 5FU combination chemotherapy regimens . . . . . . . . . . . . . . . . . . . . . . . . . 57

Table 03. Gemcitabine versus gemcitabine combination chemotherapy regimens . . . . . . . . . . . . . . . 58

Table 04. Miscellaneous chemotherapy versus chemotherapy trials for pancreatic cancer . . . . . . . . . . . . 60

Table 05. Chemoradiotherapy trials in locally advanced pancreatic cancer . . . . . . . . . . . . . . . . 60

ANALYSES . . . . . . . . . . . . . . . . . . . . . . . . . . . . . . . . . . . . . . . . 61

Comparison 01. Chemotherapy versus best supportive care for advanced pancreatic cancer . . . . . . . . . . . 61

Comparison 02.5FU alone versus another chemotherapy agent . . . . . . . . . . . . . . . . . . . . . . . . 61

Comparison 03. 5FU alone versus 5FU chemotherapy combinations . . . . . . . . . . . . . . . . . . . . . . . . 61

Comparison 04. Gemcitabine versus another chemotherapy agent . . . . . . . . . . . . . . . . . . . . 61

Comparison 05. Gemcitabine versus gemcitabine chemotherapy combinations . . . . . . . . . . . . . . 61

INDEX TERMS . . . . . . . . . . . . . . . . . . . . . . . . . . . . . . . . . . . . . . 61

COVER SHEET

GRAPHS AND OTHER TABLES . . . . . . . . . . . . . . . . . . . . . . . . . . . . . . . . . . . . . . . . . . .

Figure 01. Funnel plot of chemotherapy versus best supportive care one year mortality . . . . . . . . . . . . . . 63

Figure 02. Funnel plot of six-month mortality in gemcitabine versus gemcitabine combination studies. . . . . . . 64

Analysis 01.01. Comparison 01 Chemotherapy versus best supportive care for advanced pancreatic cancer, Outcome 0165

Mortality at 6 months

Analysis 01.02. Comparison 01 Chemotherapy versus best supportive care for advanced pancreatic cancer, Outcome 02

Mortality at 12 months

Analysis 02.01. Comparison 02 5FU alone versus another chemotherapy agent, Outcome 01 Mortality at 6 months .

Analysis 02.02. Comparison 02 5FU alone versus another chemotherapy agent, Outcome 02 Mortality at 12 months

Analysis 03.01. Comparison 03 5FU alone versus 5FU chemotherapy combinations, Outcome 01 Mortality at 6 months

Analysis 03.02. Comparison 03 5FU alone versus 5FU chemotherapy combinations, Outcome 02 Mortality at 12 months

Analysis 04.01. Comparison 04 Gemcitabine versus another chemotherapy agent, Outcome 01 Mortality at 6 months Analysis 04.02. Comparison 04 Gemcitabine versus another chemotherapy agent, Outcome 02 Mortality at 12 months

Analysis 05.01. Comparison 05 Gemcitabine versus gemcitabine chemotherapy combinations, Outcome 01 Mortality at 
Analysis 05.02. Comparison 05 Gemcitabine versus gemcitabine chemotherapy combinations, Outcome 02 Mortality at

12 months . . . . . . . . . . . . . . . . . . . . . . . . . . . . . . . . . . . 


\title{
Chemotherapy and radiotherapy for inoperable advanced pancreatic cancer (Review)
}

\author{
Yip D, Karapetis C, Strickland A, Steer CB, Goldstein D
}

This record should be cited as:

Yip D, Karapetis C, Strickland A, Steer CB, Goldstein D. Chemotherapy and radiotherapy for inoperable advanced pancreatic cancer. Cochrane Database of Systematic Reviews 2006, Issue 3. Art. No.: CD002093. DOI: 10.1002/14651858.CD002093.pub2.

This version first published online: 19 July 2006 in Issue 3, 2006.

Date of most recent substantive amendment: 25 March 2006

\section{A B S T R A C T}

\section{Background}

Pancreatic cancer has a poor prognosis. The benefit of chemotherapy, radiotherapy or both as a palliative treatment of advanced or relapsed disease is uncertain.

\section{Objectives}

To assess the effects of chemotherapy and/or radiotherapy in the management of pancreatic adenocarcinoma in people with inoperable advanced disease.

\section{Search strategy}

We searched the Cochrane Central Register of Controlled Trials (CENTRAL), which includes the Cochrane Upper Gastrointestinal and Pancreatic Diseases (UGPD) Group Trials Register (The Cochrane Library 2005, Issue 1); CANCERLIT (1975-2002); MEDLINE (1966 to January 2005); and EMBASE (1980 to January 2005). We handsearched reference lists from trials revealed by electronic searches to identify further relevant trials. We searched published abstracts from relevant conference proceedings. We contacted colleagues and experts in the field, and asked them to provide details of outstanding clinical trials and any relevant unpublished materials.

\section{Selection criteria}

Randomised controlled trials (single- or double-blind) in patients with advanced inoperable pancreatic cancer, in which one of the intervention types (chemotherapy or radiotherapy) was contrasted with either placebo or another type of intervention. Studies comparing non-chemotherapy agents such as biological agents, hormones, immunostimulants, vaccines and cytokines were excluded.

Data collection and analysis

Studies were assessed for eligibility and quality. Data were extracted by groups of two independent reviewers, with conflicts resolved by a third reviewer. Study authors were contacted for more information.

\section{Main results}

Fifty trials (7043 participants) were included. Chemotherapy significantly reduced the one-year mortality (odds ratio (OR) $0.37,95 \%$ confidence interval (CI) 0.25 to 0.57 , P value $<0.00001$ ) when compared to best supportive care. Also, chemoradiation improved one year survival ( $0 \%$ versus $58 \%, \mathrm{P}$ value 0.001$)$ when compared to best supportive care. There was no significant difference in one-year mortality for $5 \mathrm{FU}$ alone versus $5 \mathrm{FU}$ combinations (OR $0.90,95 \% \mathrm{CI} 0.62$ to 1.30 ); single-agent chemotherapy versus gemcitabine (OR 1.34, 95\% CI 0.88 to 2.02, P value 0.17 ); or gemcitabine alone versus gemcitabine combinations (OR $0.88,95 \%$ CI 0.74 to 1.05 ). However, subgroup analysis showed that platinum-gemcitabine combinations reduced six-month mortality compared to gemcitabine alone (OR $0.59,95 \%$ CI 0.43 to 0.81 , P value 0.001 ). A qualitative overview suggested that chemoradiation produced better survivals than either best supportive care or radiotherapy. Chemoradiation treatment was associated with more toxicity.

\section{Authors' conclusions}

Chemotherapy appears to prolong survival in people with advanced pancreatic cancer and can confer clinical benefits and improve quality of life. Combination chemotherapy did not improve overall survival compared to single-agent chemotherapy. Gemcitabine is

Chemotherapy and radiotherapy for inoperable advanced pancreatic cancer (Review)

Copyright $\odot 2007$ The Cochrane Collaboration. Published by John Wiley \& Sons, Ltd 
an acceptable control arm for future trials investigating scheduling and combinations with novel agents. There is insufficient evidence to recommend chemoradiation in patients with locally advanced inoperable pancreatic cancer as a superior alternative to chemotherapy alone.

\section{PLAIN LANGUAGE S MMARY}

Chemotherapy and radiotherapy may improve survival and quality of life in people with advanced pancreatic cancer

Advanced pancreatic cancer is incurable. Symptoms affect quality of life, and life expectancy is reduced. This review investigated the effect of chemotherapy and radiotherapy on survival and symptoms, and found that having chemotherapy (compared to no chemotherapy) improved survival, and sometimes symptoms and quality of life. Chemotherapy using drug combinations did not improve life expectancy compared to treatment with individual drugs. Combining chemotherapy with radiotherapy is better, in terms of survival, for fit people (with inoperable pancreatic cancer, that has not spread to other organs), than radiotherapy alone, or no treatment. There is insufficient evidence of superior benefit of chemoradiation over chemotherapy alone.

\section{B A C K G R O U N D}

Pancreatic carcinoma is the eighth commonest cause of cancerrelated death worldwide, but the 13th most common tumour type (Parkin 2005). The reported incidence is higher in developed countries (pancreatic cancer is the fourth leading cause of cancer death in the US (Jemal 2005)), probably as a result of more accurate diagnosis, rather than aetiology (cause of disease) (Parkin 2005). Approximately $20 \%$ of people diagnosed with pancreatic carcinoma present with early disease, and are able to undergo resection (surgical treatment) with curative intent. However, after surgical resection, the risk of relapse is still high, with only $10 \%$ to $25 \%$ of people surviving for five years (Conlon 1996; Geer 1993; Shahrudin 1997; Trede 1990; Wagner 2004; Yeo 1997). More recent data suggest that outcomes may be improving over time. An overview of 100,313 pancreatic cancer patients reported to the National Cancer Database of the United States found a $23.4 \%$ five-year survival with pancreatectomy (removal of the pancreas), and $5.2 \%$ in those who had not received cancer-directed treatment (Sener 1999). In a retrospective population-based study of patients receiving treatment with curative intent in the US between 1991 and 1996, the three-year survival was 34\% (Lim 2003). Attempts at improving survival by targeting micrometastatic residual disease (microscopic secondary tumours) with adjuvant (additional) therapies have been trialed. An individual patient meta-analysis (Stocken 2005) and a large randomised study (Neoptolemos 2004) have suggested that adjuvant chemotherapy following surgical resection conferred a benefit, while chemoradiation was detrimental. The benefit of chemotherapy, radiotherapy, or the combination of both, as a palliative treatment for advanced or relapsed disease is uncertain. Response rates with chemotherapy agents tested have generally been low and the benefits must be weighed up against treatment-related toxicities.

\section{O B J E C T I VES}

The primary objective was to conduct a systematic review of the published and unpublished literature to assess the effect of chemotherapy, radiotherapy or combined chemoradiotherapy on overall survival in people with pancreatic carcinoma. We examined these effects in the setting of inoperable advanced (including locallyadvanced and metastatic) or relapsed disease. Adjuvant therapy for prevention of recurrence in curatively resected patients was not examined in this review.

Comparisons were as follows:

(1) Treatment modality against best supportive care or a no treatment arm.

(2) Comparisons between modalities or types of chemotherapy regimens against each other.

\section{CRITERIA FOR CONSIDERING STUDIES FOR THIS REVIEW}

\section{Types of studies}

Randomised controlled trials with a single-blind or double blind design, in which one of the intervention types (chemotherapy or radiotherapy) was contrasted with either placebo or another type of intervention. Both published and unpublished studies were identified and assessed for inclusion.

\section{Types of participants}

Patients with a diagnosis of pancreatic adenocarcinoma established by either histological or cytological findings (investigations on body tissue or cells).

Trials enrolling patients with advanced locally-advanced/unresectable and recurrent disease (testing "palliative or non-curative chemotherapy") were eligible for inclusion. 


\section{Types of intervention}

Chemotherapy

Eligible interventions included both single-agent and combination chemotherapy. Chemotherapy with all cytotoxic or antineoplastic drug treatments, but excluding hormonal and biological therapies (e.g. interferon, somatostatin), was eligible regardless of dose or schedule.

\section{Radiotherapy}

Eligible interventions included external-beam radiotherapy (cobalt source and megavoltage external-beam) and brachytherapy (radioactive materials placed in direct contact with tissue being treated).

Combined chemoradiotherapy

Concurrent or sequential administration of chemotherapy and radiotherapy.

Best supportive care

Best supportive care in advanced disease is defined as anything other than chemotherapy, and may include symptom control by radiotherapy (not to the primary site), palliative surgery, biliary stent insertion, analgesia, blood transfusion and psychological/ social support.

\section{Types of outcome measures}

The primary outcome measure was duration of overall survival on an intention-to-treat analysis measured by the median survival time and one-year survival rate. Secondary outcomes of interest were survival rate at six months, time to progression, overall tumour response, and quality of life or clinical benefit measurements.

\section{SEARCH METHODSFOR IDENTIFICATIONOF STUDIES}

See: Cochrane Upper Gastrointestinal \& Pancreatic Diseases Group methods used in reviews.

The authors aimed to complete searches that would identify all relevant published and unpublished randomised controlled trials. Articles published in any language were eligible for inclusion. Trials were identified by searching the following electronic databases - The Cochrane Central register of Controlled Trials - CENTRAL (which includes the Cochrane Upper Gastrointestinal and Pancreatic Diseases Group Trials Register) on The Cochrane Library (Issue 1 2005) MEDLINE (1966 to January 2005) and EMBASE (1980 to January 2005). Searches were also conducted on CANCERLIT from 1999 to 2002. Subsequent searches have not been undertaken as the database has been merged into PUB MED from 2002 onwards.

To identify randomized controlled trials, the following search was combined with the Cochrane highly sensitive search strategy phases one, two and three as contained in the Reviewer's Handbook (Higgins 2005).
MEDLINE search strategy

exp pancreas/

pancrea\$.tw.

exp pancreatic neoplasms/

(pancrea\$ adj5 neoplasm\$).tw.

(pancrea $\$$ adj5 cancer\$).tw.

(pancrea $\$$ adj5 carcinoma\$).tw.

(resect\$ adj5 pancrea\$).tw.

exp pancreatectomy/

exp Pancreaticoduodenectomy/

or/30-38

exp drug therapy/

exp chemotherapy adjuvant/

chemotherap\$.tw.

chemoradiotherap\$.tw.

(combin\$ adj5 chemotherap\$).tw.

(concurrent adj5 chemoradiotherap\$).tw.

(preoperative adj5 chemotherap\$).tw.

(postoperative adj5 chemotherap\$).tw.

or/40-47

(best adj3 supportive adj3 care).tw.

(palliat\$ adj5 surg\$).tw.

or/49-50

exp radiotherapy/

exp radiotherapy adjuvant/

radiotherapy.tw.

(postoperative adj5 radiotherapy).tw.

(preoperative adj5 radiotherapy).tw.

exp drug therapy combination/

or $/ 52-57$

48 or 51 or 58

39 and 59

29 and 60

Reference lists from trials and review articles selected by electronic searching were handsearched to identify further relevant trials. Published abstracts from the following conference proceedings were handsearched:

American Gastroenterological Association (AGA) 1994-2004.

American Society of Clinical Oncology (ASCO) 1996-2005.

American Association of Cancer Research (AACR) 1957-2004.

American Pancreatic Association (APA) 2001-2004.

Digestive Disease Week (DDW) 1994-2004.

European Cancer Conference (ECCO) 1997, 1999, 2001, 2003.

European Society of Medical Oncology (ESMO) 1998, 2000,

2002, 2004.

European Pancreatic Club (EPC) 2000-2004.

United European Gastroenterology Week (UEGF) 1960-2005.

The following information resources were also searched:

National Cancer Institute Physician Data Query

UK Co-ordinating Committee on Cancer Research and National

Clinical Trials Registry: Cancer Trials (Australia)

National Research Register

Medical Research Council 
Clinicaltrials.gov

Current Controlled Trials

Trialscentral

Center Watch

World Wide Web search using Internet search engine Google. In addition, we contacted members of the Cochrane Upper Gastrointestinal and Pancreatic Diseases Group, and experts in the field, and asked them to provide details of outstanding clinical trials and any relevant unpublished materials that were known to them.

\section{METHODS OF THE REVIEW}

Trial selection and quality assessment

Trials were selected for inclusion by pairs of independent authors (CK and DG, AS and CS), with disagreements resolved by a third author (DY). Methodological quality was assessed independently by three authors using a standardised checklist to assess the degree to which each study minimised the potential for bias due to differences between treatment groups. Concealment, defined as the process used to prevent foreknowledge of group assignment, was graded. Methods of assignment such as date of birth and case record numbers (see quasi-random allocation) are open to manipulation and were considered inadequate. Methods of allocation concealment considered adequate included: centralised randomisation schemes; randomisation schemes controlled by a pharmacy; numbered or coded containers in which capsules from identical-looking, numbered bottles are administered sequentially; on-site computer systems, where allocations are in a locked unreadable file; and sequentially-numbered opaque, sealed envelopes. Data were extracted from published reports by pairs of reviewers using standardised forms, with disagreements resolved by discussion with the additional reviewer (DY). The authors were not blinded to the sources of data. We attempted to collect missing information, where possible, by contacting investigators involved with the studies. Individual patient data meta-analysis was not attempted.

\section{Statistical analyses}

Survival data were extracted by reading from the survival curves at six months and 12 months, by recording median survival times, and by recording published $\mathrm{P}$ values for comparisons of survival curves based on Mantel Cox log rank test, Cox model (univariate) or similar statistical tests. Data from individual trials were summarised by:

(1) comparing the median survival in the treatment arm to the median survival in the control arm;

(2) the reported P value for an unadjusted comparison of the survival curves; and,

(3) the odds ratios (OR) for one year survival rates for advanced disease.
Median survivals that could not be combined in a meta-analysis were recorded in a table and discussed in the text. Fixed-effect meta-analyses (Mantel-Haenszel) were used to pool results for survival at six months and 12 months, where appropriate, as this method gave more weight to larger studies than smaller ones. Exploratory subgroup analysis was performed where comparator drugs were identical, or of the same class of chemotherapy agents.

Heterogeneity was assessed with chi-squared tests as well as funnel plots, and supplemented by the $\mathrm{I}^{2}$ test for inconsistency. Randomeffects models were also examined as part of sensitivity analysis. Analyses were based on intention-to-treat data, as far as allowed by the published data.

\section{DESCRIPTION OF STUDIES}

The literature review identified one published meta-analysis (Fung 2003). This Japanese language paper reviewed randomised trials published between 1974 and 2003 and identified 43 studies. However, the authors were not strict in excluding trials that were not prospectively randomised. As a result trials were included that used matched population controls, or in which treatment allocation was not properly randomised.

Fifty reported trials fulfilled the inclusion criteria and were included in our review. Nine of these reports were in the form of conference abstracts (Cheverton 2004; Heinemann 2003; Herrmann 2005; Levi 2004; Li 2004; O’Reilly 2004; Ohkawa 2004; Riess 2005; Stathopoulos 2005). For most of these, further details on the trials were obtained from the associated PowerPoint presentations or posters posted on the conference websites.

Fifty-eight trials identified through searching were not included in the review. Reasons for their exclusion are given in the Characteristics of excluded studies table. The included trials were divided into three groups for analysis:

Best supportive care versus chemotherapy in advanced pancreatic cancer

A number of studies examining best supportive care were excluded for the following reasons: one study did not present survival data (Klapdor 1982); two studies assessed patients who had not responded to prior chemotherapy (Jacobs 2004; Ulrich-Pur 2003); four trials compared best supportive care to the biological agents octreotide (Cascinu 1995), G17DT immunogen (Gilliam 2004), and gastrazole (Chau 2003) which were not within the scope of this review. A study (Shinchi 2002) of best supportive care versus chemoradiotherapy is discussed in the section on radiotherapy with or without chemotherapy for locally-advanced disease.

Eight studies compared best supportive care to chemotherapy in advanced pancreatic carcinoma and met the inclusion criteria (Andersen 1981; Andren-Sandberg 1983; Frey 1981; Glimelius 1996; Huguier 2001; Mallinson 1980; Palmer 1994; Takada 1998). Best supportive care included surgical intervention (e.g. biliary bypass

Chemotherapy and radiotherapy for inoperable advanced pancreatic cancer (Review)

Copyright $\odot 2007$ The Cochrane Collaboration. Published by John Wiley \& Sons, Ltd 
or palliative resection) in some of the trials (Andersen 1981; Andren-Sandberg 1983; Frey 1981; Takada 1998). All patients had histological or cytological confirmation of pancreatic cancer except those in the Mallinson study (Mallinson 1980). Two trials included biliary tract cancers but separate data were available for the pancreatic cancer patients (Glimelius 1996; Takada 1998). The chemotherapy schedules used in the treatment arms were all 5-fluorouracil (5FU) combination regimens that included the cytotoxics BCNU (carmustine), CCNU (lomustine), vincristine, adriamycin, etoposide and mitomycin C. All trials enrolled both locally-advanced (inoperable cancer that has not spread to other organs) and metastatic (cancer that has spread to other organs) pancreatic cancer patients.

Quality of life (QOL) was measured in several studies. Mallinson (Mallinson 1980) scored symptoms of pain, nausea, stool frequency, hair loss and analgesic requirement on the basis of severity. Patients also rated their own well-being and body weight. AndrenSandberg (Andren-Sandberg 1983) assessed QOL by means of the Karnofsky performance score, and Anderson (Andersen 1981) by an estimate calculated from number of hospital days, need for analgesia and rate of weight loss. Glimelius used the European Organisation for Research and Treatment of Cancer (EORTC) QLC C30 questionnaire (Glimelius 1996), while Palmer (Palmer 1994) used the Hospital Anxiety and Depression (HAD) questionnaire to measure psychological status. Takada (Takada 1998) measured 'clinical effects' by changes in performance status and body weight.

Comparative studies of chemotherapy in advanced pancreatic cancer

(1) 5-fluorouracil (5FU) versus another chemotherapy

One trial that compared 5FU with a biological agent, gastrazole (Chau 2003), was excluded. Four studies compared single-agent 5FU with another single chemotherapy agent. These drugs were BCNU (Kovach 1974), gemcitabine (Burris 1997; Cantore 2004) and oxaliplatin (Ducreux 2004). The Kovach and Ducreux trials also had third arms that compared the combination of the two drugs being tested, and both had early closure of one or more of the arms due to inferior results at interim analysis. Infusional $5 \mathrm{FU}$ was used in the Ducreux trial, and bolus dosing in the other three. $5 \mathrm{FU}$ was modulated with leucovorin in the Cantore trial. Clinical benefit response was measured in the Burris, Cantore and Ducreux trials. Clinical benefit was defined as a composite endpoint of pain, performance status and weight loss.

\section{(2) 5-fluorouracil versus 5-fluorouracil-based combinations}

One study (Takada 1994) was excluded as it combined pancreatic and biliary cancer patients and separate results could not be obtained for each group. There were seven included trials that compared 5FU alone with 5FU chemotherapy combinations (Cullinan 1985a; Cullinan 1990a; Ducreux 2002; Ducreux 2004; Kovach 1974; Levi 2004; Maisey 2002). Three of the trials enrolled patients with gastric (Cullinan 1985a; Kovach 1974) and ampullary cancers (Ducreux 2002), but data on pancreatic cancer patients were available separately. All patients had pathological confirmation of pancreatic cancer except for the Ducreux 2002 trial, which enrolled eight patients without this confirmation. The Kovach trial was conducted before CT scanning became available and enrolled 33 patients whose histology of metastases, clinical presentation and negative barium studies were suggestive of pancreatic cancer. Survival data could not be obtained, so these patients were excluded from the analyses. Patients with locally-advanced and metastatic disease were enrolled in all of these studies.

Two of the trials (Cullinan 1985a; Cullinan 1990a) ran two comparative combination chemotherapy arms. The Kovach trial (Kovach 1974) compared $5 \mathrm{FU}$ to single-agent $\mathrm{BCNU}$ as well as $5 \mathrm{FU}$ in combination with BCNU. The Ducreux 2004 study (Ducreux 2004) compared 5FU to a single agent, oxaliplatin, as well as 5FU plus oxaliplatin. Three studies used infusional 5FU as the control (Ducreux 2004; Levi 2004; Maisey 2002); the rest used bolus 5FU. These three studies also used protracted infusional 5FU in the comparative combination arms with mitomycin $\mathrm{C}$, cisplatin and oxaliplatin, respectively, as did Ducreux (Ducreux 2002) with cisplatin. The Levi study (Levi 2004) also incorporated a randomisation between constant and chronomodulated administration of escalating dose 5FU. Two trials (Ducreux 2002; Maisey 2002) measured quality of life, while another assessed clinical benefit response (Ducreux 2004).

\section{(3) Gemcitabine versus other chemotherapy}

Three trials were excluded because they compared gemcitabine to the biological agents BAY 12-9566 (Moore 2003), marimastat (Bramhall 2001), and imatinib mesylate (Chen 2006). Four randomised trials were included in this group. These trials compared gemcitabine to 5FU (Burris 1997), 5FU/folinic acid (Cantore 2004), exatecan (Cheverton 2004) and NSC-631570 (Gansauge 2002).

The Cantore study had two comparator arms against gemcitabine: FLEC (fluorouracil, leucovorin, epirubicin and carboplatin) which was administered intra-arterially and 5FU/leucovorin given intravenously. The 5FU/leucovorin arm terminated early and was not reported in the two associated publications (Cantore 2004). Unpublished individual patient data were obtained from the principal author and analysis was performed. The Gansauge trial (Gansauge 2002) was also a three-armed trial incorporating a combination arm of gemcitabine and NSC-631570. All four trials enrolled both locally-advanced and metastatic pancreatic cancer patients and also assessed clinical benefit response.

(4) Gemcitabine versus gemcitabine combination chemotherapy Sixteen studies were identified in this group (Berlin 2002; Colucci 2002; Gansauge 2002; Heinemann 2003; Herrmann 2005; Li 2004; Louvet 2005; O’Reilly 2004; Ohkawa 2004; Reni 2005; Oettle 2005b; Riess 2005; Rocha Lima 2004; Scheithauer 2003; Stathopoulos 2005; Wang 2002). Seven of these were final pub- 
lications (Berlin 2002; Colucci 2002; Louvet 2005; Reni 2005; Rocha Lima 2004; Scheithauer 2003; Wang 2002; Wang 2002) and the rest were conference abstracts.

Seven studies were excluded because they compared the addition of the following biological agents to gemcitabine: SCH 66336 (Lersch 2001), marimastat (Bramhall 2002), C1-994 (Richards 2002), tipifarnib (Van Cutsem 2004), BAY 12-9566 (Moore 2003), G17DT immunogen (Shapiro 2005), and erlotinib (Moore 2005).

All studies except the Scheithauer study, which included only metastatic patients (Scheithauer 2003), enrolled both locally-advanced and metastatic pancreatic cancer patients. The Gansauge trial (Gansauge 2002) included only two locally-advanced pancreatic cancer patients. The control arm of most of the studies used either the Burris regimen (intravenous gemcitabine $1000 \mathrm{mg} / \mathrm{m}^{2}$ over 30 minutes) weekly for seven weeks out of the first eight and then three out of four weeks, or weekly for three weeks out of four from the start. The Scheithauer trial used a biweekly schedule of high dose gemcitabine $\left(2200 \mathrm{mg} / \mathrm{m}^{2}\right)$, while Stathopoulos (Stathopoulos 2005) used a three-out-of-four week schedule of gemcitabine $\left(900 \mathrm{mg} / \mathrm{m}^{2}\right)$. The gemcitabine dose or scheduling varied in the test arm in several trials. Rocha Lima (Rocha Lima 2004) and Stathopoulos (Stathopoulos 2005) both used a two out of three week schedule with irinotecan; Louvet (Louvet 2005) used a fortnightly schedule of fixed dose rate gemcitabine as described by Tempero (Tempero 2003) given in combination with the oxaliplatin; Reni (Reni 2005) used $600 \mathrm{mg} / \mathrm{m}^{2}$ of gemcitabine to allow it to be combined with three other cytotoxics; and Richards (Oettle 2005b) used a higher dose of $1250 \mathrm{mg} / \mathrm{m}^{2}$ given in a two out of three schedule in combination with pemetrexed. Four of the trials (Colucci 2002; Heinemann 2003; Li 2004; Wang 2002) compared gemcitabine with gemcitabine-cisplatin.

(5) Other comparative chemotherapy trials

Six trials compared a variety of 5-fluorouracil based combinations (Bukowski 1983; Buroker 1979; Horton 1981; Kelsen 1991; Oster 1986; Topham 1991). All enrolled both locally-advanced and metastatic pancreatic cancer patients.

\section{Radiation therapy in locally advanced pancreatic cancer}

Ten randomised trials were identified in this group (Childs 1965; Earle 1994; GITSG 1985b; GITSG 1988; Hazel 1981; Klaassen 1985; Li 2003; Moertel 1969; Moertel 1981; Shinchi 2002). Two trials were excluded: one because it utilised a radiosensitizer (PR-350), rather than a cytotoxic chemotherapy agent (Sunamura 2004), and the other (McCracken 1980) because it tested a hormonal agent (testolactone) combined with chemoradiotherapy.

\section{METHODOLOGICALQUALITY}

The quality of randomisation was assessed according to method of generation, and concealment, of the allocation sequence. Grade A was awarded for trials where these were clearly adequate, grade $\mathrm{B}$ where these were possibly adequate, and $\mathrm{C}$ where these were clearly inadequate (see Characteristics of included studies table). It was not possible to assess accurately the quality of randomisation used in most studies, due to the lack of information in the published articles. Only three studies utilised a placebo control (Andersen 1981; Childs 1965; Moertel 1969). The Andersen trial was placebo-controlled and triple-blinded (doctor, patient and pharmacist blinded to treatment allocation).

Description and meta-analysis was restricted to those trials from which suitable data could be extracted. Tumour measurements in some early studies were by clinical measurements only because of the unavailability of computed tomography. More recent studies have used World Health Organization (WHO) and response evaluation criteria in solid tumours (RECIST) objective radiological criteria for determining response. Response rates are listed as being percent of evaluable patients who achieved either partial or complete tumour response. Reporting of quality of life and clinical benefit response varied between the trials according to whether they were used as an endpoint, what instruments were used, the way they were analysed and compliance with assessments. It was not possible to analyse this quantitatively.

\section{RES U L T S}

\section{Chemotherapy versus best supportive care}

Mortality data at six and 12 months were obtained for seven of the eight studies (not available for Andren-Sandberg (Andren-Sandberg 1983) trial). Pooled data of mortality at 12 months for chemotherapy versus best supportive care resulted in an odds ratio (OR) of 0.37 ( $95 \%$ confidence interval (CI) 0.25 to 0.57 , P value $<0.00001)$ using the fixed-effect model. There was no evidence of serious heterogeneity (chi-squared test $P$ value 0.33 ) or inconsistency $\left(\mathrm{I}^{2}=12.6 \%\right)$. Pooled mortality at six months gave an OR of 0.46 (95\% CI 0.25 to 0.84 , P value 0.01 ). The chi-squared test for heterogeneity was significant at this timepoint (chi-squared $P$ value 0.02 ) and confirmed by $I^{2}=71.5 \%$. Sensitivity analysis was performed using a random-effects model and the findings remained significant, OR 0.35 (95\% CI 0.14-0.85, P value 0.02). On the forest plot, two studies (Mallinson 1980; Palmer 1994) lay to the very left of the plot with highly significant results in favour of chemotherapy, while two other trials lay to the right of the line of no difference with non-significant difference in favour of best supportive care. See Figure 01.

Mallinson found, in a non-parametric analysis of the clinical measurements, that the only difference between the two groups was in nausea, which was increased in treated patients. In the AndrenSanberg study, there was no difference in maintenance of Karnofsky performance status between arms of the study (Andren-Sandberg 1983), and no statistical difference in their quality of life 
measurement. Takada (Takada 1998) also did not observe any statistical difference in improvements in body weight or performance in both arms. Palmer found that people in the best supportive care arm of his study had similar levels of anxiety but were more depressed than those in the treatment arm. This difference persisted at two months. Quality of life measured in the Glimelius study (Glimelius 1996) using the EORTC QOL C30 questionnaire found statistically better scores in pain, fatigue, appetite and dyspnoea in the treatment group compared to best supportive care. Average quality- adjusted survival (another quantitative measure of quality of life whereby survival time is weighted by utility of quality of life experienced) was also longer.

These trials are summarised in Table 01.

\section{Comparative studies of chemotherapy in advanced pancreatic cancer}

(1) 5-fluorouracil versus another chemotherapy agent

The four studies provided mortality data at six and 12 months. Pooled data of mortality at six months for another chemotherapy agent versus 5-fluorouracil (5FU) resulted in OR 0.58 (95\% CI $0.37-0.92, \mathrm{P}$ value 0.02$)$ and at 12 months OR 0.67 (95\% CI $0.34-1.31, \mathrm{P}$ value 0.24$)$. Chi-squared tests for heterogeneity were not significant at these points ( $\mathrm{P}$ value $0.07, \mathrm{I} 2=57.9 \%$; and $\mathrm{P}$ value $0.06, \mathrm{I}^{2}=60 \%$, respectively).

The Kovach trial (Kovach 1974) randomised 31 patients to 5FU and 21 to BCNU with another 30 to the combination of both drugs. Overall response rates were not reported separately for each arm. Median survivals estimated from Kaplan Meier curves of $5 \mathrm{FU}$ compared with BCNU were 5.4 versus 5.1 months (no difference), with one-year survival being $10 \%$ and $23 \%$ respectively.

The Burris trial (Burris 1997) randomised 126 patients to receive either 5FU, as a weekly bolus, or treatment with gemcitabine. This found an improvement in median survival from 4.41 months to 5.65 months (P value 0.025 ), with the 12 -month survival being $2 \%$ and $18 \%$ respectively. However, the primary endpoint of the study was clinical benefit response, which was a composite of pain measurements (including analgesic consumption and pain intensity), Karnofsky performance status and weight. Of the patients in the gemcitabine arm $23.8 \%$ experienced an improvement in clinical benefit compared with $4.8 \%$ for the $5 \mathrm{FU}$ arm. Of the 56 gemcitabine patients with bidemensionally measurable disease on enrolment, three achieved objective tumour response (shrinkage of at least $50 \%$ of the product of bidimensional measurements on imaging) giving rise to a overall response rate of $5.4 \%$ compared to $0 \%$ for the 57 F FU patients with measurable disease. The Cantore study (Cantore 2004), which incorporated a 5FU/folinic acid and a gemcitabine arm, is discussed below in section (3).

The Ducreux trial (Ducreux 2004) randomised 15 patients to infusional 5FU, 17 patients to oxaliplatin and 31 to a combination of the two. Objective tumour responses in both the single- agent arms of the trial were $0 \%$. Comparison of $5 \mathrm{FU}$ to oxaliplatin showed that median survivals were 2.4 months and 3.4 months, six-month survival was $20 \%$ versus $40 \%$, and one-year survival was $6 \%$ versus $6 \%$, respectively. Only $51 \%$ of the patients in the study were evaluable for clinical benefit response due to poor compliance. The results were $0 \%$ versus $14 \%$, respectively.

(2) 5-fluorouracil versus 5-fluorouracil based chemotherapy combinations

Six out of the eight included studies provided mortality data at six and 12 months. Pooling mortality data for 5FU combination chemotherapy versus $5 \mathrm{FU}$ alone at 12 months resulted in an OR of 0.90 (95\% CI $0.62-1.30, \mathrm{P}$ value 0.57$)$. Pooled analysis of mortality at six months resulted in an OR of 0.79 (95\% CI 0.59 1.05, P value 0.10$)$. The chi-squared test was not significant for heterogeneity (P value $0.06, \mathrm{I}^{2}=47.7 \%$; and P value $0.32, \mathrm{I}^{2}=$ $13.7 \%$, respectively). Median survival times were available for all the trials and these are listed in Table 02.

Four of the trials found a better tumour response rate with the $5 \mathrm{FU}$ combination regimens (Ducreux 2002; Ducreux 2004; Kovach 1974; Maisey 2002). Measurement of quality of life (QOL) with the EORTC QLQC30 questionnaire found no difference between the study arms in the Maisey trial (Maisey 2002). In another study (Ducreux 2002), measurement of QOL with the Spitzer index found a significant treatment effect in favour of the combination therapy arm. Clinical benefit response was also better with the combination of oxaliplatin and $5 \mathrm{FU}$ versus $5 \mathrm{FU}$ alone in a third trial (Ducreux 2004).

These studies are listed in Table 02 .

(3) Gemcitabine versus another type of chemotherapy.

The four trials provided mortality data at six and 12 months. Pooled analysis for mortality at 12 months for gemcitabine versus another type of chemotherapy resulted in an OR of 1.34 (95\% CI 0.88 to 2.02 , $\mathrm{P}$ value 0.17 ), and at six months in an $\mathrm{OR}$ of 1.10 (95\% CI 0.80 to 1.51 , P value 0.55 ). The chi-squared test was significant for heterogeneity at six months (P value 0.006 , I2 $=76 \%$ ), but not at 12 months (P value 0.03 , I2 $=79.7 \%$ ). A sensitivity analysis using a random-effects model confirmed there was no statistical significance.

The Cheverton study (Cheverton 2004) compared gemcitabine with exatecan (DX-8951f) in 339 patients. Gemcitabine was found to be superior to exatecan for time to progression (3.8 versus 2.8 months, P value $<0.0001$ ), and six month and 12 -month survival $(51.1 \%$ versus $44.1 \%$, and $22.1 \%$ versus $17.9 \%$, respectively). The overall tumour response rate was higher with gemcitabine $(7.7 \%$ versus $<1 \%)$, and the time to worsening of weight loss and pain was also better.

Gansauge (Gansauge 2002) randomised 90 patients to gemcitabine, NSC-631570 or a combination of both. Six-month and 12 -month survival rates were $26 \%$ versus $65 \%$, and $13 \%$ versus 
29\%, for the gemcitabine and NSC-631570 arms, respectively. The median survival times were 5.2 versus 7.9 versus 10.4 months respectively. The significance values for survival in subjects receiving gemcitabine compared to NSC 631570 and to the combination were both $\mathrm{P}$ value $<0.01$. Tumour response rates in assessable patients were $4 \%, 10 \%$ and $40 \%$ respectively.

Two trials compared 5FU with gemcitabine. The Burris trial (Burris 1997) randomised 126 patients to either bolus weekly 5FU or treatment with gemcitabine. This found an improvement in median survival from 4.41 months to 5.65 months (P value 0.025 ) by the use of gemcitabine with the 12 -month survival being $2 \%$ and $18 \%$ respectively. The primary endpoint of the study, however, was clinical benefit response, which consisted of a composite score of measurements of pain (analgesic consumption, pain intensity), Karnofsky performance status (KPS) and weight. More patients in the gemcitabine arm experienced an improvement in clinical benefit $(23.8 \%)$, than did in the 5FU arm (4.8\%). Cantore (Cantore 2004) randomised 175 patients to receive gemcitabine, intraarterial FLEC with filgrastim support, or 5FU/leucovorin. The median survivals were 5.8 months, 7.9 months and 6.4 months respectively. Six-month survival was $7 \%$ versus $62 \%$ versus $51 \%$, and 12 -month survival $21 \%$ versus $35 \%$ versus $17 \%$. Median times to disease progression were 4.2 months for patients receiving gemcitabine versus 5.3 months for patients on FLEC. Insufficient data on time to progression were collected in the 5FU/leucovorin arm to permit analysis. Clinical benefit responses were $17.9 \%$ versus $26.7 \%$ versus $13 \%$, and overall tumour response $5.9 \%, 14 \%$ and $5 \%$ of those assessable. The overall survival and time to progression were statistically better in the FLEC arm compared to gemcitabine (P values 0.036 and 0.013 respectively). There was no statistically significant survival benefit of gemcitabine versus $5 \mathrm{FU} /$ leucovorin ( $\mathrm{P}$ value 0.82 ). FLEC was associated with the most grade- 3 and -4 toxicities. Pooled subgroup analysis was performed with these two trials to compare the 5FU and gemcitabine arms. Six-month pooled survival analysis showed an OR of 1.30 (95\% CI 0.76 to 2.23, P value 0.34 ) and at 12 - months OR 2.29 (95\% CI 0.99 to 5.27, P value 0.05 )

(4) Gemcitabine versus gemcitabine combination chemotherapy

Six-month pooled mortality data for gemcitabine combination chemotherapy regimens versus gemcitbine alone using the fixed effect model from 14 of the 16 trials was not significant, with an OR of 0.88 (95\% CI 0.77 to 1.02 , P value 0.08 ). There was significant evidence of heterogeneity (chi-squared $\mathrm{P}$ value $0.009, \mathrm{I}^{2}=$ $53.7 \%$ ) at this time point. Examination of the funnel plot showed asymmetry with two small trials (Gansauge 2002; Wang 2002) to the far left of the plot in favour of combination therapy (see Figure 02). Sensitivity analysis using the random-effects model showed that the difference remained non-significant at $P$ value 0.06 . Oneyear survival data were available for all except one (Ohkawa 2004) of the 16 studies. Pooled data of mortality from these trials at 12 months for gemcitabine combination chemotherapy regimens versus gemcitabine alone resulted in an OR of 0.89 (95\% CI 0.76 to $1.05, \mathrm{P}$ value 0.17$)$ which was also not significant. The chisquared test was not significant for heterogeneity (P value 0.64, I2 $=0 \%)$.

The drugs combined with gemcitabine were divided into the following subgroups: fluropyrimidines, irinotecan, platinums and other combinations. None of these subgroups showed a statistically significant difference for gemcitabine compared with the combinations for 12-month mortality. However, there was a suggestion of a statistically significant improvement in the six-month mortality figures in favour of the five platinum-gemcitabine combination regimens (OR 0.59 (95\% CI 0.43 to 0.81 , P value 0.001 ). This significant subgroup benefit persisted even when the Wang study (Wang 2002) was excluded on a sensitivity analysis (P value 0.003). Although it was small, this trial lay at the extreme of the forest plot indicating heterogeneity. Furthermore, omission of this study from the 12-month analysis did not affect the non-significance of the subgroup comparison.

Median survival times were available for all studies and only the Gansauge trial (Gansauge 2002) showed a statistically significant difference between single-agent gemcitabine and a gemcitabine combination. Progression-free survivals were statistically superior with the combination arms in five studies (Berlin 2002; Colucci 2002; Heinemann 2003; Louvet 2005; Reni 2005).

Tumour response rates were superior with gemcitabine combinations in a number of studies (Colucci 2002; Gansauge 2002; Louvet 2005; Reni 2005; Oettle 2005b; Rocha Lima 2004). Clinical benefit response was better in the combination arms in three studies (Louvet 2005; Reni 2005; Scheithauer 2003). Reni measured quality of life with the EORTC QLQ C30 and PAN26 scales (Reni 2004b). Clinically relevant improvements from baseline were seen but there were no statistically significant differences between the arms. Although there was no difference in clinical benefit response in the O'Reilly study (O'Reilly 2004), patients in the combination arm experienced improvement in time to deterioration of analgesic consumption and performance status.

These studies are summarised in Table 03.

(5) Other comparative chemotherapy trials

The trials were heterogeneous with regard to the different combinations of chemotherapy regimens tested, and a pooled analysis was not performed. Most of the trials presented data on tumour response and median survival. In this group of studies only one trial found an advantage of one regimen over another. This was the Kelsen trial (Kelsen 1991), which found a statistically significant survival benefit of SMF (streptozocin, mitomycin and fluorouracil) over CAC (cisplatin/Ara C and caffeine), but the trial enrolled only 28 people. In another trial where SMF was compared to FAM (5-fluorouracil, adriamycin and mitomycin C) (Oster 1986), the differences in response rates and survival were not statistically significant. In addition, in a third trial, the SMF reg- 
imen performed no better than mitomycin and 5FU in terms of survival, and had a higher toxicity (Bukowski 1983).

When mitomycin/5FU was compared to mitomycin/CCNU (Buroker 1979) the higher response rate (22\% versus 5\%) obtained did not translate into a better survival. Horton (Horton 1981) found no differences in survival on comparing melphalan with 5FU/CCNU and 5FU/CCNU/streptozocin. Tumour response assessment in these two trials was not reliable, as the investigators used clinical measurements rather than radiological assessments. Another study (Topham 1991) compared single-agent epirubicin with 5FU/epirubicin/mitomycin C. We have presumed, although we have been unable to confirm with the authors, that a subsequent publication (Topham 1993) is a preliminary publication of the same trial. No statistical difference was found with respect to response rate or survival. No combination schedule was clearly superior to others. These trials are summarised in Table 04.

\section{Radiation therapy in locally advanced pancreatic cancer}

The randomised studies identified in this part of the review were, once again, very heterogeneous in terms of study design, radiation schedules and techniques, as well as chemotherapy employed. A pooled analysis was not possible. A qualitative overview was performed. The studies are summarised in Table 05 .

(1) Radiation therapy with or without chemotherapy in locally advanced pancreatic cancer

The first trial to examine the role of chemoradiation in detail was a placebo-controlled study by Childs (Childs 1965), where 25 locally-advanced pancreatic cancer patients were randomised to receive either saline with radiotherapy, or $5 \mathrm{FU}$ with radiotherapy. Six-month survival was $48 \%$ and $77 \%$ respectively, and 12 -month survival $12 \%$ and $31 \%$, although these were not statistically significant because of the small number of participants. In 1967, Moertel and colleagues (Moertel 1969) randomised 64 patients with locally-advanced pancreatic cancer to radiation alone or radiation with concurrent $5 \mathrm{FU}$. There was an increase in median survival from 6.3 to 10.4 months (P value $<0.05$ ) and one-year survival improved from $5 \%$ to $25 \%$. Both these trials also enrolled patients with colon and gastric cancer. In 1981 Moertel reported the final results of a GITSG (Gastrointestinal Tumor Study Group) trial (Moertel 1981) with 194 patients randomised to either high dose radiation alone, or high dose radiation plus $5 \mathrm{FU}$, or lower dose radiation plus 5FU. The median survival for combined modality was 42 weeks versus 23 weeks for radiation and one-year survival $40 \%$ versus $12 \%$ (P value $<0.01$ ). There was no statistically significant difference between the two chemoradiation arms. A further study, reported in 1994 (Earle 1994), randomised 87 patients to radiation plus $5 \mathrm{FU}$, or radiation plus an antishistosomal drug hycanthone used as a radiosensitizer to potentiate the radiotherapy. No statistical differences were seen in relapse-free survival ( $P$ value 0.27 ), median survival (both arms 34 weeks) or one-year survival (35\% versus 28\%). Quality of life were not measured in these tri- als but the toxicity of combined modality was greater than with radiation alone.

Another Gastrointestinal Tumor Study Group study (GITSG 1985b) randomised 157 patients to receive radiation therapy combined with either adriamycin or $5 \mathrm{FU}$. No difference was seen with respect to survival ( $\mathrm{P}$ value $>0.8$ ), but adriamycin caused much more toxicity. Both the proportion of patients who experienced alleviation of pain, and the average amount of weight loss, were similar in both arms at 10 to 12 weeks into the study. The most recent study (Li 2003) randomised 34 patients to radiation (threedimensional conformal radiotherapy) plus weekly gemcitabine, or to radiation (as before) plus 5FU as a continuous infusion. All patients received maintenance gemcitabine after radiation until progression. This study showed an improvement in median survival from 6.7 months to 14.5 months (P value 0.019 ), and time to progression from 2.7 to 7.1 months (P value 0.027 ), for those in the gemcitabine arm. Response rate was also better with concurrent gemcitabine $(50 \%$ versus $12 \%$ ), as were pain control (6\% versus $39 \%$ ), performance status, and quality adjusted life months.

A recent study from Japan (Shinchi 2002) has looked at the question of combined-modality therapy (radiation plus concurrent 5FU infusion with weekly 5FU maintenance post radiation) versus best supportive care. It randomised 31 patients and showed a median survival of 13.2 months for treatment versus 6.4 months (P value 0.001 ) with supportive care, and one-year survival of $53 \%$ versus $0 \%$ (P value 0.009 ) respectively. A quality of life benefit was found with treatment measured by maintenance of performance status.

(2) Chemotherapy with or without radiation therapy in locally advanced pancreatic carcinoma

Three studies compared chemoradiotherapy with chemotherapy alone. Hazel (Hazel 1981) randomised patients either to combination chemotherapy with 5FU and CCNU, or to radiation with 5FU followed by CCNU. No difference in survival between the two groups of 15 patients in each arm was noted (median survival 7.8 months). The Eastern Cooperative Oncology Group (ECOG) study (Klaassen 1985) reported upon 91 patients randomised to weekly maintenance $5 \mathrm{FU}$ until progression, or radiation therapy with 5FU. The results included: median survival of 8.2 versus 8.3 months; median time to treatment failure of 4.4 months versus 4.2 months; and one-year survival of $28 \%$ versus $30 \%$. This trial enrolled patients with gastric cancer as well, and the randomisation was stratified on the basis of tumour aneuploidy, but not tumour site. There was a high rate of patients $(22 \%)$ who were ineligible or cancelled in the trial, and the trial closed early due to poor accrual. In 1988 the Gastrointestinal Tumor Study Group trial (GITSG 1988) compared combination chemotherapy, using streptozotocin, methotrexate and 5FU, to the same regimen plus radiation in 42 patients who experienced median survival of 32 versus 42 weeks and one-year survival of $19 \%$ versus $41 \%$ (P value $<0.05)$ respectively. This trial closed early due to lack of funding. 
None of these studies incorporated formal assessments of quality of life, however, the toxicities of treatment were higher in the arms evaluating combined modalities.

\section{ISCUSSION}

\section{Best supportive care versus chemotherapy}

A survival benefit was seen in the pooled results of combination chemotherapy against best supportive care studies at 12 months and six months. These trials all used old style chemotherapy combination regimens and none involved the use of gemcitabine which is discussed further below. Only one study (Glimelius 1996) used a validated measure of quality of life in the form of the EORTC QLC C30 questionnaire and found a clinical benefit with the use of chemotherapy.

\section{Comparative studies of chemotherapy in advanced pancreatic cancer}

5-Fluorouracil (5FU) has been the most studied agent in advanced pancreatic cancer. Pooled analysis of 5FU found it to be inferior to other single-agent chemotherapy with respect to six-month survival. When $5 \mathrm{FU}$ was compared against $5 \mathrm{FU}$ combination regimens, pooled analysis did not demonstrate a survival advantage for the 5FU combination regimens compared to 5FU alone. Although, in some trials, the objective tumour response rates were higher with the combination regimens, this did not correlate with better survival, but was usually associated with increased toxicity. This is in contrast to advanced breast cancer (Bruzzi 2002) and colon cancer (Buyse 2000) where higher response does seem to correlate with better survival. Despite this, two trials(Ducreux 2002; Ducreux 2004) did find a better clinical benefit with the combination regimen. Various 5FU combinations have been tested and there is no regimen that is clearly superior.

The Burris study (Burris 1997) introduced the concept of measurement of clinical benefit as a primary endpoint when comparing gemcitabine to 5FU. Gemcitabine exhibited superior survival and improvement in clinical benefit to 5FU, and became the standard treatment for advanced pancreatic cancer. The subsequent threearmed Cantore study (Cantore 2004) included gemcitabine and 5FU/folinic acid arms; these showed no difference in survival, but the latter arm terminated early and the resulting cross-over of patients onto the other arm may have diluted any survival difference. The Cantore study also enrolled a larger proportion of patients with locally-advanced disease than Burris. The two 5FU schedules differed, with Burris employing a weekly schedule, and Cantore a monthly five-day regimen in combination with folinic acid. The intrahepatic FLEC arm of this trial demonstrated superiority in survival over gemcitabine, but at a cost of significantly higher toxicity. Pooled subgroup analysis of these two studies showed a borderline reduction effect in one-year mortality rate of gemcitabine over 5FU, with wide confidence intervals, so evidence of superiority is inconclusive. Pooled analysis of single-agent chemotherapy versus gemcitabine did not show any statistically significant differences in 12- or six-month mortality.

A large number of trials compared gemcitabine combination chemotherapy regimens to gemcitabine alone. The pooled results for one-year and six-month survival showed no statistically significant differences. Subgroup analysis showed that six-month survival is better with the platinum-gemcitabine combinations. Once again, increased response rates seen in some of the gemcitabine combinations do not seem to correlate with improvements in survival. Several studies do show an improvement in progression-free survival with the use of combination therapy. The one-year survival rates in these studies are increasingly in excess of $20 \%$, which may reflect either better supportive care, or an increased use of secondline therapies following initial treatment failure that may dilute the overall survival differences.

Tumour response rate is a surrogate endpoint for clinical trials, which is subject to investigator bias. Some trials in the review were completed before computed tomography (CT) imaging became available. Despite the current availability of CT imaging, response in advanced pancreatic cancer can be difficult to assess because of the high incidence of peritoneal disease that does not image well, and because of desmoplastic stromal activity around the primary site. The response rates in the trials were based on the number of patients who were evaluable and not necessarily the number randomised. Combination chemotherapy regimens may be useful in rare situations, for example, where a locally-advanced pancreatic cancer could be sufficiently reduced in size to enable curative surgical resection, or when combination with radiation treatment is aimed at achieving high response rate with a view to downstaging tumours again for curative surgery (Wilkowski 2005). At present, no randomised trials support the benefit of downstaging treatment in pancreatic cancer, however, single arm studies that have shown that inoperable patients may be rendered operable, suggest a need for trials in this area.

Clinical benefit or quality of life was measured in twelve of the sixteen gemcitabine combination studies. Only three of these (Louvet 2005; Reni 2005; Scheithauer 2003) found a superiority with the combination regimens. Importantly, one study (Li 2004) found an adverse effect of combination chemotherapy on quality adjusted life months compared to single agent.

\section{Radiation therapy in locally-advanced pancreatic cancer}

Locally unresectable pancreatic cancer represents an under-researched area in which management is based more upon opinion than evidence. A series of small trials performed several decades ago continues to provide the only randomised data upon which current management decisions are made. Some of these trials were conducted before computed tomography became available, so assessment of the stage of the disease was suboptimal. Amongst these 
trials, there is a clear separation between those that offer identical treatment to patients with both metastatic disease or locallyadvanced disease stating that the outcome is identical, and those that believe that a longer natural history, a longer median survival and a differential response to radiation merit the use of combinedmodality therapy in locally advanced disease.

In one small study (Shinchi 2002), chemoradiation therapy showed a benefit in both survival and quality of life when compared to best supportive care in locally-advanced pancreatic cancer. It also produced better survival in two relatively small, randomised trials (Moertel 1969; Moertel 1981) where it was compared to radiation alone, and in another small study (GITSG 1988), that was terminated early, in which it was compared to combination chemotherapy alone. The toxicity of chemoradiation is higher than with single-modality treatment. $5 \mathrm{FU}$ is the drug that has been used in all of the studies of concurrent chemoradiation. One small study (Li 2003) compared concurrent gemcitabine to 5FU showing a better outcome with the gemcitabine. Most of the trials were conducted before the availability of conformal radiotherapy techniques, that have reduced the toxicity of radiation treatment.

The consistent difference in median survival times of 10 to 14 months for combined treatment groups, compared to half that for groups receiving radiation alone, and one-year survivals of $28 \%$ to $50 \%$ is most interesting. This suggests, firstly, that optimising chemoradiation protocols is justified in this condition, and, secondly, that people with locally-advanced disease should not be studied with those with metastatic disease in any new randomised studies, unless there is equal stratification across the arms of the study. The need to standardise tests to exclude metastatic disease makes such studies difficult and suggests that only careful, prospective, well controlled studies can provide a definitive answer to the management of this subgroup of pancreatic carcinoma. Such a study has been completed and results are expected in 2006 (ECOG-4201; assessing gemcitabine with or without radiation). In the meantime, it remains unclear whether chemotherapy alone would produce equivalent outcomes in locally-advanced disease compared to a more complex, and potentially more toxic, regimen of chemotherapy and radiation.

\section{A U THORS'CONCLUSIONS}

\section{Implications for practice}

Systemic chemotherapy appears to improve survival and quality of life in patients with advanced (metastatic and locally-advanced) pancreatic cancer when compared to best supportive care.

Gemcitabine alone is an acceptable palliative treatment for patients with locally-advanced or metastatic pancreatic cancer. Superiority of survival over $5 \mathrm{FU}$ is inconclusive, but for clinical benefit gemcitabine is better. Combination regimens with gemcitabine can produce a higher response rate, but this does not appear to translate into a survival advantage.

Chemoradiation appears to have a benefit over best supportive care, or radiation alone. There is insufficient evidence to recommend chemoradiation as a superior alternative to chemotherapy alone in fit individuals with locally advanced inoperable pancreatic cancer

\section{Implications for research}

Trial reporting and design

Survival results are still poor even with the best-studied regimens. Clinical trials need to be adequately powered to detect clinically significant differences in survival, and report on meaningful endpoints such as: time to progression, toxicities and quality of life (using validated instruments). Pharmacoeconomics data and cost effectiveness will also be important considerations. Chemotherapy studies in advanced pancreatic cancer should stratify patients with locally-advanced and metastatic disease.

Agents to compare in future trials

Gemcitabine is still an acceptable control arm in clinical trials, which should continue to explore scheduling and combinations with novel agents. There is a need to avoid further chemotherapy combinations unless a new drug has shown substantial survival benefit in a second-line setting, or has shown improvement in the expected median and 12-month survivals in a phase II setting. Improvements are unlikely to be achieved through trials that examine existing chemotherapy drug combinations and it is inadvisable to test more versions of the same classes of agents.

The impact of second-line therapies on outcome, and their possible influence on diluting the survival gains of combination therapy, needs to be quantified. A legitimate area of trials research would be the influence of second-line therapies on outcomes, with more rigorous identification of active second line drug regimens and quantification of the degree of benefit, as well as identification of predictive factors to segregate the groups most likely to gain from such treatment(s). The issue of sequential, as opposed to combination therapy, is also a legitimate area to explore in order to maximise quality of life without compromising survival.

Further chemoradiation studies employing modern conformal 3-D planning techniques to determine optimal chemoradiation schedules are required.

Randomised trials are also required in people with locally-advanced unresectable pancreatic cancer to determine whether there is any advantage to adding radiation to chemotherapy and to identify the best means of downstaging tumours for resection, as well as whether this provides sustained benefits.

Clinicians and patients should be encouraged to participate in high quality clinical trials in advanced pancreatic cancer.

Future updates of this review 
At the time of protocol conception, biological therapies such as cytokines, signal transduction inhibitors and monoclonal antibodies were excluded from this review, and it was decided to focus on cytotoxic chemotherapy and radiotherapy. However, since phase III trials of a number of these agents have either been completed or are ongoing, the next update of this review will include these therapies, and also randomised second line treatment studies.

\section{POTENTIALCONFLICTOF I N T E R E S T}

Desmond Yip has received consultancy fees from Eli Lilly for being an independent advisor in a clinical trial and was an investigator in the Shapiro 2005 and Chau 2003 studies. Andrew Strickland and Christopher Steer have received travel grants from Eli Lilly. David Goldstein has acted as an advisor for Eli Lilly, Pharmacia/Pfizer, Roche, Merck AG and Novartis. He was a principal investigator in the Moore 2005 trial and an investigator in the Van Cutsem 2004 trial. No payments of any kind have been received for preparation of this review.

\section{ACKNOW LEDGEMENTS}

The authors are indebted to the Cochrane Upper Gastrointestinal and Pancreatic Diseases Group Editorial Team in particular: Janet Lilleyman for keeping this review on track, Iris Gordon for her assistance in the periodic searches to identify relevant trials, and David Forman for his advice on methodology. We are grateful to Sarah Collin and Liz Gardener, of Hope Hospital, Manchester, for their statistical support.

We would like to acknowledge the following investigators who kindly responded to requests for further information on studies: M Cantore, B Glimelius, CW Imrie, KR Palmer, JP Pignon, M Reni, T Takada and N Tebbutt.

\section{SOURCES OF SUPPORT}

\section{External sources of support}

- No sources of support supplied

Internal sources of support

- No sources of support supplied

\section{RE F E R E N E S}

\section{References to studies included in this review}

Andersen 1981 \{published data only\}

Andersen JR, Friis-Moller A, Hancke S, Roder O, Steen J, Baden $\mathrm{H}$. A controlled trial of combination chemotherapy with 5-FU and BCNU in pancreatic cancer. Scandinavian Journal of Gastroenterology 1981;16(8):973-5. [MedLine: BSC].

Andren-Sandberg 1983 \{published data only\} Andren-Sandberg A, Holmberg JT, Ihse I. Treatment of unresectable pancreatic carcinoma with 5-fluorouracil, vincristine, and CCNU. Scandinavian Journal of Gastroenterology 1983;18(5):609-12. [MedLine: BSC].

Berlin 2002 \{published data only\}

Berlin JD, Catalano P, Thomas JP, Kugler JW, Haller DG, Benson $\mathrm{AB}, 3 \mathrm{rd}$. Phase III study of gemcitabine in combination with fluorouracil versus gemcitabine alone in patients with advanced pancreatic carcinoma: Eastern Cooperative Oncology Group Trial E2297. Journal of Clinical Oncology 2002;20(15):3270-5. [MedLine: CT].

Bukowski 1983 \{published data only\} Bukowski RM, Balcerzak SP, O'Bryan RM, Bonnet JD, Chen TT. Randomized trial of 5-fluorouracil and mitomycin $\mathrm{C}$ with or without streptozotocin for advanced pancreatic cancer. A Southwest Oncology Group study. Cancer 1983;52(9):1577-82. [MedLine: CT].

Buroker 1979 \{published data only\} Buroker T, Kim PN, Groppe C, McCracken J, O'Bryan R, Panettiere $\mathrm{F}$, et al. $5 \mathrm{FU}$ infusion with mitomycin-C vs. $5 \mathrm{FU}$ infusion with methyl-CCNU in the treatment of advanced upper gastroin- testinal cancer: a Southwest Oncology Group Study. Cancer 1979; 44(4):1215-21. [MedLine: CT].

Burris 1997 \{published data only\}

Burris H, Storniolo AM. Assessing clinical benefit in the treatment of pancreas cancer: gemcitabine compared to 5-fluorouracil. European Journal of Cancer 1997;33 Suppl(1):S18-22.

* Burris HA, 3rd, Moore MJ, Andersen J, Green MR, Rothenberg ML, Modiano MR, Cripps MC, Portenoy RK, Storniolo AM, Tarassoff P, Nelson R, Dorr FA, Stephens CD, Von Hoff DD. Improvements in survival and clinical benefit with gemcitabine as first- line therapy for patients with advanced pancreas cancer: a randomized trial. Journal of Clinical Oncology 1997;15(6):2403-13. [MedLine: CT].

Cantore 2004 \{published and unpublished data\}

* Cantore M, Fiorentini G, Luppi G, Rosati G, Caudana R, Piazza E, et al. Gemcitabine versus FLEC regimen given intraarterially to patients with unresectable pancreatic cancer: a prospective, randomised phase III trial of the Italian Society for Integrated Locoregional Therapy in Oncology. Journal of Chemotherapy 2004;16(2):589-94.

Cantore M, Fiorentini G, Luppi G, Rosati G, Caudana R, Piazza E, et al. Randomised trial of gemcitabine versus FLEC regimen given intraarterially for patients with unresectable pancreatic cancer. Journal of Experimental and Clinical Cancer Research 2003;22((4 Suppl)):5157. 
Cheverton 2004 \{published data only\}

Cheverton P, Friess H, Andras C, Salek T, Geddes C, et al. Phase III results of exatecan (DX-8951f) versus gemcitabine (Gem) in chemotherapy-naive patients with advanced pancreatic cancer (APC). Proceedings of the American Society of Clinical Oncology. 2004; Vol. 22, issue 14S:Abstract 4005.

Childs 1965 \{published data only\}

Childs DS, Moertel C, Holbrook MA, Reitemeier R, Colby M. Treatment of malignant neoplasms of the gastrointestinal tract with a combination of 5-fluorouracil and radiation. Radiology 1965;84:843-8. [MedLine: CTRT].

Colucci 2002 \{published data only\}

* Colucci G, Giuliani F, Gebbia V, Biglietto M, Rabitti P, Uomo G, et al. Gemcitabine alone or with cisplatin for the treatment of patients with locally advanced and/or metastatic pancreatic carcinoma: a prospective, randomized phase III study of the Gruppo Oncologia dell'Italia Meridionale. Cancer 1999;94(4):902-10. [MedLine: AU: Colucci G, Giuliani F, Gebbia V, Biglietto M, Rabitti P, Uomo G, Cigolari S, Testa A, Maiello E, Lopez M TI:Gemcitabine alone or with cisplatin for the treatment of patients with locally advanced and/or metastatic pancreatic carcinoma: a prospective, randomized phase III study of the Gruppo Oncologia dell'Italia Meridionale SO: Cancer YR:2002 VL:94 NO:4 PG:902-10 AN:CT NT:21916548 0008-543x Clinical Trial Clinical Trial, Phase III Journal Article Multicenter Study Randomized Controlled Trial RT:Journal Article AU: Colucci G, Giuliani F, Gebbia V, Biglietto M, Rabitti P, Uomo G, Cigolari S, Testa A, Maiello E, Lopez M TI:Gemcitabine alone or with cisplatin for the treatment of patients with locally advanced and/or metastatic pancreatic carcinoma: a prospective, randomized phase III study of the Gruppo Oncologia dell'Italia Meridionale SO: Cancer YR:2002 VL:94 NO:4 PG:902-10 AN:CT NT:21916548 0008-543x Clinical Trial Clinical Trial, Phase III Journal Article Multicenter Study Randomized Controlled Trial RT:Journal Article AU: Colucci G, Giuliani F, Gebbia V, Biglietto M, Rabitti P, Uomo G, Cigolari S, Testa A, Maiello E, Lopez M TI:Gemcitabine alone or with cisplatin for the treatment of patients with locally advanced and/or metastatic pancreatic carcinoma: a prospective, randomized phase III study of the Gruppo Oncologia dell'Italia Meridionale SO: Cancer YR:2002 VL:94 NO:4 PG:902-10 AN:CT NT:21916548 0008-543x Clinical Trial Clinical Trial, Phase III Journal Article Multicenter Study Randomized Controlled Trial].

Cullinan 1985a \{published data only\} Cullinan SA, Moertel CG, Fleming TR, Rubin JR, Krook JE, Everson LK, et al. A comparison of three chemotherapeutic regimens in the treatment of advanced pancreatic and gastric carcinoma. Fluorouracil vs fluorouracil and doxorubicin vs fluorouracil, doxorubicin, and mitomycin. JAMA 1985;253(14):2061-7. [MedLine: CT].

Cullinan 1985b \{published data only\} Cullinan SA, Moertel CG, Fleming TR, Rubin JR, Krook JE, Everson LK, et al. A comparison of three chemotherapeutic regimens in the treatment of advanced pancreatic and gastric carcinoma. Fluorouracil vs fluorouracil and doxorubicin vs fluorouracil, doxorubicin, and mitomycin. Jama 1985;253(14):2061-7.

Cullinan 1990a \{published data only\} Cullinan S, Moertel CG, Wieand HS, Schutt AJ, Krook JE, Foley JF, et al. A phase III trial on the therapy of advanced pancreatic carcinoma. Evaluations of the Mallinson regimen and combined 5fluorouracil, doxorubicin, and cisplatin. Cancer 1990;65(10):220712. [MedLine: CT].

Cullinan 1990b \{published data only\} Cullinan S, Moertel CG, Wieand HS, Schutt AJ, Krook JE, Foley JF, et al. A phase III trial on the therapy of advanced pancreatic carcinoma. Evaluations of the Mallinson regimen and combined 5fluorouracil, doxorubicin, and cisplatin. Cancer 1990;65(10):220712.

Ducreux 2002 \{published and unpublished data\}

Ducreux M, Rougier P, Pignon JP, Douillard JY, Seitz JF, Bugat R, et al. A randomised trial comparing 5-FU with 5-FU plus cisplatin in advanced pancreatic carcinoma. Annals of Oncology 2002;13(8): 1185-91. [MedLine: CT].

Rougier P, Ducreux, Douillard JY, Seitz JF, Bugat R, Bosset JF, et al. Efficacy of 5FU+cisplatin (FUP) compared to bolus 5FU (FU) in advanced pancreatic carcinoma (APC): a randomised trial conducted by the digestive group from the French Anticancer centres (FNLCC). Proceedings of the American Society of Clinical Oncology 1999;18:274a.

Ducreux 2004 \{published data only\} Ducreux M, Mitry E, Ould-Kaci M, Boige V, Seitz JF, Bugat R, et al. Randomized phase II study evaluating oxaliplatin alone, oxaliplatin combined with infusional 5-FU, and infusional 5-FU alone in advanced pancreatic carcinoma patients. Annals of Oncology 2004;15 (3):467-73

Earle 1994 \{published data only\} Earle JD, Foley JF, Wieand HS, Kvols LK, McKenna PJ, Krook JE, at al. Evaluation of external-beam radiation therapy plus 5-fluorouracil (5- FU) versus external-beam radiation therapy plus hycanthone (HYC) in confined, unresectable pancreatic cancer. International Journal of Radiation Oncology, Biology, Physics 1994;28(1): 207-11. [MedLine: CTRT].

Frey 1981 \{published data only\}

Frey C, Twomey P, Keehn R, Elliott D, Higgins G. Randomized study of 5-FU and CCNU in pancreatic cancer: report of the Veterans Administration Surgical Adjuvant Cancer Chemotherapy Study Group. Cancer 1981;47(1):27-31. [MedLine: BSC].

Gansauge 2002 \{published data only\} Gansauge F, Ramadani M, Pressmar J, Gansauge S, Muehling B, Stecker K, et al. NSC-631570 (Ukrain) in the palliative treatment of pancreatic cancer. Results of a phase II trial. Langenbecks Archives of Surgery 2002;386(8):570-4.

\section{GITSG 1985b \{published data only\}}

Gastrointestinal Tumor Study Group. Radiation therapy combined with Adriamycin or 5-fluorouracil for the treatment of locally unresectable pancreatic carcinoma. Gastrointestinal Tumor Study Group. Cancer 1985;56(11):2563-8. [MedLine: CTRT].

\section{GITSG 1988 \{published data only\}}

Gastrointestinal Tumor Study Group. Treatment of locally unresectable carcinoma of the pancreas: comparison of combinedmodality therapy (chemotherapy plus radiotherapy) to chemotherapy alone. Journal of the National Cancer Institute 1988;80(10):7515. [MedLine: CTRT] 
Glimelius 1996 \{published and unpublished data\} Glimelius B, Hoffman K, Sjoden PO, Jacobsson G, Sellstrom H, Enander LK, et al. Chemotherapy improves survival and quality of life in advanced pancreatic and biliary cancer. Annals of Oncology 1996;7(6):593-600. [MedLine: BSC].

Hazel 1981 \{published data only\}

Hazel JJ, Thirlwell MP, Huggins M, Maksymiuk A, MacFarlane JK. Multi-drug chemotherapy with and without radiation for carcinoma of the stomach and pancreas: a prospective randomized trial. Journal of the Canadian Association of Radiologists 1981;32(3):164-5. [MedLine: CTRT].

Heinemann 2003 \{published data only\}

* Heinemann V, Quietzsch D, Gieseler F, Gonnermann M, Schonekas H, Rost A, et al. A phase III trial comparing gemcitabine plus cisplatin vs. gemcitabine alone in advanced pancreatic carcinoma. Proceedings of the American Society of Clinical Oncology. 2003; Vol. 22:Abstract 1003.

Heinemann V, Quietzsch D, Gieseler F, Schönekäs H, Rost A, Neuhaus $H$, et al. Gemcitabine plus cisplatin versus gemcitabine in advanced pancreatic cancer: Preliminary results of a randomized phase III trial. Proceedings of the American Society of Clinical Oncology 2001;20:Abstract 625.

Herrmann 2005 \{published data only\}

Herrmann R, Bodoky G, Ruhstaller T, Glimelius B, Saletti P, Bajetta E, et al. Gemcitabine (G) plus Capecitabine (C) versus $G$ alone in locally advanced or metastatic pancreatic cancer. A randomized phase III study of the Swiss Group for Clinical Cancer Research (SAKK) and the Central European Cooperative Oncology Group (CECOG). Proceedings of the American Society of Clinical Oncology. 2005; Vol. 23:Abstract LBA4010.

Horton 1981 \{published data only\}

Horton J, Gelber RD, Engstrom P, Falkson G, Moertel C, Brodovsky $\mathrm{H}$, Douglass $\mathrm{H}$. Trials of single-agent and combination chemotherapy for advanced cancer of the pancreas. Cancer Treatment Reports 1981; 65(1-2):65-8. [MedLine: CT].

Huguier 2001 \{published data only\}

Huguier M, Barrier A, Valinas R, Flahault A, Adloff M, Pezet D, et al. Randomized trial of 5-fluorouracil, leucovorin and cisplatin in advanced pancreatic cancer. Hepatogastroenterology 2001;48(39): $875-8$.

Kelsen 1991 \{published data only\}

Kelsen D, Hudis C, Niedzwiecki D, Dougherty J, Casper E, Botet J, Vinciguerra V, Rosenbluth R. A phase III comparison trial of streptozotocin, mitomycin, and 5-fluorouracil with cisplatin, cytosine arabinoside, and caffeine in patients with advanced pancreatic carcinoma. Cancer 1991;68(5):965-9. [MedLine: CT].

Klaassen 1985 \{published data only\}

Klaassen DJ, MacIntyre JM, Catton GE, Engstrom PF, Moertel CG. Treatment of locally unresectable cancer of the stomach and pancreas: a randomized comparison of 5-fluorouracil alone with radiation plus concurrent and maintenance 5-fluorouracil--an Eastern Cooperative Oncology Group study. Journal of Clinical Oncology 1985;3(3):3738. [MedLine: CTRT].

Kovach 1974 \{published data only\}

Kovach JS, Moertel CG, Schutt AJ, Hahn RG, Reitemeier RJ. Proceedings: A controlled study of combined 1,3-bis-(2-chloroethyl)-1- nitrosourea and 5-fluorouracil therapy for advanced gastric and pancreatic cancer. Cancer 1974;33(2):563-7. [MedLine: CT].

Levi 2004 \{published data only\}

Levi F, Tubiana-Mathieu N, Focan C, Brézault-Bonnet C, Coudert B, Carvalho C, et al. Chronomodulated (Chrono) vs constant (Cst) rate infusional 5-fluorouracil (FU) with or without cisplatin (CDDP) in patients with advanced or metastatic pancreatic cancer. A multicenter randomized trial of the Chronotherapy Group of the European Organisation for Research and Treatment of Cancer (EORTC 05962). Proceedings of the American Society of Clinical Oncology. 2004; Vol. 22, issue 14S:Abstract 4117

Li 2003 \{published data only\}

Li CP, Chao Y, Chi KH, Chan WK, Teng HC, Lee RC, et al. Concurrent chemoradiotherapy treatment of locally advanced pancreatic cancer: gemcitabine versus 5-fluorouracil, a randomized controlled study. International Journal of Radiation Oncology Biology Physics 2003;57(1):98-104. [MedLine: CT/RT].

Li 2004 \{published data only\}

Li C, Chao Y. A prospective randomized trial of gemcitabine alone or gemcitabine + cisplatin in the treatment of metastatic pancreatic cancer. Proceedings of the American Society of Clinical Oncology 2004; 22:Abstract 4144

${ }^{*} \mathrm{Li}$ C, Chao Y. A prospective randomized trial of gemcitabine alone or gemcitabine + cisplatin in the treatment of metastatic pancreatic cancer. Proceedings of the American Society of Clinical Oncology Gastrointestinal Cancer Symposium. 2004; Vol. 1:(Abstract 140).

Louvet 2005 \{published data only\}

Louvet C, Labianca R, Hammel P, Lledo G, De Braud F, Andre T, et al. Gemcitabine versus GEMOX (gemcitabine + oxaliplatin) in non resectable pancreatic adenocarcinoma : Interim results of the GERCOR /GISCAD Intergroup Phase III. Proceedings of the American Society of Clinical Oncology 2003;22:Abstract 1004.

Louvet C, Labianca R, Hammel P, Lledo G, De Braud F, Andre T, et al. GemOx (gemcitabine + oxaliplatin) versus Gem (gemcitabine) in non resectable pancreatic adenocarcinoma: Final results of the GERCOR /GISCAD Intergroup Phase III. Proceedings of the American Society of Clinical Oncology 2004;23(14S):Abstract 4008.

* Louvet C, Labianca R, Hammel P, Lledo G, Zampino MG, Andre $\mathrm{T}$, et al. Gemcitabine in combination with oxaliplatin compared with gemcitabine alone in locally advanced or metastatic pancreatic cancer: results of a GERCOR and GISCAD phase III trial. Journal of Clinical Oncology 2005;23(15):3509-16.

Maisey 2002 \{published data only\}

Maisey N, Chau I, Cunningham D, Norman A, Seymour M, Hickish T, Iveson T, O’Brien M, Tebbutt N, Harrington A, Hill M. Multicenter randomized phase III trial comparing protracted venous infusion (PVI) fluorouracil (5-FU) with PVI 5-FU plus mitomycin in inoperable pancreatic cancer. Journal of Clinical Oncology 2002;20 (14):3130-6. [MedLine: CT]

Mallinson 1980 \{published data only\} Mallinson CN, Rake MO, Cocking JB, Fox CA, Cwynarski MT, Diffey BL, Jackson GA, Hanley J, Wass VJ. Chemotherapy in pancreatic cancer: results of a controlled, prospective, randomised, multicentre trial. British Medical Journal 1980;281(6255):1589-91. [MedLine: BSC]. 
Moertel 1969 \{published data only\}

* Moertel CG. Childs DS. Reitemeier RJ, Colby MY, Holbrook MA. Combined 5-flurouracil and supervoltage radiation therapy of locally uunresectable gastrointestinal cancer. Lancet 1969;2(7626):865-7.

Moertel 1981 \{published data only\}

Gastrointestinal Tumor Study Group. A multi-institutional comparative trial of radiation therapy alone and in combination with 5-fluorouracil for locally unresectable pancreatic carcinoma. The Gastrointestinal Tumor Study Group. Annals of Surgery 1979;189(2):205-8.

* Moertel CG, Frytak S, Hahn RG, O’Connell MJ, Reitemeier RJ, Rubin J, et al. Therapy of locally unresectable pancreatic carcinoma: a randomized comparison of high dose (6000 rads) radiation alone, moderate dose radiation (4000 rads +5 -fluorouracil), and high dose radiation + 5-fluorouracil: The Gastrointestinal Tumor Study Group. Cancer 1981;48(8):1705-10. [MedLine: CTRT].

O'Reilly 2004 \{published data only\} O’Reilly E, Abou-Alfa G, Letourneau R, Harker W, Modiano M, Hurwitz H, et al. A randomized phase III trial of DX-8951f (exatecan mesylate; DX) and gemcitabine (GEM) vs. gemcitabine alone in advanced pancreatic cancer (APC). Proceedings of the American Society of Clinical Oncology. 2004; Vol. 23, issue 14S:Abstract 4006.

Oettle 2005b \{published data only\}

* Oettle H, Richards D, Ramanathan RK, Van Laethem JL, Peeters M, Fuchs M, et al. A phase III trial of pemetrexed plus gemcitabine versus gemcitabine in patients with unresectable or metastatic pancreatic cancer. Annals of Oncology 2005;16:1639-1645.

Richards D, Kindler H, Oettle H, Ramanathan R, Van Laethem J, Peeters $\mathrm{M}$, et al. A randomized phase III study comparing gemcitabine + pemetrexed versus gemcitabine in patients with locally advanced and metastatic pancreas cancer. Proceedings of the American Society of Clinical Oncology. 2004; Vol. 23, issue 14S:Abstract 4007.

Ohkawa 2004 \{published data only\}

Ohkawa S. Randomized controlled trial of gemcitabine in combination with UFT versus gemcitabine alone in patients with advanced pancreatic cancer. Proceedings of the American Society of Clinical Oncology. 2004; Vol. 22:Abstract 4131.

Oster 1986 \{published data only\}

Oster MW, Gray R, Panasci L, Perry MC. Chemotherapy for advanced pancreatic cancer. A comparison of 5- fluorouracil, adriamycin, and mitomycin (FAM) with 5-fluorouracil, streptozotocin, and mitomycin (FSM). Cancer 1986;57(1):29-33. [MedLine: CT].

Palmer 1994 \{published data only\}

Palmer KR, Kerr M, Knowles G, Cull A, Carter DC, Leonard RC. Chemotherapy prolongs survival in inoperable pancreatic carcinoma. British Journal of Surgery 1994;81(6):882-5. [MedLine: BSC].

Reni 2005 \{published data only\}

* Reni M, Cordio S, Milandri C, Passoni P, Bonetto E, Oliani C, et al. Gemcitabine versus cisplatin, epirubicin, fluorouracil, and gemcitabine in advanced pancreatic cancer: a randomised controlled multicentre phase III trial. The Lancet Oncology 2005;6(6):369-76.

Reni M, Cordio S, Passardi A, Pannuci P, et al. Final results of a phase III trial of gemcitabine $(\mathrm{G})$ versus PEFG regimen in stage IVA or metastatic pancreatic adenocarcinoma (PA). Proceedings of the American Society of Clinical Oncology 2004;23:Abstract 4010.
Reni M, Cordio S, Passardi A, Panucci M, Passoni P, Oliani C, et al. Final results of a phase III trial of gemcitabine $(G)$ versus PEFG regimen in stage IVA or metastatic pancreatic adenocarcinoma (PA). Proceedings of the American Society of Clinical Oncology 2004;23:Abstract 4010.

Riess 2005 \{published data only\}

Riess H, Helm A, Niedergethmann M, Schmidt-Wolf I, Moik M, Hammer C, et al. A Randomised, Prospective, Multicenter, Phase III Trial of Gemcitabine, 5-Fluorouracil (5-FU), Folinic Acid vs. Gemcitabine alone in Patients with Advanced Pancreatic Cancer. Proceedings of the American Society of Clinical Oncology. 2005; Vol. 23:Abstract LBA4009.

Rocha Lima 2004 \{published data only\}

Rocha Lima C, Cisar L, Orlando N, Morganti A, Rotche R, Gruia G, et al. Gemcitabine and irinotecan (IRINOGEM) increases response rate compared to gemcitabine alone (GEM) in a randomized phase III study in patients (pts) with locally advanced or metastatic pancreatic cancer who have not received prior systemic therapy. Proceedings of the American Society of Clinical Oncology Gastrointestinal Cancer Symposium 2004;1:(Abstract 107).

Rocha Lima C, Rotche R, Jeffery M, Trudeau M, Cisar L, Morganti A, et al. A randomized phase 3 study comparing efficacy and safety of gemcitabine (GEM) and irinotecan (I), to GEM alone in patients (pts) with locally advanced or metastatic pancreatic cancer who have not received prior systemic therapy. Proceedings of the American Society of Clinical Oncology 22;2003:Abstract 1005.

* Rocha Lima CM, Green MR, Rotche R, Miller WH, Jr, Jeffrey G, Cisar LA, et al. Irinotecan plus gemcitabine results in no survival advantage compared with gemcitabine monotherapy in patients with locally advanced or metastatic pancreatic cancer despite increased tumor response rate. Journal of Clinical Oncology 2004;22(18):377683.

Scheithauer 2003 \{published data only\} Scheithauer W, Schull B, Ulrich-Pur H, Schmid K, Raderer M, Haider K, et al. Biweekly high-dose gemcitabine alone or in combination with capecitabine in patients with metastatic pancreatic adenocarcinoma: a randomized phase II trial. Annals of Oncology 2003; 14(1):97-104.

Shinchi 2002 \{published data only\}

Shinchi H, Takao S, Noma H, Matsuo Y, Mataki Y, Mori S, Aikou T. Length and quality of survival after external-beam radiotherapy with concurrent continuous 5-fluorouracil infusion for locally unresectable pancreatic cancer. International Journal of Radiation Oncology Biology Physics 2002;53(1):146-50. [MedLine: CT/RT].

Stathopoulos 2005 \{published data only\} Stathopoulos G, Aravantinos G, Syrigos K, Kalbakis K, Karvounis N, Papakotoulas P, et al. A randomized phase III study of Irinotecan/gemcitabine combination versus gemcitabine in patients with advanced/metastatic pancreatic cancer. Proceedings of the American Society of Clinical Oncology. 2005; Vol. 23:Abstract 4106.

Takada 1998 \{published data only\}

Takada T, Kato H, Matsushiro T, Nimura Y, Nagakawa T, Nakayama T, et al. Prospective randomized trial comparing 1/2 FAM (5-fluorouracil (5-FU) + adriamycin + mitomycin C) versus palliative therapy for the treatment of unresectable pancreatic and biliary tract carcinomas (the 2nd trial in non-resectable patients). Japanese Study 
Group of Surgical Adjuvant Therapy for Carcinomas of the Pancreas and Biliary Tract. Gan To Kagaku Ryoho 1996;23:707-14.

* Takada T, Nimura Y, Katoh H, Nagakawa T, Nakayama T, Matsushiro T, Amano H, Wada K. Prospective randomized trial of 5fluorouracil, doxorubicin, and mitomycin $\mathrm{C}$ for non-resectable pancreatic and biliary carcinoma: multicenter randomized trial. Hepatogastroenterology 1998;45(24):2020-6. [MedLine: BSC].

Topham 1991 \{published data only\}

Topham C, Glees J, Rawson NS, Woods EM, Coombes RC. Randomised trial of epirubicin alone versus 5-fluorouracil, epirubicin and mitomycin $\mathrm{C}$ in locally advanced and metastatic carcinoma of the pancreas. British Journal of Cancer 1991;64(1):179-81. [MedLine: $\mathrm{CT}]$.

Topham 1993 \{published data only\}

Topham C, Glees J, Coombes RC. Comparison of single-agent epirubicin and 5- fluorouracil/epirubicin/mitomycin in patients with advanced adenocarcinoma of the pancreas. Oncology 1993;50 Suppl 1: 78-80. [MedLine: CT].

Wang 2002 \{published data only\}

Wang X, Ni Q, Jin M, Li Z, Wu Y, Zhao Y, at al. Gemcitabine (G) or gemcitabine plus cisplatin (GC) as first-line treatment in Chinese patients (pts) with locally advanced (LAPC) and metastatic pancreatic cancer (MPC): a multicenter, randomized, study. Proceedings of the American Society of Clinical Oncology 2002;21:Abstract 616.

* Wang X, Ni Q, Jin M, Li Z, Wu Y, Zhao Y, Feng F. Gemcitabine or gemcitabine plus cisplatin for in 42 patients with locally advanced or metastatic pancreatic cancer. Zhonghua Zhong Liu Za Zhi 2002; 24(4):404-7. [MedLine: CT].

\section{References to studies excluded from this review Aigner 1998}

Aigner KR, Gailhofer S, Kopp S. Regional versus systemic chemotherapy for advanced pancreatic cancer: a randomized study. Hepatogastroenterology 1998;45(22):1125-9. [MedLine: Regional vs systemic].

Alberts 2004

Alberts S, Foster N, Morton R, Kugler J, Schaefer P, Wiesenfeld $\mathrm{M}$, et al. PS-341 and gemcitabine in patients with metastatic pancreatic adenocarcinoma:a North Central Cancer Treatment Group (NCCTG) randomized phase II study. Annals of Oncology 2005;16: 1854-61.

\section{Asbury 1994}

Asbury RF, Cnaan A, Johnson L, Harris J, Zaentz SD, Haller DG. An Eastern Cooperative Oncology Group phase II study of single agent DHAD, VP-16, aclacinomycin, or spirogermanium in metastatic pancreatic cancer. American Journal of Clinical Oncology 1994;17(2): 166-9. [MedLine: Non randomised].

\section{Auerbach 1997}

Auerbach M, Wampler GL, Lokich JJ, Fryer D, Fryer JG, Ahlgren JD. Treatment of advanced pancreatic carcinoma with a combination of protracted infusional 5-fluorouracil and weekly carboplatin: a MidAtlantic Oncology Program Study. Annals of Oncology 1997;8(5): 439-44. [MedLine: Non randomised].

\section{Bramhall 2001}

Bramhall SR, Rosemurgy A, Brown PD, Bowry C, Buckels JA. Marimastat as first-line therapy for patients with unresectable pancreatic cancer: a randomized trial. Journal Clinical Oncology 2001;19(15): $3447-55$.

\section{Bramhall 2002}

Bramhall SR, Schulz J, Nemunaitis J, Brown PD, Baillet M, Buckels JA. A double-blind placebo-controlled, randomised study comparing gemcitabine and marimastat with gemcitabine and placebo as first line therapy in patients with advanced pancreatic cancer. British Journal Cancer 2002;87(2):161-7. [MedLine: CT].

Bukowski 1993

Bukowski RM, Fleming TR, Macdonald JS, Oishi N, Taylor SA, Baker LH. Evaluation of combination chemotherapy and phase II agents in pancreatic adenocarcinoma. A Southwest Oncology Group study. Cancer 1993;71(2):322-5. [MedLine: Randomised phase II].

\section{Cascinu 1995}

Cascinu S, Del Ferro E, Catalano G. A randomised trial of octreotide vs best supportive care only in advanced gastrointestinal cancer patients refractory to chemotherapy ]. British Journal of Cancer 1995; 71(1):97-101. [MedLine: Biological]

\section{Chau 2003}

Chau I, Cunningham, Russell C, Norman A, Harper P, Harrison $\mathrm{P}$, et al. Gastrazole, a novel CCK B/gastrin receptor antagonist, in the treatment of advanced pancreatic cancer: results from two randomised controlled trials. European Journal of Cancer 2003;1(S5): Abstract 222.

\section{Chen 2006}

Chen J, Rocken C, Nitsche B, Hosius C, Gschaidmeier H, Kahl S, et al. The tyrosine kinase inhibitor imatinib fails to inhibit pancreatic cancer progression. Cancer Letters 2006;233(2):328-37.

\section{Colucci 1999}

Colucci G, Riccardi F, Giuliani F, Lopez M, Gebbia V, Uomo G, et al. Randomised Trial of Gemcitabine (GEM) alone or with cisplatin (CDDP) for the treatment advanced pancreatic carcinoma (APC): a phase II multicentre study of the Southern Italian Oncology Group. Proceedings of the American Society of Clinical Oncology. 1999; Vol. 18:250a.

\section{Ebert 2004}

Ebert M, Nitsche B, Roecken C, Fahlke J, Hosius C, Gschaidmeier $\mathrm{H}$, et al. A prospective and randomised clinical trial of the tyrosine kinase inhibitor imatinib mesylate as an initial therapy of advanced pancreatic cancer. Proceedings of the American Society of Clinical Oncology. 2004; Vol. 22, issue 14S:Abstract 4151.

\section{Gilliam 2004}

Gilliam AD, Topuzov EG, Garin AM, Pulay I, Broome P, Watson SA, et al. Randomised, double blind, placebo-controlled, multi-centre, group-sequential trial of G17DT for patients with advanced pancreatic cancer unsuitable or unwilling to take chemotherapy. Proceedings of the American Society of Clinical Oncology. 2004; Vol. 22, issue 14S:Abstract 2511.

\section{GITSG 1985a}

Gastrointestinal Tumor Study Group. Phase II trials of maytansine, low-dose chlorozotocin, and high-dose chlorozotocin as single agents against advanced measurable adenocarcinoma of the pancreas. Gastrointestinal Tumor Study Group. Cancer Treatment Reports 1985;69 (4):417-20. [MedLine: Randomised phase II]. 
Heinemann 2004

Heinemann V, Golf A, Seipelt G, Bauer J, Höhler T, Clemens M, et al. Randomised trial of capecitabine plus oxaliplatin (CapOx) versus capecitabine plus gemcitabine (CapGem) versus gemcitabine plus oxaliplatin $(\mathrm{GemOx})$ in advanced pancreatic cancer. Proceedings of the American Society of Clinical Oncology. 2004; Vol. 22, issue 14S: Abstract 4108 .

\section{Jacobs 2004}

Jacobs A, Burris H, Rivkin S, Ritch P, Eisenberg P, Mettinger K. A randomized phase III study of rubitecan (ORA) vs. best choice (BC) in 409 patients with refractory pancreatic cancer report from a NorthAmerican multi-center study. Proceedings of the American Society of Clinical Oncology. 2004; Vol. 22, issue 14S:Abstract 4013.

\section{Johnson 2001}

Johnson CD, Puntis M, Davidson N, Todd S, Bryce R. Randomized, dose-finding phase III study of lithium gamolenate in patients with advanced pancreatic adenocarcinoma. British Journal of Surgery 2001; 88(5):662-8. [MedLine: Same agent].

\section{Jones 1987}

Jones KG, Lindberg RD, Epremian B, Jose B, Spanos WJ, Jr. Radiation therapy with and without chemotherapy in the treatment of localized unresectable pancreatic carcinoma. A retrospective analysis. Journal of the Kentucky Medical Association 1987;85(6):305-9. [MedLine: Non randomised].

\section{Klapdor 1982}

* Klapdor R, Lehmann U, Bahlo M, Grabbe E, Kloppel G, Schreiber HW, et al. Palliative chemotherapy of pancreatic carcinoma. A prospective randomized study with 5-FU + BCNU and FAM. ZGASTROENTEROL. 1982; Vol. 20, issue 9:534.

Klapdor R, Lehmann U, Kloppel G, Schreiber HW, Greten H. Palliative treatment of pancreatic carcinoma with 5-FU + BCNU and FAM: a prospective randomised study. XIV meeting of the European Pancreatic Club. 1982:43.

\section{Klein 2000}

Klein B, Sadikov E, Mishaeli M, Levin I, Figer A. Comparison of 5$\mathrm{FU}$ and leucovorin to gemcitabine in the treatment of pancreatic cancer. Oncology Reports 2000;7(4):875-7. [MedLine: Not randomised].

\section{Kojima 1983}

Kojima J, Kamada T, Monna J. Clinical study on combination chemotherapy of primary liver cancer. Gan To Kagaku Ryoho 1983;10(4 Pt 1):997-1006. [MedLine: CT].

\section{Lersch 2001}

Lersch C, Van Cutsem E, Amado R, Ehninger G, Heike M, Kerr D, et al. Randomized phase II study of SCH 66336 and gemcitabine in the treatment of metastatic adenocarcinoma of the pancreas. Proceedings of the American Society of Clinical Oncology. 2001; Vol. 20:Abstract 608.

\section{Lokich 1974}

Lokich J, Chawla PL, Brooks J, Frei E. Chemotherapy in pancreatic carcinoma: 5 fluorouracil (5FU) and 1,3 bis- (2 chloroethyl)-1nitrosourea (BCNU). Annals of Surgery 1974;179(4):450-3. [MedLine: Non randomised].

\section{Lygidakis 1995}

Lygidakis NJ, Ziras N, Kyparidou E, Parissis J, Papadopoulou P, Venetsanou B. Combined immunopharmaceutical therapy of pa- tients with unresectable pancreatic carcinoma. Hepato-Gastroenterology 1995;42:1039-52.

\section{McCracken 1980}

McCracken JD, Ray P, Heilbrun LK, Vaitkevicius VK, Saiki JH, Rivkin SE, et al. 5-Fluorouracil, methyl-CCNU, and radiotherapy with or without testolactone for localized adenocarcinoma of the exocrine pancreas: a Southwest Oncology Group Study. Cancer 1980; 46(7):1518-22.

\section{Moore 2003}

Moore MJ, Hamm J, Dancey J, Eisenberg PD, Dagenais M, Fields A, et al. Comparison of gemcitabine versus the matrix metalloproteinase inhibitor BAY 12-9566 in patients with advanced or metastatic adenocarcinoma of the pancreas: a phase III trial of the National Cancer Institute of Canada Clinical Trials Group. Journal of Clinical Oncology 2003;21(17):3296-302.

\section{Moore 2005}

Moore M, Goldstein D, Hamm J, Figer A, A. Figer, J. Hecht, S. Gallinger, et al. Erlotinib plus gemcitabine compared to gemcitabine alone in patients with advanced pancreatic cancer. A phase III trial of the National Cancer Institute of Canada Clinical Trials Group [NCIC-CTG]. Proceedings of the American Society of Clinical Oncology 2005;23:Abstract 1

Moore MJ, Goldstein D, Hamm J, Figer A, Hecht J, Gallinger S, et al. Erlotinib improves survival when added to gemcitabine in patients with advanced pancreatic cancer. A phase III trial of the National Cancer Institute of Canada Clinical Trials Group. Proceedings of the American Society of Clinical Oncology Gastrointestinal Cancer Symposium. 2005; Vol. 2:Abstract 77.

\section{Oettle 2005a}

Oettle H, Pelzer UJ, Stieler J, Hilbig A, Roll L, Schwaner I, et al. Oxaliplatin/folinic acid/5-fluorouracil [24h] (OFF) plus best supportive care versus best supportive care alone (BSC) in second-line therapy of gemcitabine-refractory advanced pancreatic cancer (CONKO 003). Proceedings of the American Society of Clinical Oncology. 2005; Vol. 23:Abstract 4031.

Pancreatic Soc 1989

Imrie CW, Mallinson CN, Soukop M, Thomas G. Phase III study of 5 fluorouracil and epirubicin versus normal supportive treatment. Pancreatic Society of Great Britain (Clinical Trial Protocol) 1989.

Richards 2002

Richards D, Waterhouse D, Wagener D, Krishnamurthi S, Rosemurgy A, Dasse K, et al. Randomized, double-blind, placebo-controlled phase 2 study of the histone deacetylase inhibitor CI-994 plus gemcitabine $(\mathrm{CI}-994+\mathrm{G})$ versus placebo plus gemcitabine $(\mathrm{P}+\mathrm{G})$ in the treatment of patients with advanced pancreatic cancer (APC). Proceedings of the American Society of Clinical Oncology. 2002; Vol. 21:Abstract 644.

\section{Schein 1978}

Schein PS, Lavin PT, Moertel CG, Frytak S, Hahn RG, O'Connell $\mathrm{MJ}$, et al. Randomized phase II clinical trial of adriamycin, methotrexate, and actinomycin-D in advanced measurable pancreatic carcinoma: a Gastrointestinal Tumor Study Group Report. Cancer 1978;42(1):19-22.

\section{Shapiro 2005}

Shapiro J, Marshall J, Karasek P, Figer A, Oettle H, Coutureet F, et al. G17DT+gemcitabine $[\mathrm{Gem}]$ versus placebo+Gem in untreated 
subjects with locally advanced, recurrent, or metastatic adenocarcinoma of the pancreas: Results of a randomized, double-blind, multinational, multicenter study. Proceedings of the American Society of Clinical Oncology. 2005; Vol. 23:Abstract LBA4012.

\section{Stephens 1978}

Stephens RL, Hoogstraten B, Haas C, Clark G. Pancreatic cancer treated with carmustine, fluorouracil, and spironolactone: a randomized study. Archives of Internal Medicine 1978;138(1):115-7.

\section{Stolinsky 1975}

Stolinsky DC, Pugh RP, Bateman JR. 5-Fluorouracil (NSC-19893) therapy for pancreatic carcinoma: comparison of oral and intravenous routes. Cancer Chemotherapy Reports 1975;59(5):1031-3. [MedLine: Same agent].

Sunamura 2004

Sunamura M, Karasawa K, Okamoto A, Ogata Y, Nemoto K, Hosotani R, et al. Phase III trial of radiosensitizer PR-350 combined with intraoperative radiotherapy for the treatment of locally advanced pancreatic cancer. Pancreas 2004;28(3):330-4.

\section{Takada 1994}

Takada T, Kato H, Sasaki M, Matsushiro T, Yamauchi H, Kajihara T, et al. Prospective randomized trial comparing modified FAM (5-fluorouracil (5-FU) + adriamycin + mitomycin C) versus 5-FU alone for the treatment of non-resectable pancreatic and biliary tract carcinomas (the 1st trial in non-resectable patients). Study Group of Surgical Adjuvant Therapy for Carcinomas of the Pancreas and Biliary Tract. Gan To Kagaku Ryoho 1992;19(9):1295-301.

* Takada T, Lato H, Nimura Y, Nagakawa T, Nakayama T. Comparison of 5-fluorouracil, doxorubicin and mitomycin $\mathrm{C}$ with 5-fluorouracil alone in the treatment of pancreatic-biliary carcinomas. $\mathrm{On}$ cology 1994;51:396-400. [MedLine: CT].

Tempero 2003

Tempero M, Plunkett W, Ruiz Van Haperen V, Hainsworth J, Hochster H, Lenzi R, et al. Randomized phase II comparison of doseintense gemcitabine: thirty-minute infusion and fixed dose rate infusion in patients with pancreatic adenocarcinoma. Journal of Clinical Oncology 2003;21(18):3402-8.

Ulrich-Pur 2003

Ulrich-Pur H, Raderer M, Verena Kornek G, Schull B, Schmid K, Haider $\mathrm{K}$, et al. Irinotecan plus raltitrexed vs raltitrexed alone in patients with gemcitabine-pretreated advanced pancreatic adenocarcinoma. British Journal of Cancer 2003;88(8):1180-4.

\section{Van Cutsem 2004}

Van Cutsem E, Karasek P, Oettle H, Vervenne WL, Szawlowski A, Schoffski P, et al. Phase III trial comparing gemcitabine + R115777 (Zarnestra) versus gemcitabine + placebo in advanced pancreatic cancer (PC). Proceedings of the American Society of Clinical Oncology 2002; 21:Abstract 517.

* Van Cutsem E, Van De Velde H, Karasek P, Oettle H, Vervenne WL, Szawlowski A, et al. Phase III trial of gemcitabine plus tipifarnib compared with gemcitabine plus placebo in advanced pancreatic cancer. Journal of Clinical Oncology 2004;22(8):1430-8. [MedLine: Biological].

\section{Wagener 2002}

Wagener DJ, Wils JA, Kok TC, Planting A, Couvreur ML, Baron B. Results of a randomised phase II study of cisplatin plus 5-fluo- rouracil versus cisplatin plus 5-fluorouracil with alpha-interferon in metastatic pancreatic cancer: an EORTC gastrointestinal tract cancer group trial. European Journal of Cancer 2002;38(5):648-53. [MedLine: Biological].

\section{Zemskov 2000}

Zemskov VS, Procopchuk OL, Susak YM, Zemskov SV, Hodysh YY, Zemskova MV. Ukrain (NSC-631570) in the treatment of pancreas cancer. Drugs under Experimental and Clinical Research 2000;26(56):179-90.

\section{References to studies awaiting assessment}

Cohen 2005

Cohen SJ, Dobelbower R, Jr, Lipsitz S, Catalano PJ, Sischy B, Smith TJ, et al. A randomized phase III study of radiotherapy alone or with 5-fluorouracil and mitomycin-C in patients with locally advanced adenocarcinoma of the pancreas: Eastern Cooperative Oncology Group study E8282. International Journal of Radiation Oncology Biology Physics 2005;62(5):1345-50.

\section{Cunningham 2005}

Cunningham D, Chau I, Stocken D, Davis C, Dunn J, Valle J, et al. Phase III randomised comparison of gemcitabine (GEM) versus gemcitabine plus capecitabine (GEM-CAP) in patients with advanced pancreatic cancer. European Journal of Cancer Supplements. 2005; Vol. 3, issue 4:PS11.

\section{References to ongoing studies}

\section{CALGB 80303}

Randomized phase III trial of gemcitabine plus bevacizumab vs. gemcitabine plus placebo in patients with advanced pancreatic cancer. Ongoing study Starting date of trial not provided. Contact author for more information.

\section{CALGB-89904}

Phase II randomised study of gemcitabine alone vs gemcitabine with cisplatin vs gemcitabine with Docetaxel vs gemcitabine with irinotecan in patients With metastatic pancreatic cancer. Ongoing study Starting date of trial not provided. Contact author for more information.

\section{ECOG-4201}

Phase III randomised study of gemcitabine with or without radiotherapy in patients with locally advanced, unresectable pancreatic cancer. Ongoing study 03/2003.

\section{ECOG-6201}

Phase III randomised study of standard infusion gemcitabine vs prolonged infusion gemcitabine with or without oxaliplatin patients with locally advanced or metastatic pancreatic cancer.. Ongoing study 03/2003.

\section{ECOG-E8200}

Phase II randomised study of irinotecan and docetaxel with or without cetuximab in patients with metastatic adenocarcinoma of the pancreas.. Ongoing study Starting date of trial not provided. Contact author for more information.

\section{EORTC 40033}

Phase III trial of docetaxel/gemcitabine vs gemcitabine in advanced pancreatic cancer.. Ongoing study Starting date of trial not provided. Contact author for more information. 


\section{EORTC-05962}

Phase III randomised multicentre trial of infusional fluorouracil with or without cisplatin and with or without chronomodulation against locally advanced or metastatic pancreatic cancer.. Ongoing study Starting date of trial not provided. Contact author for more information.

\section{FRE-GERCOR-GEM-GEMOX}

Phase III randomised study of gemcitabine with or without oxaliplatin in patients with locally or advanced or metastatic unresectable pancreatic cancer.. Ongoing study Starting date of trial not provided. Contact author for more information.

\section{Heinemann 2005}

Heinemann V, Hoehler T, Seipelt G, Wein A, et al. Capecitabine plus Oxaliplatin (CapOx) versus Capecitabine plus Gemcitabine (CapGem) versus Gemcitabine plus Oxaliplatin (GemOx) : A randomized phase II trial in advanced pancreatic cancer. Proc Am Soc Clin Oncol. 2005; Vol. 23:Abstract 4030.

\section{LORUS-LOR-VIR-PO3-00}

Phase III randomised study of gemcitabine with or without virulizin followed by optional secondline therapy with virulizin or placebo with or without fluorouracil in patients with chemotherapy-naive locally-advanced or metastatic pancreatic cancer.. Ongoing study 09/2002.

\section{MEYER-AIT-PAN-201}

Phase II randomised study of gemcitabine vs immunotherapy with CYTOIMPLANT as first line therapy in patients with unresectable, locally advanced or metastatic pancreatic cancer.. Ongoing study $12 / 1998$.

\section{MRC PANRAD}

A randomised trial of CF (Infusional 5-Fluorouracil and Cisplatin) alone versus CF plus concurrent radiotherapy in patients with locally advanced pancreatic carcinoma. Ongoing study Starting date of trial not provided. Contact author for more information.

\section{NCCTG-N014C}

Phase II randomized study of bortezomib with or without gemcitabine in patients with metastatic pancreatic adenocarcinoma. Ongoing study Study closed.

\section{NCI-6580}

Phase II randomised study of bevacizumab and gemcitabine with either cetuximab or erlotinib in patients with advanced adenocarcinoma of the pancreas.. Ongoing study Starting date of trial not provided. Contact author for more information.

\section{NCT00051467}

A randomised, phase II, study of TNFerade ${ }^{\mathrm{TM}}$ biologic with 5-FU and radiation therapy for first-line treatment of unresectable locally advanced pancreatic cancer. Ongoing study Starting date of trial not provided. Contact author for more information.

\section{RTOG-PA-0020}

Randomised phase II trial to compare the effectiveness of gemcitabine, paclitaxel, and radiation therapy with or without tipifarnib in treating patients who have locally-advanced pancreatic cancer.. Ongoing study Starting date of trial not provided. Contact author for more information.

\section{SWOG S0205}

Phase III randomised open label study comparing gemcitabine with cetuximab vs gemcitabine as first line therapy of patients with ad- vanced pancreatic carcinoma.. Ongoing study Starting date of trial not provided. Contact author for more information.

\section{TBC-PAN-003}

Phase III randomised controlled study to evaluate the safety and efficacy of PANVAC-VF in combination with GM-CSF vs best supportive care or palliative chemotherapy in patients with metastatic adenocarcinoma of the pancreas who have failed a gemcitabine containing chemotherapy regimen.. Ongoing study 06/2004.

\section{TC-CR-302}

Study of efficacy and safety of glufosfamide compared with best supportive care in metastatic pancreatic cancer. Ongoing study 09/2004.

\section{WELLSTAT-401.00.0012}

Phase III randomised study of triacetyleluridine and high dose fluorouracil versus gemcitabine in patients with unresectable locallyadvanced or metastatic pancreatic cancer.. Ongoing study 09/01.

\section{Additional references}

\section{Bruzzi 2002}

Bruzzi P. Objective response to treatment as a potential surrogate marker of survival in breast cancer. Annals of the New York Academy of Science 2002;963:144-7.

\section{Buyse 2000}

Buyse M, Thirion P, Carlson RW, Burzykowski T, Molenberghs G, Piedbois P. Relation between tumour response to first-line chemotherapy and survival in advanced colorectal cancer: a meta-analysis. Meta-Analysis Group in Cancer. Lancet 2000;356(9227):373-8.

\section{Conlon 1996}

Conlon KC, Klimstra DS, Brennan MF. Long term survival after curative resection for pancreatic ductal adenocarcinoma. Clinicopathologic analysis of 5-year survivors. Annals of Surgery 1996;223:273-9.

Fung 2003

Fung MC, Takayama S, Ishiguro H, Sakata T, Adachi S, Morizane T. Chemotherapy for advanced or metastatic pancreatic cancer: analysis of 43 randomized trials in 3 decades (1974-2002). Gan To Kagaku Ryoho 2003;30(8):1101-11.

\section{Geer 1993}

Geer RJ, Brennan MF. Prognostic indicators for survival after resection of pancreatic adenocarcinoma. American Journal of Surgery 1993;165(1):68-72; discussion 72-3.

\section{Higgins 2005}

Higgins JPT, Green S, editors. Cochrane Handbook for Systematic Reviews of Interventions 4.2.5 [updated May 2005]. In: The Cochrane Library, 3, 2005. Chichester, UK: John Wiley \& Sons, Ltd.

\section{Jemal 2005}

Jemal A, Murray T, Ward E, Samuels A, Tiwari RC, Ghafoor A, et al. Cancer statistics, 2005. CA: a Cancer Journal for Clinicians 2005; 55(1):10-30.

\section{Lim 2003}

Lim JE, Chien MW, Earle CC. Prognostic factors following curative resection for pancreatic adenocarcinoma: a population-based, linked database analysis of 396 patients. Annals of Surgery 2003;237(1):7485.

\section{Neoptolemos 2004}

Neoptolemos JP, Stocken DD, Friess H, Bassi C, Dunn JA, Hickey $\mathrm{H}$, et al. A randomized trial of chemoradiotherapy and chemotherapy 
after resection of pancreatic cancer. New England Journal of Medicine 2004;350(12):1200-10.

Parkin 2005

Parkin DM, Bray F, Ferlay J, Pisani P. Global cancer statistics, 2002. CA: a Cancer Journal for Clinicians 2005;55(2):74-108.

\section{Reni 2004b}

Reni M, Bonetto E, Cordio S, Passoni P, et al. Quality of life outcome in advanced pancreatic adenocarcinoma:results from a phase III trial. Annals of Oncology 2004;15(Suppl 4):Abstract 911P.

Sener 1999

Sener SF, Fremgen A, Menck HR, Winchester DP. Pancreatic cancer: a report of treatment and survival trends for 100,313 patients diagnosed from 1985-1995, using the National Cancer Database. Journal of the American College of Surgeons 1999;189(1):129-30.

Shahrudin 1997

Shahrudin MD. Carcinoma of the pancreas: resection outcome at the University Hospital Kuala Lumpur. International Surgery 1997; 82:269-74.

Stocken 2005

Stocken DD, Buchler MW, Dervenis C, Bassi C, Jeekel H, Klinkenbijl JH, et al. Meta-analysis of randomised adjuvant therapy trials for pancreatic cancer. British Journal of Cancer 2005;92(8):1372-81.
Trede 1990

Trede M, Schwall G, Saeger HD. Survival after pancreatoduodenectomy. 118 consecutive resections without an operative mortality. $A n-$ nals of Surgery 1990;211(4):447-58.

\section{Wagner 2004}

Wagner M, Redaelli C, Lietz M, Seiler CA, Friess H, Buchler MW. Curative resection is the single most important factor determining outcome in patients with pancreatic adenocarcinoma. British Journal of Surgery 2004;91(5):586-94.

\section{Wilkowski 2005}

Wilkowski R, Thoma M, Schauer R, Wagner A, Heinemann V. Effect of chemoradiotherapy with gemcitabine and cisplatin on locoregional control in patients with primary inoperable pancreatic cancer. World Journal of Surgery 2004;28(10):1011-8.

Yeo 1997

Yeo CJ, Cameron JL, Sohn TA, Lillemoe KD, Pitt HA, Talamini MA, et al. Six hundred fifty consecutive pancreaticoduodenectomies in the 1990s: pathology, complications, and outcomes. Annals of Surgery 1997;226(3):248-57; discussion 257-60.

* Indicates the major publication for the study

T A B LE S

\section{Characteristics of included studies}

\begin{tabular}{|c|c|}
\hline Study & Andersen 1981 \\
\hline Methods & $\begin{array}{l}\text { Randomised controlled trial } \\
\text { Single centre study } \\
\text { Recruitment period: August 1974-January } 1978 \\
\text { Funding not stated }\end{array}$ \\
\hline Participants & $\begin{array}{l}\text { Inclusion criteria: microscopically-proven pancreatic carcinoma. } \\
\text { Exclusion criteria: terminal disease; previous chemotherapy; concomitant disease precluding evaluation of } \\
\text { response. } \\
\text { Total patients enrolled: } 40 \text { (A: } 20, \mathrm{~B}: 20) \text {. } \\
\text { Median age: } 67 \text { y (range } 34-81 \text { y) } \\
\text { M:F ratio: } 16: 24 \text {. } \\
\text { Disease extent: locally advanced and metastatic or relapsed: A: } 19: 1 \text {, B. } 18: 2 .\end{array}$ \\
\hline Interventions & $\begin{array}{l}\text { A. Best supportive care+ placebo (isotonic saline). } \\
\text { B. Best supportive care+ } 5 \text { FU } 10 \mathrm{mg} / \mathrm{kg}+\text { BCNU } 40 \mathrm{mg} / \mathrm{sqm} \text { days } 1-5 \text {. }\end{array}$ \\
\hline Outcomes & $\begin{array}{l}\text { Median survival } \\
\text { One year survival }\end{array}$ \\
\hline$\overline{\text { Notes }}$ & 'Triple blind' randomised scheme. \\
\hline Allocation concealment & A-Adequate \\
\hline Study & Andren-Sandberg 1983 \\
\hline Methods & Randomised controlled trial, \\
\hline
\end{tabular}




\section{Characteristics of included studies (Continued)}

\begin{tabular}{|c|c|}
\hline & $\begin{array}{l}\text { single-centre study, } \\
\text { Recruitment period not stated } \\
\text { Funding not stated. }\end{array}$ \\
\hline Participants & $\begin{array}{l}\text { Inclusion criteria: inoperable pancreatic cancer with pathological confirmation, age }<71 \text { years, no prior } \\
\text { chemotherapy. } \\
\text { Number randomised: } 47 \text { (A: } 22, \text { B:25). } \\
\text { Median age: A: } 61 \text { y (range } 40-69 \text { y), B: } 60 \text { (range } 28-78 \text { y) } \\
\text { M } \\
\text { M:F ratio: A: } 15: 7 \text {, B: } 15: 10 . \\
\text { Locally-advanced: metastatic: A: 10:12, B: } 14: 11 .\end{array}$ \\
\hline Interventions & $\begin{array}{l}\text { A. Best supportive care. } \\
\text { B. Vincristine } 1 \mathrm{mg} / \mathrm{sqm} \text { IVI d1, 5FU 500mg PO d2-5+CCNU PO d2-3 q six weekly }\end{array}$ \\
\hline Outcomes & $\begin{array}{l}\text { Median survival } \\
\text { QOL (Karnofsky scale) }\end{array}$ \\
\hline Notes & $\begin{array}{l}\text { Randomisation not assessable } \\
\text { In control group, } 16 \text { had undergone gastroenterostomy and two had percutaneous biliary stents } \\
\text { In the treatment group } 18 \text { had undergone gastroenterostomy and } 4 \text { had percutaneous biliary stents. }\end{array}$ \\
\hline Allocation concealment & $\mathrm{B}$ - Unclear \\
\hline Study & Berlin 2002 \\
\hline Methods & $\begin{array}{l}\text { Randomised controlled trial, multicentred government-funded } \\
\text { Recruitment period: April 1998- November } 1999 . \\
\text { Planned enrolment: } 320 .\end{array}$ \\
\hline Participants & $\begin{array}{l}\text { Inclusion criteria: microscopically-confirmed pancreatic cancer not amenable to resection; >18 y; ECOG } \\
\text { performance status } 0-2 \text {; no active malignancy or active disease; adequate organ function } \\
\text { Exclusion criteria: prior chemotherapy for advanced disease; pregnant or lactating female. } \\
\text { Total patients randomised:322 (A: 162, B: } 160) \text {. } \\
\text { Mean age: A: } 64 \text { y (33-85 y), B } 65 \text { (28-84 y) } \\
\text { M:F ratio: A: } 87: 75 \text {, B: } 83: 77 \text {. } \\
\text { Locally-advanced:metastatic: A: } 16: 145 \text { B: 17:143. }\end{array}$ \\
\hline Interventions & $\begin{array}{l}\text { A. Gemcitabine } 1 \mathrm{~g} / \mathrm{sqm} \text { IV weekly for } 3 \text { weeks out of } 4 \text {. } \\
\text { B. Gemcitabine } 1 \mathrm{~g} / \mathrm{sqm}+5 \mathrm{FU} 600 \mathrm{mg} / \mathrm{sqm} \text { IV for } 3 \text { weeks in } 4\end{array}$ \\
\hline$\overline{\text { Outcomes }}$ & $\begin{array}{l}\text { Median survival. } \\
\text { Progression free survival. } \\
\text { Overall survival at } 6 \text { and } 12 \text { months. }\end{array}$ \\
\hline Notes & $\begin{array}{l}\text { Prior radiotherapy allowed if }>4 \text { weeks prior, and adjuvant chemotherapy allowed if }>6 \text { months prior } \\
\text { Survival figures obtained from survival curve. }\end{array}$ \\
\hline Allocation concealment & A-Adequate \\
\hline Study & Bukowski 1983 \\
\hline Methods & $\begin{array}{l}\text { Randomised controlled trial, multicentre government -funded trial. } \\
\text { Recruitment period: not stated. }\end{array}$ \\
\hline Participants & $\begin{array}{l}\text { Inclusion criteria: histologically confirmed adenocarcinoma of pancreas; no prior chemotherapy or radio- } \\
\text { therapy; adequate renal function. } \\
\text { Total number randomised: } 181 \text { (A: } 88, \mathrm{~B}: 93) \text {. } \\
\text { Bypass surgery: A: } 27, \mathrm{~B}: 32 \text {. }\end{array}$ \\
\hline$\overline{\text { Interventions }}$ & $\begin{array}{l}\text { A. MF chemotherapy (5FU } 1000 \mathrm{mg} / \mathrm{sqm} \text { IV d1-4, 29-32, mitomycin C 20-30mg/sqm IV d1) every } 56 \\
\text { days. }\end{array}$ \\
\hline
\end{tabular}




\section{Characteristics of included studies (Continued)}

B. SMF chemotherapy (5FU 1000mg/sqm IV d1-4, d29-32, mitomycin C 10-15 mg/sqm IV, streptozotocin $400 \mathrm{mg} / \mathrm{sqm} \mathrm{d} 1-4, \mathrm{~d} 29-32)$ every 56 days.

\begin{tabular}{ll}
\hline Outcomes & Median survival. \\
& 1-year survival. \\
& Response rate. \\
\hline Notes & Patients stratified according to risk status, presence of measurable or non-measurable disease. \\
& Poor risk patients received the lower dose level of mitomycin C. \\
& Results given separately for measurable and non-measurable disease patients. \\
\hline Allocation concealment & B - Unclear \\
\hline
\end{tabular}

\begin{tabular}{|c|c|}
\hline Study & Buroker 1979 \\
\hline Methods & $\begin{array}{l}\text { Randomised control trial, multicentre study (11 institutions), government funded. } \\
\text { Recruitment period: March 1975-March } 1977 .\end{array}$ \\
\hline Participants & $\begin{array}{l}\text { Inclusion criteria: histologically confirmed adenocarcinoma of pancreas; clinical evidence of gross locally } \\
\text { recurrent or metastatic tumour; no prior chemotherapy; life expectancy }>8 \text { weeks; WCC }>4000 \text {; platelets } \\
>1000 \text {; } \mathrm{Cr}<1.5 \mathrm{mg} / \mathrm{dL} \text {. } \\
\text { Total enrolled (pancreatic): } 144 \\
\text { Total eligible(pancreatic): } 140 \text { (A:69, B: } 71 \text { ) } \\
\text { Seven dropouts: } 3 \text { refused further therapy, one incomplete form, } 3 \text { lost to follow-up. }\end{array}$ \\
\hline Interventions & $\begin{array}{l}\text { A. } 5 \mathrm{FU} 1 \mathrm{~g} / \mathrm{sqm} / \text { day infusion for } 4 \text { days every } 4 \text { weeks + mitomycin C } 15-20 \mathrm{mg} / \mathrm{sqm} \text { IVon d } 1 \text { every } 8 \text { weeks. } \\
\text { B. } 5 \mathrm{FU} 1 \mathrm{~g} / \mathrm{sm} / \text { day infusion x } 4 \text { days every } 4 \text { weeks, MeCCNU } 150-175 \mathrm{mg} / \mathrm{sqm} \text { PO on d } 1 \text { every } 8 \text { weeks. }\end{array}$ \\
\hline Outcomes & $\begin{array}{l}\text { Median survival. } \\
\text { Response rate. } \\
\text { Toxicity. }\end{array}$ \\
\hline$\overline{\text { Notes }}$ & $\begin{array}{l}\text { Trial enrolled both pancreatic and gastric cancers. Separate data available for pancreatic cancer. } \\
3 \text { patients ineligible in arm A and } 1 \text { on arm B. } \\
\text { Patients stratified for presence or absence of measurable disease and liver metastases. } \\
\text { Dose of mitomycin C reduced by } 50 \% \text { once } 3 \text { rd course reached. } \\
\text { Lower dose of MeCCNU used if age }>65 \text {, concurrent radiotherapy or bilirubin }>2 \text { times normal. }\end{array}$ \\
\hline Allocation concealment & B - Unclear \\
\hline
\end{tabular}

\begin{tabular}{|c|c|}
\hline Study & Burris 1997 \\
\hline Methods & $\begin{array}{l}\text { Randomised controlled trial, multicentred (17 sites), pharmaceutical company funded (Eli Lilly). } \\
\text { Planned enrolment: not stated, enrolment period: July 1992-March } 1994 .\end{array}$ \\
\hline Participants & $\begin{array}{l}\text { Inclusion criteria: locally-advanced or metastatic pancreatic cancer with pathological diagnosis not amenable } \\
\text { to curative resection; life expectancy }>12 \text { months; Karnofsky score }>50 ; \mathrm{Cr}<1.5 \text {; WCC }>3.5 ; \mathrm{Hb}>9.5 \text {; AST } \\
\text { and ALT <3 x upper limit of normal unless tumour involvement where }<5 \mathrm{x} \text { upper limit of normal. } \\
\text { Exclusion criteria : prior chemotherapy, prior radiotherapy unless the only site of measurable disease. } \\
\text { Number enrolled: } 160 \text {. } \\
\text { Number randomised: } 126 \text { (A:63,B:63). } \\
\text { Median age: A: } 61 \text { y (36-77 y) and B: } 62 \text { y (37-79 y). } \\
\text { M:F ratio: A: } 34: 29, \text { B: } 34: 29 . \\
\text { Metastatic: A: } 76 \% \text {, B: } 72 \% \text {. } \\
\text { Dropouts prior to randomisation=34. Reasons: due to ineligibility (17), inadequate pain control (10), medical } \\
\text { problems (4) and declined further evaluation (3). }\end{array}$ \\
\hline Interventions & $\begin{array}{l}\text { A. } 5 \mathrm{FU} 600 \mathrm{mg} / \mathrm{sqm} \text { IV bolus weekly until progression. } \\
\text { B. Gemcitabine } 1000 \mathrm{mg} / \mathrm{sqm} \text { IV weekly for } 7 \text { weeks then } 1 \text { week off and weekly for } 3 \text { weeks out of } 4 \text { until } \\
\text { progression. }\end{array}$ \\
\hline
\end{tabular}




\section{Characteristics of included studies (Continued)}

Outcomes Clinical benefit (composite measure of pain, analgesic consumption, performance status, weight).

Median survival.

1 year survival.

Response rate.

\begin{tabular}{ll}
\hline Notes & $\begin{array}{l}\text { Pain stabilisation lead in period of 2-7d prior to treatment commencement. } \\
\text { Clinical benefit was the primary endpoint of trial. }\end{array}$ \\
\hline Allocation concealment & A - Adequate
\end{tabular}

Study

Methods

Participants

\section{Cantore 2004}

Randomised controlled trial, multicentre (9 sites).

Enrollment period: June 1997-June 2001.

Funding not stated.

Inclusion criteria: histologically-proven adenocarcinoma of pancreas not suitable for curative resection; KPS $>50$; adequate bone marrow reserve; hepatic function and renal function.

Exclusion criteria: peritoneal metastases; previous chemotherapy; radiotherapy or both; previous myocardial infarct; severe coagulopathy; second malignancy or pregnancy.

Number enrolled and randomised: 175 (A: 67, B: 71, C: 37).

Median age: A: 64 y (37-79 y), B: 61 y (38-76y), C:64 y (41-78 y).

M:F ratio: A: 70:30, B: 63:37, C: 57:43.

Locally advanced: metastatic: A: 48:52, B: 49:51, C 43: 57.

Two patients lost to followup in Arm C.

Interventions A. Gemcitabine $1 \mathrm{~g} / \mathrm{sqm}$ IV weekly for 7 weeks then 1 week off and weekly for 3 weeks out of 4 .

B. FLEC (Leucovorin $100 \mathrm{mg} / \mathrm{sqm}+5 \mathrm{FU} 1000 \mathrm{mg} / \mathrm{sqm}+$ carboplatin $300 \mathrm{mg} / \mathrm{sqm}+$ epirubicin $60 \mathrm{mg} / \mathrm{sqm}$ ) intra-arterial every 3 weeks for 3 cycles.

C. $5 \mathrm{FU} 400 \mathrm{mg} / \mathrm{sqm}+$ folinic acid $20 \mathrm{mg} / \mathrm{sqm}$ for $\mathrm{d} 1-5$ every 28 days $\mathrm{x} 6$ cycles

\begin{tabular}{ll}
\hline Outcomes & Overall survival \\
& Time to treatment failure \\
& Clinical benefit response \\
& Response rate \\
\hline Notes & FLEC arm received filgrastim (G-CSF) support for d10-d16 after treatment. \\
& Arm C terminated early in December 1998 by scientific committee due to reluctance of clinicians and \\
& patients to have patients randomised to this arm. \\
& Arm C data unpublished and provided by author. \\
\hline Allocation concealment & A- Adequate \\
\hline
\end{tabular}

Study Cheverton 2004

Methods

Randomised trial; multicentre (USA, Europe, South Africa).

Pharmaceutical industry sponsored (Daiichi).

Recruitment period: July 2001-January 2003.

Participants

Inclusion criteria: histologically or cytologically-proven locally advanced or metastatic adenocarcinoma of the pancreas; KPS>60\%; no prior chemotherapy.

Planned recruitment: 340 .

Number randomised: 339 (A: 170. B: 169).

Number completing: 330 .

M: F ratio: A: 96:73, B: 100:70.

Locally advanced: metastatic: A: 49:121, B: 51:118.

5 dropouts in $\mathrm{A}$ and 4 in $\mathrm{B}$, reasons not given.

Interventions

A. Gemcitabine $1000 \mathrm{mg} / \mathrm{sqm}$ IV weekly for 7 weeks, 1 week break then for 3 weeks out of 4

Chemotherapy and radiotherapy for inoperable advanced pancreatic cancer (Review)

Copyright (c) 2007 The Cochrane Collaboration. Published by John Wiley \& Sons, Ltd 


\section{Characteristics of included studies (Continued)}

B. Exatecan (DX-8951f) $0.5 \mathrm{mg} / \mathrm{sqm}$ daily for d1-5 every 3 weeks

\begin{tabular}{ll}
\hline Outcomes & Median survival. \\
& Survival at 6 months, 12 months and 21 months. \\
& Time to progression. \\
& Time to worsening of clinical benefit. \\
& Response rate. \\
& Time to marker progression. \\
\hline Notes & \\
\hline Allocation concealment & A-Adequate
\end{tabular}

Study

Childs 1965

Methods

Randomised double blind controlled trial.

Single centre study supported in part by the American Cancer Society. 5FU supplied by Hoffman La Roche. No information on recruitment period or dropouts from study.

Participants Inclusion criteria: inoperable histologically proven adenocarcinoma of the gastrointestinal tract; localised no distant metastases at operation; disease within $20 \times 20 \mathrm{~cm}$ radiation field.

Total enrolled (pancreatic only): 25 (A: 12 B: 13).

Mean age: A: 59 y (range 47-74 y) B: 56 y (44-72 y).

M:F ratio: A: 11:1 B: 8:5.

Interventions A. Radiotherapy (3500-4000 rad $6 \mathrm{~d}$ per week, 900-1200 rad /week) +saline.

B. Radiotherapy (3500-4000 rad $6 \mathrm{~d}$ per week, 900-1200 rad $/$ week $)+5 \mathrm{FU}(15 \mathrm{mg} / \mathrm{kg} /$ day on consecutive days until $40-50 \mathrm{mg} / \mathrm{kg}$ total dose reached).

Outcomes Survival at 6 and 12 months.

Median survival.

Notes $\quad$ Placebo controlled study. Pharmacists made up solutions but clinicians blinded.

Further radiotherapy and chemotherapy allowed on progression. Approximately equally distributed.

Allocation concealment A-Adequate

\begin{tabular}{|c|c|}
\hline Study & Colucci 2002 \\
\hline Methods & $\begin{array}{l}\text { Randomised controlled trial, multicentred. } \\
\text { Funding not stated. } \\
\text { Enrolment period:not stated. }\end{array}$ \\
\hline Participants & $\begin{array}{l}\text { Inclusion criteria: histologically or cytologically diagnosed locally advanced and/or metastatic pancreatic } \\
\text { carcinoma; bidimensionally measurable disease; no prior chemotherapy; radiotherapy or hormonal therapy; } \\
\text { age } 18-75 \text { y, KPS }>50 \text {; no congestive cardiac failure; serious arrhythmia or coronary heart disease; absence } \\
\text { of severe uncontrolled metabolic; infectious; or neurological disease; absence of other malignant neoplasms } \\
\text { except CIS of the uterine cervix and nonmelanotic skin cancers; geographic accessibility; adequate baseline } \\
\text { bone marrow reserve; adequate hepatic function and adequate renal function. } \\
\text { Exclusion criteria : brain metastases; pre-existing medical condition of sufficient severity to prevent full } \\
\text { compliance with the study. } \\
\text { Planned accrual: } 106 \text {. } \\
\text { Total enrolled: } 107 \text { (A: } 54 \text {, B: } 53) \text {. } \\
\text { M:F ratio: A: } 50: 50 \text {, B: } 66: 34 \text {. } \\
\text { Median age: A: } 63 \text { y ( } 43-75 \text { y) B } 60(33-71 \text { y). } \\
\text { Metastatic: A: } 50 \%, \text { B } 57 \% \text {. }\end{array}$ \\
\hline Interventions & 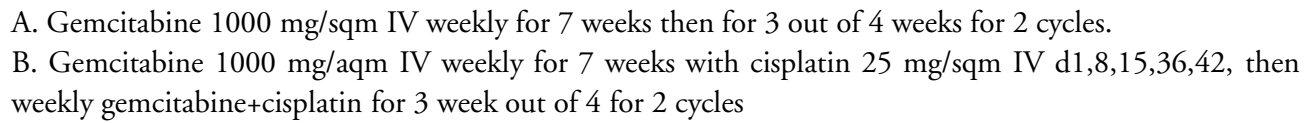 \\
\hline
\end{tabular}

Chemotherapy and radiotherapy for inoperable advanced pancreatic cancer (Review)

Copyright $($ C 2007 The Cochrane Collaboration. Published by John Wiley \& Sons, Ltd 


\section{Characteristics of included studies (Continued)}

Outcomes

Median survival.

Survival at 6 and 12 months.

Objective response rate.

Time to progression.

Toxicity.

\begin{tabular}{ll} 
Notes \\
Allocation concealment $\quad \mathrm{A}-$ Adequate \\
\hline
\end{tabular}

Study

Methods

Participants

\section{Cullinan 1985a}

Randomised controlled trial; multicentred study (12 centres) funded by National Cancer Institute. Recruitment period uncertain Planned accrual: 300 .

Inclusion criteria: unresectable or metastatic histologically proven pancreatic or gastric adenocarcinomas; minimum 3 weeks post major surgical procedure or 2 weeks post exploration and biopsy; ambulatory and capable of maintaining oral nutrition; ECOG status 0-3.

Exclusion criteria: prior chemotherapy; active infectious process; leucopenia; $(<4000)$, thrombocytopenia $(<130$; active heart disease; azotaemia or concomitant second primary cancer.

Total randomised: 305 .

Patients with pancreatic cancer randomised: 144 (A: 50, B: 44, C: 50).

Interventions

A. $5 \mathrm{FU}$ alone chemotherapy $(500 \mathrm{mg} / \mathrm{sqm}$ for $\mathrm{d} 1-5)$ every 4 weeks for 3 cycles then every 5 weeks.

B. Mallinson regimen: FA chemotherapy ( $5 \mathrm{FU} 400 \mathrm{mg} / \mathrm{sqm}$ for d1-4 + Adriamycin $40 \mathrm{mg} / \mathrm{sqm}$ d1) every 4 weeks for 3 cycles then every 5 weeks

C. FAM chemotherapy (5FU $600 \mathrm{mg} / \mathrm{sqm}$ for d1,8,29,36+ doxorubicin $30 \mathrm{mg} / \mathrm{sqm}$ for d1,29+mitomycin C $10 \mathrm{mg} / \mathrm{sqm}$ for $\mathrm{d} 1$ ) every 8 weeks.

Maximal cumulative dose adriamycin $=500 \mathrm{mg} / \mathrm{sqm}$

\begin{tabular}{ll}
\hline Outcomes & Response rate. \\
& Median survival. \\
& Time to progression. \\
& Palliative effects (weight gain, symptoms and performance score). \\
\hline Notes & Stratification within institution according to primary site, disease stage, presence of measurable disease and \\
& performance status. \\
& Survival figures obtained from survival curves. \\
& Cullinan 1985a and b are same trial. \\
& Arm B in pooled analysis. \\
\hline Allocation concealment & B - Unclear
\end{tabular}

\section{Cullinan 1985b}

Methods $\quad$ Randomised controlled trial, multicentred study (12 centres) funded by National Cancer Institute. Recruitment period uncertain.

Planned accrual: 300 .

Participants Inclusion criteria: unresectable or metastatic histologically proven pancreatic or gastric adenocarcinomas; minimum 3 weeks post major surgical procedure or 2 weeks post exploration and biopsy; ambulatory and capable of maintaining oral nutrition; ECOG status 0-3.

Exclusion criteria: prior chemotherapy; active infectious process; leucopenia; $(<4000)$; thrombocytopenia $(<130)$; active heart disease; azotaemia or concomitant second primary cancer.

Total randomised: 305 .

Patients with pancreatic cancer randomised: 144 (A: 50, B: 44, C: 50). 


\section{Characteristics of included studies (Continued)}

B. Mallinson regimen: FA chemotherapy (5FU $400 \mathrm{mg} / \mathrm{sqm}$ for d1-4 + Adriamycin $40 \mathrm{mg} / \mathrm{sqm}$ for d1) every 4 weeks for 3 cycles then every 5 weeks.

C. FAM chemotherapy (5FU $600 \mathrm{mg} / \mathrm{sqm}$ for d1,8,29,36+ doxorubicin $30 \mathrm{mg} / \mathrm{sqm}$ for d1,29+mitomycin C $10 \mathrm{mg} / \mathrm{sqm} \mathrm{d} 1$ ) every 8 weeks.

Maximal cumulative dose adriamycin $=500 \mathrm{mg} / \mathrm{sqm}$.

\begin{tabular}{ll}
\hline Outcomes & Response rate. \\
& Median survival. \\
& Time to progression. \\
& Palliative effects (weight gain, symptoms and performance score). \\
\hline Notes & Stratification within institution according to primary site, disease stage, presence of measurable disease and \\
& performance status. \\
& Survival figures obtained from survival curves. \\
& Cullinan 1985a and b are same trial. \\
& Arm C in pooled analysis \\
\hline Allocation concealment & B - Unclear \\
\hline
\end{tabular}

\begin{tabular}{|c|c|}
\hline Study & Cullinan 1990a \\
\hline Methods & $\begin{array}{l}\text { Randomised controlled study, multicentre study. } \\
\text { Funding not stated. } \\
\text { Accrual period not stated. }\end{array}$ \\
\hline Participants & $\begin{array}{l}\text { Inclusion criteria: histologically-proven ductal or undifferentiated adenocarcinoma of the pancreas; ambula- } \\
\text { tory; maintaining unassisted oral food intake of at least } 1200 \text { calories a day; minimum of } 3 \text { weeks recovery } \\
\text { from any major surgical procedure involving resection or bypass or } 2 \text { weeks from exploration and biopsy } \\
\text { only. } \\
\text { Exclusion criteria: ECOG } 4 \text {; prior chemotherapy; active infectious process; severe malnutrition; severe } \\
\text { nausea or frequent vomiting; leucopenia, thrombocytopenia; elevation of serum creatinine above the upper } \\
\text { limit of the institutional normal; active heart disease; known active second primary malignancy and prior } \\
\text { radiotherapy within previous } 4 \text { weeks. } \\
\text { Number randomised: } 187 \text {. } \\
\text { Eligible patients randomised: } 184 \text { (A: } 64 \text {, B:61,C:59). } \\
\text { Median age: A: } 60 \text { y ( } 35-79 \text { y), B: } 62 \text { y (34-79 y), C: } 62 \text { y }(27-76 \text { y) } \\
\text { M:F ratio A: } 66: 33 \text {, B: } 56: 44 \text {, C: } 64: 36 \text {. }\end{array}$ \\
\hline
\end{tabular}

\begin{tabular}{|c|c|}
\hline Interventions & 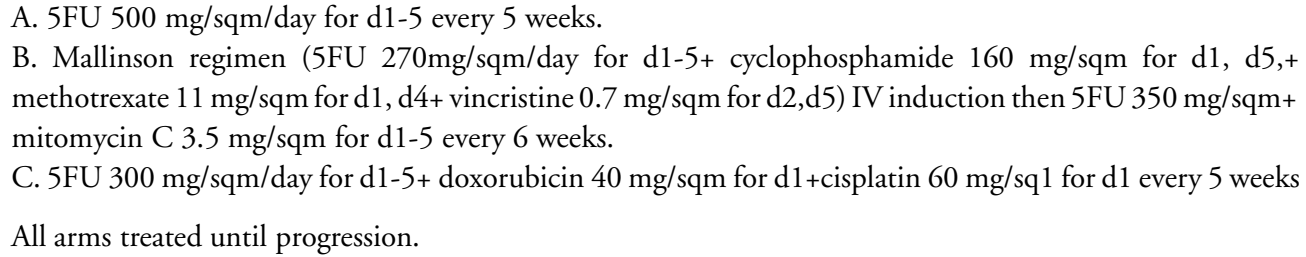 \\
\hline Outcomes & $\begin{array}{l}\text { Median survival. } \\
\text { Survival at } 6 \text { months and } 1 \text { year. } \\
\text { Response rate. } \\
\text { Toxicity. }\end{array}$ \\
\hline Notes & $\begin{array}{l}\text { Patients stratified according to presence of measurable disease, extent of metastasis and ECOG performance } \\
\text { status. } \\
3 \text { patients ineligible and not included in analysis. } \\
6 \text { and } 12 \text {-month survival read from survival curves. } \\
\text { Cullinan } 1990 \text { a and b are same trial. } \\
\text { Arm B comparison in pooled analysis. }\end{array}$ \\
\hline Allocation concealment & B - Unclear \\
\hline
\end{tabular}




\section{Characteristics of included studies (Continued)}

\section{Study}

Methods

Participants

\section{Cullinan 1990b}

Randomised controlled study, multicentre study.

Funding not stated.

Accrual period not stated.

Inclusion criteria: histologically proven ductal or undifferentiated adenocarcinoma of the pancreas;ambulatory; maintaining unassisted oral food intake of at least 1200 calories/d; minimum of 3 weeks recovery from any major surgical procedure involving resection or bypass, or 2 weeks from exploration and biopsy only.

Exclusion criteria: ECOG 4; prior chemotherapy; active infectious process; severe malnutrition; severe nausea or frequent vomiting; leucopenia; thrombocytopenia; elevation of serum creatinine above the upper limit of the institutional normal; active heart disease; known active second primary malignancy and prior radiotherapy within previous 4 weeks.

Number randomised: 187.

Eligible patients randomised: 184 (A: 64, B:61,C:59).

Median age: A: 60 y (35-79 y), B: 62 y (34-79 y), C: 62 y (27-76 y).

M:F ratio A: 66:33, B: 56:44, C: 64:36.

Interventions A. $5 \mathrm{FU} 500 \mathrm{mg} / \mathrm{sqm} /$ day for d1-5 every 5 weeks.

B. Mallinson regimen $(5 \mathrm{FU} 270 \mathrm{mg} / \mathrm{sqm} /$ day for $\mathrm{d} 1-5+$ cyclophosphamide $160 \mathrm{mg} / \mathrm{sqm}$ for $\mathrm{d} 1, \mathrm{~d} 5,+$ methotrexate $11 \mathrm{mg} / \mathrm{sqm}$ for $\mathrm{d} 1, \mathrm{~d} 4+$ vincristine $0.7 \mathrm{mg} / \mathrm{sqm}$ for d2, $\mathrm{d} 5$ ) IV induction then $5 \mathrm{FU} 350 \mathrm{mg} / \mathrm{sqm}+$ mitomycin C $3.5 \mathrm{mg} / \mathrm{sqm}$ for d $1-5$ every 6 weeks.

C. $5 \mathrm{FU} 300 \mathrm{mg} / \mathrm{sqm} /$ day for d1-5+ doxorubicin $40 \mathrm{mg} / \mathrm{sqm} \mathrm{d} 1+$ cisplatin $60 \mathrm{mg} / \mathrm{sqm}$ for $\mathrm{d} 1$ every 5 weeks.

All arms treated until progression.

\begin{tabular}{ll}
\hline Outcomes & Median survival \\
& Survival at 6 months and 1 year. \\
& Response rate \\
& Toxicity \\
\hline Notes & Patients stratified according to presence of measurable disease, extent of metastasis and ECOG performance \\
& status. \\
& 3 patients ineligible and not included in analysis. \\
& 6 and 12-month survival read from survival curves. \\
& Cullinan 1990 a and b are same trial. \\
& Arm C comparison in pooled analysis \\
\hline Allocation concealment & B - Unclear \\
\hline
\end{tabular}

Study

\section{Ducreux 2002}

Methods

Randomised controlled trial, multicentre trial (18 sites), government-funded.

Recruitment period: December 1992-January 1998.

No patients lost to follow up.

Participants

Inclusion criteria: histologically or cytologically proven adenocarcinoma of pancreas or ampulla; locallyadvanced or metastatic; life expectancy $>2$ months; WHO $<3$; age $<75$ y; no prior CT or RT of marker lesion; no hormonal treatment within 3 months; adequate hepatic; renal and bone marrow function.

Exclusion criteria: leucopenia $(<4000)$; thrombocytopenia $(<130)$; raised creatinine $(>110)$; hyperbilirubinaemia ( $>34)$; active heart disease; known previous second primary malignancy.

Total randomised (pancreatic) 198 (A:99, B:99).

Number with histological confirmation: 190 (A 94, B: 96).

Interventions A. $5 \mathrm{FU} 500 \mathrm{mg} / \mathrm{sqm} /$ day bolus IV for $\mathrm{d} 1-5$ days every 4 weeks until progression.

B. $5 \mathrm{FU} 1000 \mathrm{mg} / \mathrm{sqm} /$ day infusion $\mathrm{x} 5$ days+cisplatin $100 \mathrm{mg} / \mathrm{sqm}$ for $\mathrm{d} 1$ or 2 every 4 weeks until progression.

Outcomes Median survival.

1 year survival.

Chemotherapy and radiotherapy for inoperable advanced pancreatic cancer (Review)

Copyright $($ C 2007 The Cochrane Collaboration. Published by John Wiley \& Sons, Ltd 


\section{Characteristics of included studies (Continued)}

\begin{tabular}{|c|c|}
\hline & $\begin{array}{l}\text { Progression-free survival. } \\
\text { Response rate. } \\
\text { Symptoms and performance status. } \\
\text { QOL (Spitzer index). }\end{array}$ \\
\hline Notes & $\begin{array}{l}\text { Patients stratified by centre, presence of metastatic disease and by primary site. } \\
\text { In arm B cisplatin could be ceased because of renal, neurological or otological toxicity and 5FU alone } \\
\text { continued if stabilisation or response. } \\
\text { Radiation therapy and surgery allowed. } \\
\text { Second line chemotherapy given to } 26 \text { patients in arm A and } 17 \text { in arm B. } \\
\text { Eight patients (A:5, B:3) did not have histological or cytological diagnoses. } \\
\text { Data reported for combined group of pancreatic and ampullary cancers. Authors supplied survival figures } \\
\text { for pancreatic cancer subgroup, but this included the patients without pathological diagnosis. }\end{array}$ \\
\hline Allocation concealment & A-Adequate \\
\hline Study & Ducreux 2004 \\
\hline Methods & $\begin{array}{l}\text { Randomised controlled trial, multicentre trial (10 centres). } \\
\text { Pharmaceutical company sponsored (Sanofi Synthelabo). } \\
\text { Recruitment period: November } 1997-\text { July } 1999 . \\
\text { Planned recruitment: } 84 \text { (maximum } 28 \text { per arm). }\end{array}$ \\
\hline Participants & $\begin{array}{l}\text { Inclusion criteria: histologically or cytologically proven non resectable locally advanced or metastatic pancre- } \\
\text { atic carcinoma; at least one measurable lesion; no prior chemotherapy except } 5 \mathrm{FU} \text { administered with radio- } \\
\text { therapy with disease free interval of }>3 \text { months from completion of treatment; aged } 18-75 \text { y; life expectancy } \\
>12 \text { weeks; WHO PS 0-2; adequate bone marrow; renal and liver function. } \\
\text { Exclusion criteria: concomitant second malignancy; symptomatic peritoneal carcinomatosis or gastric steno- } \\
\text { sis; cerebral or leptomeningeal disease; peripheral neuropathy; concurrent other experimental drugs; hyper- } \\
\text { sensitivity to 5FU; pregnancy or breast feeding; pleural effusion or ascites as the only sign of disease. } \\
\text { Number randomised: } 65 \text { (2 dropouts due to deaths after randomisation, treatment allocations not stated). } \\
\text { Number treated } 63 \text { (A: } 15 \text {, B: } 17 \text {, C: } 31) \text {. } \\
\text { Median age: A: } 57 y \text { (35-66 y), B: } 55 \text { y }(21-74 \text { y), C: } 60 \text { y }(27-75 \text { y). } \\
\text { M:F ratio: A: } 60: 40 \text {, B: } 65: 35, \text { C: } 71: 29 \text {. } \\
\text { Locally advanced:metastatic: A: } 0: 100, \text { B: } 6: 94 \text {, C: } 16: 84 \text {. }\end{array}$ \\
\hline Interventions & $\begin{array}{l}\text { A. } 5 \text { FU } 1000 \mathrm{mg} / \mathrm{sqm} / \text { day continuous infusion for d1-4 every } 3 \text { weeks. } \\
\text { B. Oxaliplatin } 130 \mathrm{mg} / \mathrm{sqm} \text { IV over } 2 \text { hours every } 3 \text { weeks. } \\
\text { C. Oxaliplatin } 130 \mathrm{mg} / \mathrm{sqm} \text { IV over } 2 \text { hours for } \mathrm{d} 1+5 \mathrm{FU} 1000 \mathrm{mg} / \mathrm{sqm} / \text { day continuous infusion for } \mathrm{d} 1-4 \\
\text { every } 3 \text { weeks }\end{array}$ \\
\hline Outcomes & $\begin{array}{l}\text { Response rate. } \\
\text { Time to progression. } \\
\text { Median survival. } \\
6 \text { and } 12 \text {-month survival. } \\
\text { Clinical benefit response. }\end{array}$ \\
\hline Notes & $\begin{array}{l}13 \% \text { of patients had prior surgery. } \\
3 \% \text { received prior radiation therapy with } 5 \mathrm{FU} \text { treatment. } \\
3 \text { patients ( } 1 \text { in each arm) found to be ineligible but analysed: } 1 \text { non measurable disease and abnormal } \\
\text { bilirubin, } 1 \text { baseline CT }>6 \text { weeks prior to study start and one with disease free interval }<3 \text { months after } \\
\text { local regional chemoradiotherapy. } \\
\text { Second line therapy given in some patients but details not given of number or type. } \\
\text { Poor compliance with clinical benefit response assessment with only } 51 \% \text { evaluable. } \\
2 \text { deaths not related to disease: } 1 \text { suicide and } 1 \text { pulmonary embolism. }\end{array}$ \\
\hline Allocation concealment & A-Adequate \\
\hline
\end{tabular}




\section{Characteristics of included studies (Continued)}

\begin{tabular}{|c|c|}
\hline Study & Earle 1994 \\
\hline Methods & $\begin{array}{l}\text { Randomised trial, multicentre, funded by Public Health Service Grant. } \\
\text { Planned accrual: } 128 . \\
\text { Recruitment period: March 1981-November } 1987 . \\
\text { No patients lost to follow-up. }\end{array}$ \\
\hline Participants & $\begin{array}{l}\text { Inclusion criteria: histologically confirmed adenocarcinoma of pancreas; inoperable due to local extent or } \\
\text { regional nodes. } \\
\text { Exclusion criteria: direct extension into liver; peritoneal seeding; unable to be included in a } 20 \times 20 \mathrm{~cm} \\
\text { radiation port; coexistent malignant disease; prior chemotherapy; prior radiotherapy within the field for } \\
\text { study, coexisting infection; primary liver disease; ECOG performance status 4; bilirubin }>2 \times \text { upper limit of } \\
\text { normal or SGOT <2 x upper limit of normal; white cell count }<4.1 \text {; platelets }<130 \text {. } \\
\text { Total enrolled: } 87 \text { (A: } 44, \text { B:43). } \\
\text { Median age: A: } 64 \text { y, B: } 62 \text { y. } \\
\text { M:F ratio: A: } 28: 16 \text {, B: } 28: 15 \\
\text { Surgical exploration: A } 36, \text { B } 38 \text {. }\end{array}$ \\
\hline Interventions & $\begin{array}{l}\text { A. Radiotherapy ( } 40-50 \text { Gy }+5 \text { Gy boost split course ( } 20 \text { Gy over } 10 \mathrm{~d} \text { each with } 2 \text { week break })+5 \text { Gy boost) } \\
+5 \mathrm{FU} 500 \mathrm{mg} / \mathrm{sqm} / \mathrm{d} \text { IVI for } \mathrm{d} 1-3 \text {. of each radiotherapy course. } \\
\text { vs } \\
\text { B. Radiotherapy ( } 50 \mathrm{~Gy} \text { straight course over } 25 \mathrm{~d})+ \text { hycanthone } 60 \mathrm{mg} / \mathrm{sqm} \text { IV for } \mathrm{d} 1-5 \text { in week } 1 \text { and } 5 \text { of } \\
\text { radiotherapy }\end{array}$ \\
\hline Outcomes & Median survival. \\
\hline Notes & Study accrual slower than expected and trial closed when more than 70 deaths had been observed. \\
\hline ion concealment & $B-U$ \\
\hline
\end{tabular}

\section{Study}

\section{Frey 1981}

Methods

Randomised controlled trial, multicentre Veterans' Hospital study.

Recruitment period: January 1973- May 1977.

Planned recruitment: 190.

Participants

Inclusion criteria: histologically-proven non-resectable carcinoma of pancreas; drug therapy able to commence between 10 to $60 \mathrm{~d}$ postoperatively.

Number randomised: 152 (A: 87, B 65).

Histologically confirmed adenocarcinoma: 148 (A:84, B:64).

Liver metastases: A 44.8\%, B 47.7\%.

All male.

Disease extent ( locally advanced:metastatic): A10:12, B 14:11.

Interventions A. Best supportive care.

B. $5 \mathrm{FU} 9 \mathrm{mg} / \mathrm{kg}$ IVI for $\mathrm{d} 1-5+\mathrm{CCNU} 70 \mathrm{mg} / \mathrm{sqm}$ for $\mathrm{d} 1 \mathrm{q} 6$ weekly indefinitely in absence of toxicity.

Outcomes

Median survival.

Notes Randomisation by numbered envelopes.

All had undergone initial laparotomies.

$20 \%$ required reoperation.

Several patients required palliative radiotherapy (number not stated).

Bypass surgery control $86.2 \%$ and chemotherapy $74.5 \%$.

Survivals at 6 and 12 months obtained from survival curve.

Allocation concealment A-Adequate

Study

\section{GITSG 1985b}

Methods Randomised controlled trial, multicentred government funded study.

Chemotherapy and radiotherapy for inoperable advanced pancreatic cancer (Review)

Copyright ( 2007 The Cochrane Collaboration. Published by John Wiley \& Sons, Ltd 


\section{Characteristics of included studies (Continued)}

Recruitment period not stated.

Participants Inclusion criteria: histologically proven exocrine pancreatic adenocarcinoma; surgically staged with confirmation of locally-unresectable pancreatic adenocarcinoma; pancreas and area of known malignant disease encompassable in a $400 \mathrm{sqcm}$ anterior-posterior field.

Exclusion criteria: islet cell, cystadenocarcinoma, carcinoid, ampullary, duodenal cancer; distant metastases; prior chemotherapy or radiotherapy; prior malignancy within 3 years; ECOG performance score 3 or 4; coexisting infection; history of active heart disease; WCC $<400$; platelet $<150$; $\mathrm{Hb}<10$; bilirubin $>3 \mathrm{mg} / \mathrm{dL}$.

Total patients enrolled: 157

Ten patients ineligible.

Patients analysed 143 (A: 73, B: 78).

Median age: A: 62 y, B: 62 y.

M:F ratio: A: 44:29, B: 41:29.

Surgical bypass: A: 48 B: 49.

Interventions A. Radiotherapy $6000 \mathrm{rad}(200 \mathrm{rad} / \mathrm{d}$ for $5 \mathrm{~d}$ for 2 weeks) 33 split course with 2 week break $+5 \mathrm{FU} 500 \mathrm{mg} / \mathrm{sqm}$ for $\mathrm{d} 1-3$ with each course of radiotherapy then weekly $5 \mathrm{FU} 500 \mathrm{mg} / \mathrm{sqm}$ until tumour progression.

B. Radiotherapy $4000 \mathrm{rad}$ ( $200 \mathrm{r} /$ day for 5 days for 2 weeks) x 2 split course with 2 week break+adriamycin IV $15 \mathrm{mg} / \mathrm{sqm}$ for $\mathrm{d} 1,12 \mathrm{mg} / \mathrm{sqm}$ weekly for minimum 5 doses, $60 \mathrm{mg} / \mathrm{sqm}$ three weekly for 3 doses, 60 $\mathrm{mg} / \mathrm{sqm} 4$ weekly for 5 doses then $5 \mathrm{FU} 500 \mathrm{mg} / \mathrm{sqm}$ IV weekly for 2 years

\begin{tabular}{ll}
\hline Outcomes & Median survival. \\
\hline Notes & \\
\hline Allocation concealment & A - Adequate \\
\hline
\end{tabular}

\section{Study}

Methods

Participants

\section{GITSG 1988}

Randomised trial, multicentred study funded by a government grant.

Recruitment period: August 1983-October 1985.

Planned accrual: 152 .

Inclusion criteria: surgically-staged pathologically-confirmed adenocarcinoma of the pancreas; locally unresectable cancer confined to pancreas and contiguous organs; nodes or peritoneum overlying the pancreas; oral intake $>1500$ calories/day for 3 days; ambulant for more than half the day; free of infection; white cell count $>4000$; platelets $>150 ; \mathrm{HB}>10$ and bilirubin $<3 \mathrm{mg} / \mathrm{dL}$; creatinine clearance $>70 \mathrm{ml} / \mathrm{min}$.

Total enrolled 48 (A: 24, B: 24).

Number of patients eligible: 43 ( A:22, B:21).

Median age: A: 61 y B: $60 \mathrm{y}$.

M/F ratio: A:14:8 B:13:8.

Biliary bypass A: 13 , B: 15 .

Interventions A. SMF chemotherapy ( $5 \mathrm{FU} 600 \mathrm{mg} / \mathrm{sqm}$ IV on day 1,8,29,26; streptozotocin $1 / \mathrm{g} / \mathrm{sqm}$ every 8 weeks, mitomycin $10 \mathrm{mg} / \mathrm{sqm}$ IV every 8 weeks) for 2 years or until progression.

B. Radiotherapy (5400 rad (180 rad x 5 days every week for 6 weeks) with $5 \mathrm{FU} 350 \mathrm{mg} / \mathrm{sqm}$ IV daily on first last $3 \mathrm{~d}$ of radiotherapy,followed by SMF chemotherapy beginning on day 64 every 8 weeks for 2 years or until progression.

\begin{tabular}{ll}
\hline Outcomes & Median survival. \\
& Survival at $6,12,18$ and 24 months. \\
\hline Notes & Stratified by performance status and presence of surgical clips. \\
& Study terminated early due to lack of funding.
\end{tabular}

Allocation concealment $\mathrm{D}-$ Not used

\begin{tabular}{ll} 
Study & Gansauge 2002 \\
\hline Methods & Randomised trial, single centre study (Ulm). \\
& Gemcitabine supplied by Lilly and NSC 631570 supplied by Nowicky Pharma.
\end{tabular}

Chemotherapy and radiotherapy for inoperable advanced pancreatic cancer (Review)

Copyright ( 2007 The Cochrane Collaboration. Published by John Wiley \& Sons, Ltd 


\section{Characteristics of included studies (Continued)}

Other funding not stated.

Accrual period: August 1999-July 2001.

No patients lost to followup.

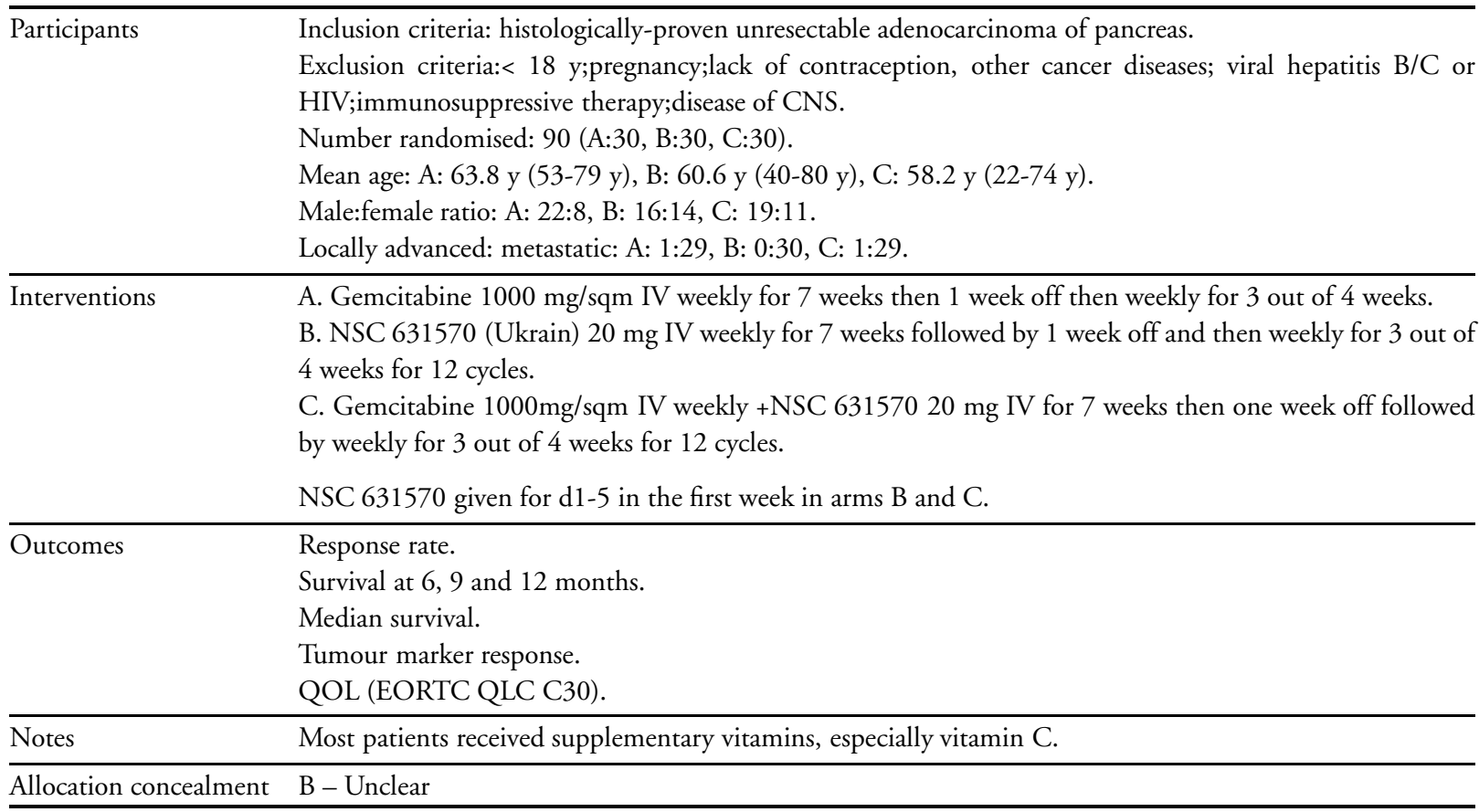

\begin{tabular}{|c|c|}
\hline Study & Glimelius 1996 \\
\hline Methods & $\begin{array}{l}\text { Randomised controlled trial, multicentred study. } \\
\text { Recruitment period: January } 1991 \text { to February } 1995 \\
\text { Planned recruitment: at least } 60 \text { patients. }\end{array}$ \\
\hline Participants & $\begin{array}{l}\text { Inclusion criteria: pancreatic and biliary adenocarcinoma with histological or cytological confirmation; non } \\
\text { curable by surgery; less than } 76 \text { years of age. } \\
\text { Exclusion criteria: creatinine }>125 \text {, bilirubin }>60 \text { and KPS }<50 \text {. } \\
\text { Total enrolled: } 90,53 \text { pancreatic (A: } 24 \text {, B: } 29 \text { ). } \\
\text { No patients lost to follow up. }\end{array}$ \\
\hline Interventions & $\begin{array}{l}\text { A. Best supportive care. } \\
\text { B. FLv ( } 5 \mathrm{FU} \text { bolus } 500 \mathrm{mg} / \mathrm{sqm} \text { IV+leucovorin } 60 \mathrm{mg} / \mathrm{sqm} \text { on d1, and d } 2 \text { every fortnight) if }>60 \text { years old } \\
\text { with KPS }<70 \text {. } \\
\text { or FELv ( } 5 \mathrm{FU} \text { bolus } 500 \mathrm{mg} / \mathrm{sqm}+\text { leucovorin } 60 \mathrm{mg} / \mathrm{sqm}+\text { etoposide } 120 \mathrm{mg} / \mathrm{sqm} \text { on } \mathrm{d} 1 \text {-d } 3 \text { three weekly) } \\
\text { otherwise. } \\
\text { Treatment until tumour progression or discontinuation if stable disease for } 4 \text { months or treatment to } 6 \\
\text { months if no symptoms at randomisation. }\end{array}$ \\
\hline Outcomes & $\begin{array}{l}\text { Median survival. } \\
\text { QOL (EORTC QLQ C30 scale). } \\
\text { Average quality adjusted survival. }\end{array}$ \\
\hline Notes & $\begin{array}{l}\text { Radiation therapy allowed in both arms of trial. } \\
\text { 1-year survival obtained by personal communication wiht author. } \\
\text { Survival curve for combined biliary and pancreatic patients in paper. } \\
\text { Survival figures for pancreas subgroup obtained by personal communication with first author. }\end{array}$ \\
\hline Allocation concealment & A - Adequate \\
\hline
\end{tabular}




\section{Characteristics of included studies (Continued)}

\begin{tabular}{ll} 
Study & Hazel $\mathbf{1 9 8 1}$ \\
\hline Methods & $\begin{array}{l}\text { Randomised trial, single centre study. } \\
\text { Source of funding not stated. }\end{array}$ \\
\hline Participants & $\begin{array}{l}\text { Inclusion criteria: biopsy proven adenocarcinoma of the pancreas; advanced disease; "non curative surgery" } \\
\text { undertaken. } \\
\text { Total number randomised: (pancreas only): } 30 \text { (A: 15; B 15). } \\
\text { Mean age: } 62 \mathrm{y} . \\
\text { M:F ratio: } 2.4: 1 .\end{array}$ \\
\hline Anterventions & $\begin{array}{l}\text { Antil disease progression. } \\
\text { B. Radiotherapy ( } 4600 \text { rad over } 4.5 \text { weeks) with weekly } 5 \mathrm{FU} 500 \mathrm{mg} / \mathrm{sqm} \text { IV and methyl CCNU 100mg/sqm } \\
\text { added } 6 \text { weekly after completion of radiotherapy for } 2 \text { y or until disease progression. }\end{array}$ \\
\hline Outcomes & $\begin{array}{l}\text { Median survival. } \\
\text { 2-year survival. }\end{array}$ \\
\hline Notes & Gastric and pancreas patients enrolled. Data available separately for pancreatic cancer. \\
\hline Allocation concealment & B - Unclear \\
\hline
\end{tabular}

\begin{tabular}{|c|c|}
\hline Study & Heinemann 2003 \\
\hline Methods & $\begin{array}{l}\text { Randomised study, multicentre study (34 centres). } \\
\text { Recruitment period: December 1997-January } 2002 . \\
\text { Funding not stated. }\end{array}$ \\
\hline Participants & $\begin{array}{l}\text { Inclusion criteria: histologically confirmed advanced pancreatic carcinoma. } \\
\text { Number randomised: } 198 \text { (A: 100, B:98). } \\
\text { Median age: A: } 66 \text { (43-85) B:64 (37-82). } \\
\text { Locally-advanced: A: } 20.9 \% \text { B: } 19.7 \% \text {. } \\
\text { Metastatic: } 79.2 \% \text { B: } 80.2 \% \text {. }\end{array}$ \\
\hline Interventions & $\begin{array}{l}\text { A. Gemcitabine } 1000 \mathrm{mg} / \mathrm{sqm} \text { on d1,8,15 IV of } 28 \text { day cycle } \\
\text { B. Gemcitabine } 1000 \mathrm{mg} / \mathrm{sqm}+\text { cisplatin } 50 \mathrm{mg} / \mathrm{sqm} \text { on } \mathrm{d} 1, \mathrm{~d} 15 \mathrm{IV} \text { of } 28 \text { day cycle }\end{array}$ \\
\hline Outcomes & $\begin{array}{l}\text { Median survival } \\
\text { Time to progression } \\
\text { Tumour response } \\
\text { Toxicity } \\
\text { QOL }\end{array}$ \\
\hline Notes & $\begin{array}{l}\text { Three patients lost to follow up in each arm. } \\
\text { Second-line chemotherapy used in } 16.5 \% \text { of arm A and } 15.8 \% \text { of arm B } \\
\text { Non-adenocarcinoma histology in } 7.1 \% \text { of arm A and } 3.2 \% \text { of arm B }\end{array}$ \\
\hline Allocation concealment & A-Adequate \\
\hline
\end{tabular}

\begin{tabular}{|c|c|}
\hline Study & Herrmann 2005 \\
\hline Methods & $\begin{array}{l}\text { Randomised study, multicentred study (8 countries (Europe and Isreal) } 30 \text { centres). } \\
\text { Recruitment period: June 2001-June } 2004 . \\
\text { Planned recruitment: not stated. }\end{array}$ \\
\hline Participants & $\begin{array}{l}\text { Inclusion criteria: histological proof of primary inoperable pancreatic adenocarcinoma; KPS }>60 \text {; adequate } \\
\text { organ function; no prior chemotherapy; adjuvant } 5 \mathrm{FU} / \text { radiotherapy allowed if more than } 2 \text { months prior. } \\
\text { Number randomised: } 319 \text { (A: } 159 \text {, B: } 160) \text {. } \\
\text { Median age: A: } 62 \text { y (36-84 y), B: } 62 \text { y }(27-83 \text { y). } \\
\text { M: F: ratio: A: } 53: 47 \text {, B: } 54: 46 \text {. } \\
\text { Locally-advanced:metastatic:A } 21: 79 \text {, B: } 20: 80 \text {. }\end{array}$ \\
\hline
\end{tabular}




\section{Characteristics of included studies (Continued)}

Interventions

Outcomes

Methods

Participants

Notes

Allocation concealment

A. Gemcitabine $1000 \mathrm{mg} / \mathrm{sqm}$ IV weekly for 7 weeks then 1 week off and weekly for 3 out of 4 weeks.

B. Gemcitabine $1000 \mathrm{mg} / \mathrm{sqm}$ IV for d1,d8+ capecitabine $650 \mathrm{mg} / \mathrm{sqm}$ PO bd for d1-14 every 3 weeks.

Median survival.

Response rate.

Progression free survival.

Clinical benefit response.
Patients stratified on basis of KPS, disease extent and presence or absence of pain.

A - Adequate

\begin{tabular}{|c|c|}
\hline Study & Horton 1981 \\
\hline Methods & $\begin{array}{l}\text { Randomised controlled trial.multicentred study ( } 31 \text { institutions), government-funded. } \\
\text { Recruitment period not stated. }\end{array}$ \\
\hline Participants & $\begin{array}{l}\text { Inclusion criteria: histologically proven carcinoma of the pancreas; residual recurrent or metastatic disease. } \\
\text { Exclusion criteria: major surgery within } 2 \text { weeks; exploratory procedures within } 2 \text { weeks; prior chemotherapy } \\
\text { or radiotherapy within the previous month; prior VP-16-213 or melphalan chemotherapy; active infectious } \\
\text { disease process; severe malnutrition; leucopenia }>4500 \text {; thrombocytopenia }<150 \text {; evidence of renal or liver } \\
\text { function impairment. } \\
\text { Total enrolled: } 140 \text { (chemonaive). } \\
\text { Dropouts: } 15 \text { patients cancelled or not eligible. } \\
\text { Number of eligible randomised: } 127 \text { (A: } 43, \mathrm{~B}: 41, \mathrm{C}: 43 \text { ). }\end{array}$ \\
\hline Interventions & $\begin{array}{l}\text { A. Melphalan } 6 \mathrm{mg} / \mathrm{sqm} \text { PO for d1-5 every } 6 \text { weeks. } \\
\text { B. } 5 \mathrm{FU} 350 \mathrm{mg} / \mathrm{sqm} \text { IV d1-5, } 5 \mathrm{FU} 400 \mathrm{mg} / \mathrm{sqm} \text { IV d36-40, Me CCNU } 150 \mathrm{mg} / \mathrm{sqm} / \text { day PO d1 every } 10 \\
\text { weeks. } \\
\text { C. } 5 \mathrm{FU} 350 \mathrm{mg} / \mathrm{sqm} \text { IV d1-5, } 5 \mathrm{FU} 400 \mathrm{mg} / \mathrm{sqm} \text { IV d } 36-40 \text {, MeCCNU } 150 \mathrm{mg} / \mathrm{sqm} \text { PO d1, streptozocin } \\
400 \mathrm{mg} / \mathrm{sqm} \text { D } 1-5 \text { IVI every } 10 \text { weeks.. } \\
\text { Treatment crossover of arm A to arm B on progression. } \\
\text { Salvage treatment of arms B and C to VP-16-213 on progression. }\end{array}$ \\
\hline Outcomes & Median survival. \\
\hline Notes & \\
\hline Allocation concealment & B - Unclear \\
\hline
\end{tabular}

\begin{tabular}{ll} 
Study & Huguier 2001 \\
\hline Methods & Randomised controlled trial, multicentre study (8 sites in France). \\
& Funding source not stated. \\
& Recruitment period: June 1992-December 1996. \\
& Planned enrollment: 120. \\
\hline Participants & Inclusion criteria: histologically proven pancreatic adenocarcinoma not resectable for cure. \\
& Exclusion criteria: other histology: neuroendocrine, mucinous, cholangiocarcinoma, ampullary; active heart \\
& disease; abnormal creatinine clearance; WHO PS >2; prior chemotherapy or radiation therapy. \\
& Number randomised: 45 (A:23; B:22). \\
& Mean age: A: 62.2 y (36-77y), B: 64.7 y (67-75 y). \\
& M:F: A: 6:17, B: $18: 4$. \\
& Locally-advanced:metastatic: A: 13:10, B:11:11. \\
\hline A: Best supportive care. \\
B. Leucovorin 200 mg/day IV+ 5FU 365 mg/sqm/day+cisplatin 15 mg/sqm/day for d1-5 q 21 days. \\
\hline Outcomes & Median survival. \\
\hline Notes & 2 patients in arm B did not receive chemotherapy but were included in intention to treat analysis. \\
& Unplanned interim safety analysis. Study ceased early as suggested that endpoints could not be reached. \\
\hline
\end{tabular}




\section{Characteristics of included studies (Continued)}

Overall survivals estimated from survival curves.

Allocation concealment A-Adequate

Study

Methods

Participants

\section{Kelsen 1991}

Randomised trial, multicentre government funded.

Planned enrolment: 80.

Recruitment period: September 1987-November 1989.

Histologically confirmed adenocarcinoma of the pancreas

Inclusion: KPS $>60 \%$; life expectancy $>8$ weeks; no symptomatic or labile cardiac disease; WCC $>3.5$; platelets $>150$; bilirubin $<2.0$; normal auditory function; adequate renal function

Exclusion: Prior chemotherapy or external beam radiotherapy

Number enrolled: 82 (A: 42, B: 40)

Median age: A: 58 (32-74), B: $60(28-74)$

Male: Female ratio: A: (26:16), B(26:14)

Locally advanced /metastatic: A 17/25. B: 14/26

Interventions

A. SMF chemotherapy (streptozotocin $1 \mathrm{~g} / \mathrm{sqm}$ for d1,8,29,36, mitomycin C $10 \mathrm{mg} / \mathrm{sqm}$ for d1, 5FU 600 $\mathrm{mg} / \mathrm{sqm}$ for $\mathrm{d} 1,8,29,36)$ every 8 weeks.

B. CAC chemotherapy (cisplatin 100mg/sqm d1, Ara C 2g/sqm 2 doses 12 hours apart on d1, caffeine 400 $\mathrm{mg} / \mathrm{sqm} 2$ doses at end of each Ara C) every 4 weeks for 3 cycles then 6 weekly in responding patients.

Outcomes

Median survival.

Response rate.

Time to progression.

Notes Anticipated non-prespecified safety analysis after 45 patients.

Study ceased early as suggested that endpoints could not be reached.

Allocation concealment $\mathrm{B}-$ Unclear

Methods Randomised trial, multicentred government funded.

Enrollment period: $1974-$ not stated.

11 patients lost to follow up.

Participants

Inclusion criteria: histologically confirmed; non-resectable; less than 75 years; no simultaneous; heterochromic multiple or recurrent carcinoma; performance status 0-3; no severe complications; white cell count $>4000$; platelets $>100$; GPT $<100$ and urinary protein negative.

Total enrolled (pancreatic): 52 (A: 24 B: 28)

Mean age: A: 61.5 (43-74) B: (46-74)

Male/female ratio: A: $15 / 9$ B: $22 / 6$

Surgical treatment (laparotomy or palliative bypass): A 20, B:22

Metastatic disease; A: 24 B: 27

Interventions A. $5 \mathrm{FU} 600 \mathrm{mg} / \mathrm{sqm}$ IV once weekly until disease progression.

B. Radiotherapy (4000 rad over four weeks in 25 fractions) $+5 \mathrm{FU} 600 \mathrm{mg} / \mathrm{sqm}$ d $1-3$ then maintenance $5 \mathrm{FU}$ $600 \mathrm{mg} / \mathrm{sqm}$ weekly beginning on day of completion of radiotherapy continuing until disease progression.

\begin{tabular}{ll}
\hline Outcomes & Median survival \\
& Locoregional progression.
\end{tabular}

Notes $\quad$ Patients stratified by grade of anaplasia and randomised within strata by permuted block design. Dynamic method of Zelen used to ensure treatment balance within institutions.

Outcome data for pancreatic cancer available separately in this study.

Allocation concealment A-Adequate

Chemotherapy and radiotherapy for inoperable advanced pancreatic cancer (Review)

Copyright @ 2007 The Cochrane Collaboration. Published by John Wiley \& Sons, Ltd 


\section{Characteristics of included studies (Continued)}

\begin{tabular}{|c|c|}
\hline Study & Kovach 1974 \\
\hline Methods & Randomised trial, multicentred study, government funded. \\
\hline Participants & $\begin{array}{l}\text { Inclusion criteria: histologically proven unresectable adenocarcinoma of the pancreas and stomach; measur- } \\
\text { able disease; ambulatory outpatients; reasonable nutritional status. } \\
\text { Exclusion criteria: moribund state; leucopenia; thrombocytopenia; major surgery or radiotherapy within } 3 \mathrm{~d} \text {; } \\
\text { extensive pelvic radiotherapy; previous chemotherapy with 5FU; 5-fluoro2 deoxyuridine; other chemotherapy } \\
\text { or radiotherapy in last month. } \\
\text { Total patients enrolled: } 167 \text {. } \\
\text { Number pancreatic cancer patients randomised: } 82 \text { (A: } 31 \text {, B: } 21 \text { C: } 30 \text { ). } \\
\text { Mean age: A } 59.2 \text { y, B } 60.0 \text { y, C:59.2 y. } \\
\text { M:F ratio: A 1.4:1, B: } 1.7: 1, \text { C } 1.7: 1 \text {. }\end{array}$ \\
\hline Interventions & $\begin{array}{l}\text { A: } 5 \text { FU } 13.5 \mathrm{mg} / \mathrm{kg} \text { IV for } \mathrm{d} 1-5 \mathrm{IV} \text { every } 5 \text { weeks. } \\
\text { B. BCNU } 50 \mathrm{mg} / \mathrm{sqm} \text { for d } 1-5 \mathrm{IV} \text { every } 8 \text { weeks. } \\
\text { C. } 5 \mathrm{FU} 10 \mathrm{mg} / \mathrm{kg}+\text { BCNU } 40 \mathrm{mg} / \mathrm{sqm} \text { IV for d } 1-5 \text { every } 8 \text { weeks. }\end{array}$ \\
\hline$\overline{\text { Outcomes }}$ & $\begin{array}{l}\text { Response. } \\
\text { Overall survival. }\end{array}$ \\
\hline Notes & $\begin{array}{l}\text { Trial enrolled pancreatic and gastric cancer patients. Data for pancreatic cancer available separately. } \\
\text { Stratification for site of origin, grade and site of primary indicator lesion } \\
33 \text { patients presumed to have pancreatic carcinoma on the basis of histology of metastatic lesion, negative } \\
\text { barium exam and convincing clinical presentation. } \\
\text { At interim analysis after } 130 \text { patients BCNU found to have significantly worse response rate so enrolment } \\
\text { continued on the two other arms only. }\end{array}$ \\
\hline nent & $3-U_{n}$ \\
\hline
\end{tabular}

\begin{tabular}{|c|c|}
\hline Study & Levi 2004 \\
\hline Methods & $\begin{array}{l}\text { Randomised trial, multicentred (15 European centres). } \\
\text { Funding: EORTC trial with NCI, ARC, ARTBG. } \\
\text { Planned accrual not stated. }\end{array}$ \\
\hline Participants & $\begin{array}{l}\text { Inclusion criteria: histologically-proven locally advanced or metastatic cancer of the pancreas. } \\
\text { Number randomised: } 107 \text { (A: 55, B:52). } \\
\text { Chronotherapy: constant rate: 54:53. } \\
\text { Median age: } 63 \text { y. } \\
\text { Locally-advanced:metastatic: } 25: 82 \text {. }\end{array}$ \\
\hline Interventions & $\begin{array}{l}2 \text { by } 2 \text { factorial design. } \\
\text { A. } 5 \mathrm{FU} \text { constant rate or chronomodulated IV infusion,over } 5 \text { days every } 3 \text { weeks cycle } 15 \mathrm{~g} / \mathrm{sqm} \text {, cycle } 2 \\
6 \mathrm{~g} / \mathrm{sqm} \text {, cycle } 36.5 \mathrm{~g} / \mathrm{sqm} \text {. } \\
\text { B. } 5 \mathrm{FU} \text { constant rate or chronomodulated IV infusion cycle } 15 \mathrm{~g} / \mathrm{sqm} \text {, cycle } 2 \mathrm{6g} / \mathrm{sqm} \text {, cycle } 36.5 \mathrm{~g} / \mathrm{sqm}+ \\
\text { cisplatin } 100 \mathrm{mg} / \mathrm{sqm} \text { IV day } 1\end{array}$ \\
\hline Outcomes & $\begin{array}{l}\text { Progression free survival. } \\
\text { Median overall survival. } \\
\text { Toxicity. }\end{array}$ \\
\hline$\overline{\text { Notes }}$ & $\begin{array}{l}\text { Chronomodulation infusion: 5FU 10pm-10am, peak at 4am, cisplatin } 10 \mathrm{am}-10 \mathrm{pm} \text { peak at } 4 \mathrm{pm} \text {. } \\
\text { Escalation of } 5 \mathrm{FU} \text { dose on successive cycles. }\end{array}$ \\
\hline Allocation concealment & A-Adequate \\
\hline
\end{tabular}

\begin{tabular}{ll} 
Study & Li $\mathbf{2 0 0 3}$ \\
\hline Methods & $\begin{array}{l}\text { Randomised trial; single centre study (Taiwan), government funded. } \\
\text { Planned accrual: 34 patients. }\end{array}$
\end{tabular}




\section{Characteristics of included studies (Continued)}

Recruitment period: January 1998- December 2001.

\begin{tabular}{|c|c|}
\hline Participants & $\begin{array}{l}\text { Inclusion criteria: histologically proven locally advanced pancreatic carcinoma; AJCC Stage IVA; Karnofsky } \\
\text { performance status }>50 \text {; neutrophil count }>1500 \text {; platelets }>100 \text {; AST/ALT }<5 \text { x upper limit of normal; } \\
\text { no prior chemotherapy or radiotherapy; no other malignancy; no serious medical or psychological problems } \\
\text { that would prevent informed consent. } \\
\text { Total patients enrolled: } 34 \text { (A: } 16 \text {, B:18). } \\
\text { Median age: A: } 69 \text { (range } 31-77 \text { ) B: } 68.5 \text { (range 45-83). } \\
\text { M:F ratio: A } 12: 4 \text { B 13:5. } \\
\text { No patients had surgery. } \\
\text { No patients lost to follow-up. }\end{array}$ \\
\hline Interventions & $\begin{array}{l}\text { A. Radiotherapy (50.4- } 61.2 \mathrm{~Gy} \text { in } 1.8 \mathrm{~Gy} \text { fractions) + 5FU 500mg/sqm IV over } 30 \mathrm{~min} \text { for d } 1-3 \text { fortnightly } \\
\mathrm{x} 3 \text { concurrent with radiotherapy. } \\
\text { B. Radiotherapy ( } 50.4-61.2 \mathrm{~Gy} \text { in } 1.8 \text { Gy fractions) + Gemcitabine } 600 \mathrm{mg} / \mathrm{sqm} \text { IV weekly x } 6 \text { over } 30 \mathrm{~min} \\
\text { concurrent with radiotherapy. } \\
\text { All patients then received maintenance gemcitabine } 1000 \mathrm{mg} / \mathrm{sqm} \text { IV weekly for } 3 \text { out of } 4 \text { weeks indefinitely } \\
\text { after chemoradiotherapy. }\end{array}$ \\
\hline Outcomes & $\begin{array}{l}\text { Median survival. } \\
1 \text { and 2-year survival. } \\
\text { Time to progression. } \\
\text { Time to local progression. } \\
\text { Time to metastasis. } \\
\text { Response rate. } \\
\text { Quality of survival. } \\
\text { Quality adjusted life months. }\end{array}$ \\
\hline$\overline{\text { Notes }}$ & This study employed 3D conformal radiotherapy. \\
\hline Allocation concealment & B - Unclear \\
\hline
\end{tabular}

Study

\section{Li 2004}

Methods

Randomised controlled trial, single centre study (Taiwan).

Funding source not stated.

Recruitment period: Jan 1998-June 2002.

Participants Inclusion criteria: metastatic pancreatic carcinoma; KPS $>50$.

Total patients enrolled: 46 (A: 25, B:21).

Mean age: A: 66 y, B: 69 y.

M:F ratio: A: 17:8, B: 19:2.

Interventions A: Gemcitabine $1000 \mathrm{mg} / \mathrm{sqm}$ IV weekly for 3 out of 4 weeks.

B: Gemcitabine $1000 \mathrm{mg} / \mathrm{sqm}$ IV + cisplatin $25 \mathrm{mg} / \mathrm{sqm}$ IV weekly for 3 out of 4 weeks.

Outcomes Median survival.

Survival at 6, 12 and 24 months.

Time to progression.

Clinical benefit.

Response rate.

Quality adjusted life months.

Notes Survivals read off Kaplan Meier survival curves.

Allocation concealment $\mathrm{B}-$ Unclear

\section{Study}

\section{Louvet 2005}

Methods Randomised study,multicentre (France and Italy).

Chemotherapy and radiotherapy for inoperable advanced pancreatic cancer (Review)

Copyright $\odot 2007$ The Cochrane Collaboration. Published by John Wiley \& Sons, Ltd 


\section{Characteristics of included studies (Continued)}

Pharmaceutical company sponsorship (Sanofi-Synthelabo).

Enrolment period: March 2001-February 2003.

Planned recruitment: 300 .

\begin{tabular}{ll}
\hline Participants & Inclusion criteria: pathologically proven adenocarcinoma of the pancreas; locally advanced or metastatic; \\
measurable disease; no prior radiation or chemotherapy; WHO performance status 0-2; adequate biological \\
parameters; pain and jaundice controlled; written informed consent. \\
Number enrolled: 326. \\
Number randomised: 313 (A: $156, \mathrm{~B}: 157)$. \\
Mean age: A :60.1 y (22-75 y). B: 61.3 (35-77 y). \\
M:F ratio: A: $53: 47$, B: $60: 40$. \\
Locally advanced:metastatic: A 30:70, B: $32: 68$.
\end{tabular}

Interventions A: Gemcitabine $1 \mathrm{~g} / \mathrm{sqm}$ IV weekly for 7 weeks, 1 week break then 3 out of 4 weeks.

B. GEMOX (Gemcitabine $1 \mathrm{~g} / \mathrm{sqm}$ IV d1 + oxaliplatin $100 \mathrm{mg} / \mathrm{sqm} \mathrm{d} 2$ every 2 weeks)

Gemcitabine in arm A was administered over 30 minutes and in arm B as a 100 minute fixed dose rate infusion.

\begin{tabular}{ll}
\hline Outcomes & Survival \\
& Progression free survival. \\
& Response rate. \\
& Clinical benefit. \\
& Tolerability. \\
& QOL. \\
\hline Notes & Stratification on centre, performance status and disease extent. \\
& 13 patients ineligible, 2 neuroendocrine, 8 high bilirubin level, 2 died before randomisation, 1 withdrawal \\
& of consent. \\
& Second-line chemotherapy received by $53.4 \%$ in A and $52.3 \%$ in B. \\
& Chemoradiation recommended in both arms in locally-advanced disease after 3 months if stable disease or \\
& response but left to investigator discretion. \\
& Chemoradiation received by $11 / 33$ in arm A and $16 / 40$ in arm B. \\
\hline Allocation concealment & A-Adequate \\
\hline
\end{tabular}

\begin{tabular}{|c|c|}
\hline Study & Maisey 2002 \\
\hline Methods & $\begin{array}{l}\text { Randomised controlled trial, unfunded } \\
\text { Multicentred ( } 5 \text { sites). } \\
\text { Enrolment period: July } 1994-\text { October } 2000 . \\
\text { Planned recruitment: } 208 .\end{array}$ \\
\hline Participants & $\begin{array}{l}\text { Inclusion criteria:histologically confirmed locally advanced or metastatic pancreatic cancer; not amenable to } \\
\text { radiotherapy or surgery; adequate marrow reserve; renal and hepatic function } \\
\text { Exclusion criteria: intracerebral metastases; ethanol or drug abuse; prior malignancy; uncontrolled angina; } \\
\text { psychological condition preventing informed consent. } \\
\text { Number randomised: } 209 \text { (A } 107, \text { B:102). } \\
\text { Median age: A: } 62 \text { (29-80), B: } 61 \text { ( 28-86). } \\
\text { M:F ratio: A: } 64: 36 \text {, B: } 61: 39 \text {. } \\
\text { Metastatic: A: } 64 \% \text {, B: } 56 \%\end{array}$ \\
\hline Interventions & $\begin{array}{l}\text { A: Epirubicin } 100 \mathrm{mg} / \mathrm{sqm} \text { IV every } 28 \text { days until progression } \\
\text { B: FEM ( } 5 \mathrm{FU} 600 \mathrm{mg} / \mathrm{sqm}(\max 1 \mathrm{~g}) \text {, epirubicin } 50 \mathrm{mg} / \mathrm{sqm} \text {, mitomycin } 6 \mathrm{mg} / \mathrm{sqm}(\mathrm{max} 10 \mathrm{mg}) \text { ) IV every } \\
28 \text { days until progression }\end{array}$ \\
\hline Outcomes & $\begin{array}{l}\text { Median survival. } \\
\text { Response rate. } \\
\text { Toxicity. }\end{array}$ \\
\hline
\end{tabular}




\section{Characteristics of included studies (Continued)}

QOL (EORTC QLQ C30).

Notes Second-line chemotherapy given in 43 patients (A: 20 and B: 23)

Crossover in A: 13 , and B: 5 .

Allocation concealment A-Adequate

\begin{tabular}{|c|c|}
\hline Study & Mallinson 1980 \\
\hline Methods & $\begin{array}{l}\text { Randomised controlled trial,multicentred study. } \\
\text { Accrual commenced } 1975 . \\
\text { Funding not stated. } \\
\text { Planned recruitment not stated. }\end{array}$ \\
\hline Participants & $\begin{array}{l}\text { Inclusion criteria: unresectable pancreas cancer diagnosed at laparotomy; age between } 35 \text { and } 75 \text { y. } \\
\text { Exclusion criteria: unable to attend outpatients department regularly; unrelievable gastrointestinal obstruc- } \\
\text { tion; reduced renal function; WCC }<3.5 \text {, platelets<80; prior radiotherapy or chemotherapy. } \\
\text { Total enrolled: } 40 \text { (A: } 19, \mathrm{~B}: 21 \text { ). } \\
\text { Histology confirmed: A: } 11, \mathrm{~B}: 7 \text {. } \\
\text { Median age: A: } 66.9 \text { y, B: } 63.4 \text { y. } \\
\text { M:F ratio: A: } 10: 9, \text { B: } 12: 9 \text {. } \\
\text { Disease extent: locally-advanced: metastatic A: } 11: 8, \text { B: } 14: 7 \text {. }\end{array}$ \\
\hline Interventions & $\begin{array}{l}\text { A. Best supportive care. } \\
\text { B. Cyclophosphamide } 300 \mathrm{mg} \text { for d } 1 \text { and d } 5(4.5 \mathrm{mg} / \mathrm{kg} \text { if weight }<60 \mathrm{~kg} \text { or }>80 \mathrm{~kg})+5 \mathrm{FU} 500 \mathrm{mg} \mathrm{d} 1-5(7.5 \\
\mathrm{mg} / \mathrm{kg} \text { if weight }<60 \mathrm{~kg} \text { or }>80 \mathrm{~kg})+ \text { vincristine } 1 \mathrm{mg} \text { for d } 2 \text { and d } 5(0.02 \mathrm{mg} / \mathrm{kg} \text { if weight }<60 \mathrm{~kg} \text { or }>80 \mathrm{~kg})+ \\
\text { methotrexate } 20 \mathrm{mg} \text { for d } 1 \text { and d } 4(0.3 \mathrm{mg} / \mathrm{kg} \text { if weight }<60 \mathrm{~kg} \text { or }>80 \mathrm{~kg}) \text { induction then } 5 \mathrm{FU} 10 \mathrm{mg} / \mathrm{kg} \mathrm{d} 1- \\
\mathrm{d} 5+\text { mitomycin C } 100 \mathrm{ug} / \mathrm{kg} \mathrm{d} 1-\mathrm{d} 5 \text { a month post induction and q } 6 \text { weekly until death or for } 2 \mathrm{y} \text {. }\end{array}$ \\
\hline Outcomes & Median survival. \\
\hline Notes & $\begin{array}{l}\text { All patients had laparotomy. } \\
\text { Method of randomisation not assessable. } \\
\text { Survival obtained from survival curves that included histologically confirmed and unconfirmed patients.. } \\
\text { Statement in manuscript that "relatives and family doctors of the patients were informed of the diagnosis } \\
\text { but the patients themselves were not necessarily aware of the finding of a malignant tumour". This would } \\
\text { suggest that informed consent was not always obtained. }\end{array}$ \\
\hline Allocation concealment & B - Unclear \\
\hline
\end{tabular}

\begin{tabular}{ll} 
Study & Moertel $\mathbf{1 9 6 9}$ \\
\hline Methods & $\begin{array}{l}\text { Randomised double blind controlled trial, single institution. } \\
\text { Recruitment period not stated. }\end{array}$ \\
\hline Participants & $\begin{array}{l}\text { Inclusion criteria: histologically confirmed locally-advanced adenocarcinoma of the stomach, pancreas or } \\
\text { bowel. } \\
\text { Total enrolled (pancreatic only): 64 (A:32, B:32). }\end{array}$ \\
\hline Interventions & $\begin{array}{l}\text { A. Radiotherapy (3500-4000 rad } 6 \mathrm{~d} \text { per week, } 900-1200 \mathrm{rad} / \mathrm{week})+ \text { saline. } \\
\text { B. Radiotherapy }(3500-4000 \mathrm{rad} 6 \mathrm{~d} \text { per week, } 900-1200 \mathrm{rad} / \mathrm{week})+5 \mathrm{FU} \text { (Divided doses on first 3 days } \\
\text { of radiation with } 45 \mathrm{mg} / \mathrm{kg} \text { total dose). }\end{array}$ \\
\hline Outcomes & Mean survival. \\
\hline Notes & $\begin{array}{l}\text { Randomisation stratified on basis of primary site and histologic grade. } \\
\text { Ideal or actual body weight was used whichever was less. } \\
\text { Survival curves available for pancreatic patients. } \\
\text { This trial is likely to be an expanded and update of the series reported by Childs 1965 }\end{array}$ \\
\hline Allocation concealment & B - Unclear \\
\hline Chemotherapy and radiotherapy for inoperable advanced pancreatic cancer (Review) \\
Copyright @ 2007 The Cochrane Collaboration. Published by John Wiley \& Sons, Ltd
\end{tabular}




\section{Characteristics of included studies (Continued)}

\begin{tabular}{|c|c|}
\hline Study & Moertel 1981 \\
\hline Methods & $\begin{array}{l}\text { Randomised controlled trial, multicentre study (7 centres). } \\
\text { Government funded. } \\
\text { Recruitment period: January } 1974 \text { - not stated. } \\
\text { No patients lost to follow up. }\end{array}$ \\
\hline Participants & $\begin{array}{l}\text { Inclusion criteria: locally-unresectable histologically confirmed adenocarcinoma of the pancreas; tumour } \\
\text { confined to pancreas; regional lymph nodes; regional lymph nodes and regional peritoneum or peripancreatic } \\
\text { organs provided entire area of involvement could be encompassed within a } 400 \mathrm{sq} \mathrm{cm} \text { area. } \\
\text { Exclusion criteria: Coexistent malignant disease; prior radiotherapy or chemotherapy; islet cell carcinoma or } \\
\text { cystadenocarcinoma. } \\
\text { Total enrolled: } 227 \text {. } \\
\text { Number completing trial } 194 \text { (14 cancelled due to disease complications or rapid deterioration, } 19 \text { ineligible). } \\
\text { Number in each group: A: } 25 \text { B: } 86 \text { C: } 83 \text {. } \\
\text { Median age: A: } 54 \text {, B 60, C: } 61 \text {. } \\
\text { Patients undergoing biliary bypass: A } 32 \%, \text { B } 44 \% \text {, C 34\%. }\end{array}$ \\
\hline Interventions & $\begin{array}{l}\text { A. Radiation therapy alone ( } 6000 \text { rads) split course } \\
\text { B. Radiation therapy ( } 6000 \mathrm{rads}) \text { split course+ } 5 \mathrm{FU} \text { chemotherapy }(500 \mathrm{mg} / \mathrm{sqm} / \text { day IV) for first } 3 \mathrm{~d} \text { of each } \\
\text { course+ weekly maintenance } 5 \mathrm{FU}(500 \mathrm{mg} / \mathrm{sqm} / \text { week IV) indefinitely } \\
\text { C. Radiation therapy ( } 4000 \mathrm{rads}) \text { split course+ } 5 \mathrm{FU} \text { chemotherapy }(500 \mathrm{mg} / \mathrm{sqm} / \text { day IV) for first } 3 \mathrm{~d} \text { of each } \\
\text { course+ weekly maintenance } 5 \mathrm{FU}(500 \mathrm{mg} / \mathrm{sqm} / \text { week IV) indefinitely }\end{array}$ \\
\hline Outcomes & $\begin{array}{l}\text { Median survival. } \\
\text { Time to progression. }\end{array}$ \\
\hline Notes & $\begin{array}{l}\text { Split course treatment consisted of } 2000 \text { rad courses given over } 2 \text { weeks with a } 2 \text { week break in between. } \\
\text { Enrolment into radiation alone arm terminated after } 106 \text { patients enrolled as preliminary analysis indicated } \\
\text { a significantly inferior survival compared to combined-modality therapy. } \\
\text { Stratification of assigned treatment by research institution. }\end{array}$ \\
\hline ent & B - Unclear \\
\hline
\end{tabular}

\begin{tabular}{|c|c|}
\hline Study & O’Reilly 2004 \\
\hline Methods & $\begin{array}{l}\text { Randomised trial,multicentred study, sponsored by pharmaceutical company (Daiichi). } \\
\text { Recruitment period: August 2001-January } 2003 . \\
\text { Planned recruitment: } 340 \text { patients. }\end{array}$ \\
\hline Participants & $\begin{array}{l}\text { Inclusion criteria:histological or cytological proof of locally-advanced or metastatic pancreatic cancer; } \\
\text { KPS }>60 \text {; no prior chemotherapy; prior radiation therapy allowed for locally advanced disease; good major } \\
\text { organ function. } \\
\text { Patients randomised: } 349 \text { (A: } 174 \text {, B: } 175) \text {. } \\
\text { Median age:A. } 62 \text { y (30-84 y) B: } 64 \text { y }(36-85 y) \text {. } \\
\text { M:F ratio: A: } 57: 43 \text { B: } 53: 47 \text {. } \\
\text { Locally advanced: metastatic: A: } 22: 78 \text { B: } 21: 79 \text {. }\end{array}$ \\
\hline Interventions & $\begin{array}{l}\text { A. Gemcitabine } 1 \mathrm{~g} / \mathrm{sqm} \text { IV weekly for } 7 \text { weeks, one week break then weekly for } 3 \text { out of } 4 \text { weeks. } \\
\text { B. Exatecan mesylate (DX-8951f) } 2.0 \mathrm{mg} / \mathrm{sqm} \text { IV+gemcitabine } 1 \mathrm{~g} / \mathrm{sqm} \text { IV for } \mathrm{d} 1 \text {, d } 8 \text { every } 3 \text { weeks }\end{array}$ \\
\hline Outcomes & $\begin{array}{l}\text { Median survival. } \\
1 \text { year survival. } \\
\text { Time to progression. } \\
\text { Time to marker progression. } \\
\text { Tumour response. } \\
\text { Toxicity. } \\
\text { Clinical benefit response. }\end{array}$ \\
\hline Notes & Patients stratified according to KPS, disease stage and prior radiation therapy. \\
\hline
\end{tabular}




\section{Characteristics of included studies (Continued)}

Intent to treat analysis. 27 patients randomised but did not receive treatment (A: 17, B: 7).

Reasons for no treatment: patient request (A: 10, B:3), progressive disease (A: 3, B:1), non compliance (A: $1, B: 1)$ and other $(\mathrm{A}: 3, \mathrm{~B}: 2)$.

Allocation concealment A-Adequate

\begin{tabular}{|c|c|}
\hline Study & Oettle 2005b \\
\hline Methods & $\begin{array}{l}\text { Randomised study, multicentred (USA and Europe). } \\
\text { Pharmaceutical company sponsored (Eli Lilly). } \\
\text { Planned recruitment: } 520 . \\
\text { Recruitment period: not stated. }\end{array}$ \\
\hline Participants & $\begin{array}{l}\text { Inclusion criteria: histologically or cytologically confirmed adenocarcinoma of the pancreas; locally advanced } \\
\text { or metastatic; ECOG 0-2; measurable disease; no prior chemotherapy; adequate haematological; renal and } \\
\text { liver function; informed consent. } \\
\text { Number randomised: } 565 \text { (A: } 282 \text {, B: } 283) \text {. } \\
\text { Number completing trial: } 546 . \\
\text { Median age: A: } 63 \text { y (28-82 y), B: } 63(27-82 \text { y). } \\
\text { M:F ratio: A: } 54: 47 \text {, B: } 60: 40 \text {. } \\
\text { Losses to follow-up: A:9, B: } 10 \text {. }\end{array}$ \\
\hline Interventions & $\begin{array}{l}\text { A. Gemcitabine } 1 \mathrm{~g} / \mathrm{sqm} \text { IV d1,d8,d15 every } 4 \text { weeks. } \\
\text { B. Gemcitabine } 1.25 \mathrm{~g} / \mathrm{sqm} \text { Iv d1,d8+ pemetrexed } 500 \mathrm{mg} / \mathrm{sqm} \text { IV d8 every } 3 \text { weeks. }\end{array}$ \\
\hline Outcomes & $\begin{array}{l}\text { Median survival. } \\
\text { Median progression free survival. } \\
\text { Overall survival at } 12 \text { months. } \\
\text { Median time to progression. } \\
\text { Response rate. } \\
\text { Duration of response. } \\
\text { QOL (EORTC QLQ C30). }\end{array}$ \\
\hline Notes & $\begin{array}{l}\text { Patients receiving pemetrexed received vitamin B12 and folic acid supplementation. Patients stratified for } \\
\text { performance status, disease stage, centre and baseline homocysteine level. } \\
3 \text { treatment deaths reported in the combination therapy arm. }\end{array}$ \\
\hline ment & te \\
\hline
\end{tabular}

\section{Study}

Methods

Participants

\section{Ohkawa 2004}

Randomised trial, two centred study (Japan).

Funding source not stated.

Recruitment period: July 2001-March 2003.

Planned recruitment not stated.

Inclusion criteria locally-advanced or metastatic pancreatic cancer; no pretreatment (radiotherapy or chemotherapy); KPS 50-100; $<75$ years old.

Number randomised: 19 (A: 9, B:10)

M:F ratio: A. 7:2, B: 7:3.

Median age: A: 58 y.4, B: 60.5 y.

Locally-advanced:metastatic: A 2:7, B: 3:7.

Interventions $\quad$ A. Gemcitabine $1 \mathrm{~g} / \mathrm{sqm}$ IV for $\mathrm{d} 1, \mathrm{~d} 8, \mathrm{~d} 15$ every 4 weeks.

B. Gemcitabine $1 \mathrm{~g} / \mathrm{sqm}$ IV for d1,d8,d15 +UFT $300 \mathrm{mg} /$ day PO continuous every 4 weeks.

Outcomes

Response rate.

Time to progression.

Clinical benefit response. 


\section{Characteristics of included studies (Continued)}

\begin{tabular}{|c|c|}
\hline$\overline{\text { Notes }}$ & Study stopped early due to inferiority of combination arm with respect to time to progression. \\
\hline Allocation concealment & B - Unclear \\
\hline Study & Oster 1986 \\
\hline Methods & $\begin{array}{l}\text { Randomised trial,single centred, government-funded. } \\
\text { Recruitment period: August 1979-November } 1981 \\
12 \text { patients ineligible or not evaluable. }\end{array}$ \\
\hline Participants & $\begin{array}{l}\text { Inclusion criteria: histologically confirmed adenocarcinoma of the pancreas;not suitable for surgery and/or } \\
\text { radiotherapy; no prior chemotherapy. } \\
\text { Total number enrolled: } 196 . \\
\text { Number evaluable: } 184 \text { (A: } 94 \text { B:90). } \\
\text { M:F ratio: A: } 61: 39 \text {, B: } 52: 48 . \\
\text { Bypass surgery: A: } 41 \%, \text { B: } 39 \% \text {. }\end{array}$ \\
\hline Interventions & $\begin{array}{l}\text { A. FSM chemotherapy (fluorouracil } 600 \mathrm{mg} / \mathrm{sqm} \text { for } \mathrm{d} 1,8,29,36 \text {, streptomycin } 1 \mathrm{~g} / \mathrm{sqm} \text { for } \mathrm{d} 1,8,29,36 \text {, } \\
\text { mitomycin C } 10 \mathrm{mg} / \mathrm{sqm} \mathrm{d} 1 \text { ) every } 8 \text { weeks until progression or relapse. } \\
\text { B. FAM chemotherapy (fluorouracil } 600 \mathrm{mg} / \mathrm{sqm} \text { for } \mathrm{d} 1,8,29,36 \text { ), Adriamycin } 30 \mathrm{mg} / \mathrm{sqm} \text { for d1,29, mito- } \\
\text { mycin C } 10 \mathrm{mg} / \mathrm{sqm} \mathrm{d} 1 \text { ) every } 8 \text { weeks until progression or relapse. }\end{array}$ \\
\hline Outcomes & $\begin{array}{l}\text { Median survival. } \\
\text { Response rate. }\end{array}$ \\
\hline$\overline{\text { Notes }}$ & $\begin{array}{l}\text { Stratified by measurable versus non-measurable disease. } \\
\text { Adriamycin discontinued after a total dose of } 480 \mathrm{mg} / \mathrm{sqm} \text {. }\end{array}$ \\
\hline Allocation concealment & B - Unclear \\
\hline Study & Palmer 1994 \\
\hline Methods & $\begin{array}{l}\text { Randomised controlled trial, two-centred study. } \\
\text { Recruitment period: April 1989-September } 1991 . \\
\text { Planned recruitment: not stated. }\end{array}$ \\
\hline Participants & $\begin{array}{l}\text { Irresectable advanced pancreatic cancer } \\
\text { Exclusion: Previous malignancy;significant renal or cardiovascular disease; thrombocytopenia or leucopenia; } \\
\text { gross psychiatric disease; WHO PS>3. } \\
\text { Patients randomised: } 43 \text { (Control 20, Treatment 23) } \\
\text { Median age: Control } 62 \text { (range 41-81) and Treatment } 61 \text { (45-76). } \\
\text { M:F ratio: A: 15:5 B: 16:7. } \\
31 \text { patients had histological confirmation. }\end{array}$ \\
\hline Interventions & $\begin{array}{l}\text { A. Best supportive care. } \\
\text { B. } 5 \mathrm{FU} 600 \mathrm{mg} / \mathrm{sqm} \mathrm{IV} \mathrm{d} 1 \text { and } 29 \text {, oral } 5 \mathrm{FU} \mathrm{d} 8 \text { and } 36 \text {, adriamycin } 30 \mathrm{mg} / \mathrm{sqm} \mathrm{d} 1 \text { and } 29 \text {. Mitomycin } \\
10 \mathrm{mg} / \mathrm{sqm} \mathrm{d} 1 \text { and } 29 \text { on an } 8 \text { week cycle until disease progression or unacceptable toxicity. }\end{array}$ \\
\hline Outcomes & $\begin{array}{l}\text { Median survival. } \\
1 \text { year survival. } \\
\text { Quality of survival. }\end{array}$ \\
\hline Notes & $\begin{array}{l}\text { Survivals at } 6 \text { and } 12 \text { months obtained from survival curve. } \\
\text { Randomised using permuted block technique. } \\
\text { Author contacted: no separate survival figures for patients with histological diagnosis. }\end{array}$ \\
\hline Allocation concealment & A-Adequate \\
\hline Study & Reni 2005 \\
\hline Methods & Randomised controlled trial, multicentred ( 5 centres Italy) \\
\hline
\end{tabular}




\section{Characteristics of included studies (Continued)}

\begin{tabular}{|c|c|}
\hline & $\begin{array}{l}\text { Unfunded study. } \\
\text { Recruitment period: April 2000-March } 2003 . \\
\text { Planned recruitment: } 100 .\end{array}$ \\
\hline Participants & $\begin{array}{l}\text { Inclusion criteria: Stage IVa or IV b adenocarcinoma of the pancreas confirmed histologically; measurable } \\
\text { disease; age 18-70 years; KPS >40; adequate bone marrow; renal and hepatic function; no prior radiotherapy } \\
\text { or chemotherapy. } \\
\text { Number randomised: } 104 . \\
\text { Number treated: } 99 \text { (M:F: 48:51). } \\
\text { Median age: A: } 59 \text { y (25-69 y) B: } 62 \text { y (37-69 y). } \\
\text { M:F ratio: A: } 24: 23 \text {, B: } 24: 28 . \\
\text { Locally advanced: metastatic A: } 30 \%: 70 \%, \text { B: } 29 \%: 71 \% \text {. }\end{array}$ \\
\hline$\overline{\text { Interventions }}$ & $\begin{array}{l}\text { A: Gemcitabine } 1 \mathrm{~g} / \mathrm{sqm} \text { weekly for } 7 \text { weeks then } 1 \text { week off and weekly for } 3 \text { out of } 4 \text { weeks until progression. } \\
\text { B:PEFG (Cisplatin } 40 \mathrm{mg} / \mathrm{sqm} \mathrm{IV} \mathrm{d} 1+\text { epirubicin } 40 \mathrm{mg} / \mathrm{sqm} \text { IV for } \mathrm{d} 1+5 \mathrm{FU} \text { continuous infusion } 200 \\
\mathrm{mg} / \mathrm{sqm} / \text { day+ gemcitabine } 600 \mathrm{mg} / \mathrm{sqm} \text { IV for } \mathrm{d} 1, \mathrm{~d} 8 \text { every } 28 \text { days). }\end{array}$ \\
\hline Outcomes & $\begin{array}{l}4 \text { month progression free survival. } \\
\text { Response rate. } \\
\text { Clinical benefit. } \\
\text { QOL (EORTC QLQ C30 and PAN26). } \\
\text { Overall survival. }\end{array}$ \\
\hline$\overline{\text { Notes }}$ & $\begin{array}{l}\text { Five patients not eligible (A:3, B:2). Reasons: } 4 \text { had liver dysfunction and } 1 \text { had biliary tract cancer. } \\
\text { Crossover from gemcitabine to PEFG was allowed in protocol after disease progression. }\end{array}$ \\
\hline Allocation concealment & A-Adequate \\
\hline
\end{tabular}

\begin{tabular}{|c|c|}
\hline Study & Riess 2005 \\
\hline Methods & $\begin{array}{l}\text { Randomised study, multicentred ( } 98 \text { centres). } \\
\text { Funding: German Cancer Society and Eli Lilly. } \\
\text { Recruitment period: August 2000-November } 2003 . \\
\text { Planned recruitment: } 472 .\end{array}$ \\
\hline Participants & $\begin{array}{l}\text { Inclusion criteria: histological or cytological proven locally advanced or metastatic pancreatic cancer; mea- } \\
\text { surable disease; KPS } 60 \% \text { or better; no prior chemotherapy or radiation therapy; adequate haematological, } \\
\text { renal and hepatic function; written and informed consent. } \\
\text { Number randomised: } 473 \text {. } \\
\text { Number eligible: } 466 \text { (A: } 230 \text {, B: } 236 \text { ). } \\
\text { Mean age: A: } 63.7 \text { y, B: } 62.7 \text { y. } \\
\text { Locally advanced:metastatic: A: } 23: 77 \text { B: } 23: 77 \text {. }\end{array}$ \\
\hline Interventions & $\begin{array}{l}\text { A. Gemcitabine } 1 \mathrm{~g} / \mathrm{sqm} \text { weekly for } 7 \text { weeks then one week off and weekly for three weeks out of four until } \\
\text { progression. } \\
\text { B. Gemcitabine } 1000 \mathrm{mg} / \mathrm{sqm}+5 \mathrm{FU} 750 \mathrm{mg} / \mathrm{sqm} \text { continuous infusion over } 24 \mathrm{~h}+\text { folinic acid } 200 \mathrm{mg} / \mathrm{sqm} \\
\text { fir } \mathrm{d} 1, \mathrm{~d} 8, \mathrm{~d} 15, \mathrm{~d} 22 \text { every } 6 \text { weeks until progression. }\end{array}$ \\
\hline Outcomes & $\begin{array}{l}\text { Median survival. } \\
1 \text { year survival. } \\
\text { Time to progression } \\
\text { Overall response rate. } \\
\text { Toxicity. } \\
\text { QOL. }\end{array}$ \\
\hline Notes & $\begin{array}{l}\text { Seven patients ineligible ( } 3 \text { had other tumours, } 2 \text { were resectable, } 1 \text { had concomitant methotrexate and } 1 \\
\text { was without histological diagnosis). } \\
\text { Secondline chemotherapy given in } 37.4 \% \text { of arm A and } 32.8 \% \text { of arm B. A variety of different salvage } \\
\text { regimens were used but notably } 21 \% \text { of arm B received paclitaxel compared to none in arm A. }\end{array}$ \\
\hline
\end{tabular}

Chemotherapy and radiotherapy for inoperable advanced pancreatic cancer (Review)

Copyright $\odot 2007$ The Cochrane Collaboration. Published by John Wiley \& Sons, Ltd 


\section{Characteristics of included studies (Continued)}

Allocation concealment A-Adequate

\begin{tabular}{|c|c|}
\hline Study & Rocha Lima 2004 \\
\hline Methods & $\begin{array}{l}\text { Randomised trial, multicentred (USA, Canada, NZ, Australia). } \\
\text { Pharmaceutical company funded (Pfizer). } \\
\text { Recruitment period: February 2000-December } 2001 . \\
\text { Planned recruitment: } 350 .\end{array}$ \\
\hline Participants & $\begin{array}{l}\text { Inclusion criteria: histologically or cytologically confirmed locally advanced or metastatic pancreatic carci- } \\
\text { noma; measurable disease; ECOG } 0-2 \text {; no prior systemic chemotherapy except } 5 \mathrm{FU} \text { as a radiosensitizer } \\
\text { adequate haematogical; renal and hepatic function. } \\
\text { Total enrolled: } 360 \text {. } \\
\text { Treated patients: } 342 \text { (A: } 173 \text {, B: } 169) \text {. } \\
\text { Median age: A: } 60 \text { (32-83) B } 63(39-81) \text {. } \\
\text { M:F ratio: A: } 57: 43 \text {, B: } 58: 42 \text {. } \\
\text { Locally advanced:metastatic: A: } 14 \%: 86 \%, \text { B: } 16 \%: 84 \% \text {. }\end{array}$ \\
\hline Interventions & $\begin{array}{l}\text { A: Gemcitabine } 1000 \mathrm{mg} / \mathrm{sqm} \text { IV weekly for } 7 \text { weeks then one week break and weekly for } 3 \text { out of } 4 \text { weeks. } \\
\text { B: Gemcitabine } 1000 \mathrm{mg} / \mathrm{sqm} \text { IV followed by irinotecan } 100 \mathrm{mg} / \mathrm{sqm} \text { IV on d } 1 \text { and d } 8 \text { every } 21 \text { days. }\end{array}$ \\
\hline Outcomes & $\begin{array}{l}\text { Tumour response. } \\
\text { Median survival. } \\
1 \text { year survival. } \\
\text { Time to progression. } \\
\text { QOL. }\end{array}$ \\
\hline$\overline{\text { Notes }}$ & $\begin{array}{l}18 \text { patients randomised but not treated. (A:11, B:7) Reasons withdrawal of consent } 10 \text {, protocol violation } \\
4 \text {, disease progression 3, adverse event } 1 . \\
\text { Second-line therapy given in } 46 \% \text { of } \mathrm{A} \text { and } 39 \% \text { of } \mathrm{B} \text {. }\end{array}$ \\
\hline lent & $\overline{A-A}$ \\
\hline
\end{tabular}

\section{Study}

\section{Scheithauer 2003}

Methods

Randomised controlled trial, multicentred (4 Austrian sites).

Government funded.

Recruitment period: June 1999-May 2001.

Planned recruitment: 41 .

Participants

Inclusion criteria: histologically or cytologically ascertained metastatic adenocarcinoma of the exocrine pancreas; bidimensionally measurable; age 19-75; life expectancy > 3 months; KPS >50; informed consent.

Exclusion criteria: operable patients or locally-advanced disease; serious medical illness; CNS metastases.

Number randomised: 83 (A: 42,B:41).

Median age: A 66 y (39-75 y), B: 64 y $(40-75$ y).

M:F ratio: A:55:45, B: 27:14.

Prior palliative surgery: A 26\%, B: $12 \%$.

All patients had metastatic disease.

Interventions A: Gemcitabine $2200 \mathrm{mg} / \mathrm{sqm}$ IV over 30 minutes d1 fortnightly.

B. Gemcitabine $2200 \mathrm{mg} / \mathrm{sqm}$ IV over 30 minutes fortnightly d1+ capecitabine $1250 \mathrm{mg} / \mathrm{sqm}$ PO bd for d1-7 fortnightly.

Outcomes

Response rate.

Median duration of response.

Median progression-free survival.

Median survival.

Clinical benefit response.

Toxicity.

Chemotherapy and radiotherapy for inoperable advanced pancreatic cancer (Review)

Copyright $(2007$ The Cochrane Collaboration. Published by John Wiley \& Sons, Ltd 


\section{Characteristics of included studies (Continued)}

Notes

7 patients ineligible ( 3 had other tumours, 2 were resectable, 1 had concomitant methotrexate and one without histological diagnosis)

Second-line chemotherapy given in $37.4 \%$ of arm A and $32.8 \%$ of arm B. A variety of difference salvage regimens were used but notably $21 \%$ of arm B received paclitaxel compared to none in arm A.

Allocation concealment A-Adequate

\begin{tabular}{|c|c|}
\hline Study & Shinchi 2002 \\
\hline Methods & $\begin{array}{l}\text { Randomised controlled trial. } \\
\text { Single-site study. } \\
\text { Recruitment period: January 1997-June } 2000 . \\
\text { Planned recruitment not stated. }\end{array}$ \\
\hline Participants & $\begin{array}{l}\text { Inclusion criteria: histologically or cytologically confirmed pancreatic adenocarcinoma; locally advanced } \\
\text { disease at laparotomy or inoperable on CT scan; adequate biliary drainage; Karnofsky score }>60 \text {; normal } \\
\text { renal function. } \\
\text { Total enrolled: } 31 \text { (A:15, B: 16). } \\
\text { Mean age: A: } 64.6 \text { y, } 62.0 \text { y. } \\
\text { M:F ratio: A. } 68: 32, \text { B: } 63: 37 \\
\text { Obstructive jaundice in } 15 \text { patients treated with biliary bypass (9)and endoprosthesis (6). } \\
\text { No patients lost to follow up. }\end{array}$ \\
\hline Interventions & $\begin{array}{l}\text { A. Best supportive care. } \\
\text { B. Radiotherapy ( } 50.8 \mathrm{~Gy} 1.8 \mathrm{~Gy} \text { daily } 5 \text { days a week })+5 \mathrm{FU} \text { continuous infusion } 200 \mathrm{mg} / \mathrm{sqm} / \text { day during } \\
\text { radiation therapy then maintenance weekly } 5 \mathrm{FU} 500 \mathrm{mg} / \mathrm{sqm} \text { IVI until progression or toxicity. }\end{array}$ \\
\hline Outcomes & $\begin{array}{l}\text { Median survival } \\
\text { One year survival } \\
\text { Quality of survival. }\end{array}$ \\
\hline Notes & $\begin{array}{l}\text { 4-field radiotherapy technique. } \\
\text { Best supportive care patients did not receive any chemotherapy or radiotherapy. }\end{array}$ \\
\hline cation conc & B - Unclear \\
\hline
\end{tabular}

\begin{tabular}{ll} 
Study & Stathopoulos 2005 \\
\hline Methods & Randomised trial. \\
& Funding source not stated. \\
& Recruitment period not stated. \\
& Planned recruitment not stated. \\
\hline Participants & Inclusion criteria: chemotherapy naive patients with histologically or cytologically confirmed pancreatic \\
& cancer and documented extrapancreatic disease. \\
& Number randomised: 92 (A: $50, \mathrm{~B}:$ 42). \\
& Patients balanced in respect of age, gender,stage, performance status and organ involvement. \\
\hline Interventions & A. Gemcitabine $1000 \mathrm{mg} / \mathrm{sqm}$ IV for d1,d8,d15 every $4 \mathrm{weeks.}$ \\
& B. Gemcitabine $1000 \mathrm{mg} / \mathrm{sqm}$ IV d1,d8+ irinotecan $300 \mathrm{mg} / \mathrm{sqm}$ on d8 every 3 weeks. \\
\hline Outcomes & Objective response rate. \\
& Median time to progression. \\
\hline 1-year survival. \\
\hline Notes & G-CSF support was given in the study. \\
\hline Allocation concealment & B- Unclear \\
\hline
\end{tabular}

Study

Takada 1998

Methods Randomised controlled trial, multicentre (32 centres).

Chemotherapy and radiotherapy for inoperable advanced pancreatic cancer (Review)

Copyright $($ C 2007 The Cochrane Collaboration. Published by John Wiley \& Sons, Ltd 


\section{Characteristics of included studies (Continued)}

Recruitment period: August 1981-July 1991.

\begin{tabular}{|c|c|}
\hline Participants & $\begin{array}{l}\text { Inclusion criteria: histologically confirmed; non-resectable, }<75 \text { y; no simultaneous, heterochromic multiple } \\
\text { or recurrent carcinoma; performance status } 0-3 \text { (Japanese Cancer Therapy Efficacy Evaluation Criteria); no } \\
\text { severe complications; white cell count }>4000 \text {; platelets }>100 \text {; GPT }<100 \text { and urinary protein negative. } \\
\text { Total enrolled (pancreatic): } 52 \text { (A: } 24 \text { B: } 28) \text {. } \\
\text { Mean age: A: } 61.5 \text { y ( } 43-74 \text { y), B: } 62.8 \text { y }(46-74 \text { y). } \\
\text { M:F ratio: A: } 15: 9, \text { B: } 22: 6 \text {. } \\
\text { Surgical treatment (laparotomy or palliative bypass): A 20, B: } 22 \text {. } \\
\text { Metastatic disease: A: } 24 \text {, B: } 27 \text {. }\end{array}$ \\
\hline Interventions & $\begin{array}{l}\text { A. Best supportive care } \\
\text { B. Modified FAM (5FU } 200 \mathrm{mg} / \mathrm{sqm}+\text { doxorubicin } 15 \mathrm{mg} / \mathrm{sqm})+ \text { mitomycin C } 5 \mathrm{mg} / \mathrm{sqm} \text { ) IV on day of surgery } \\
\text { 4-weekly until severe adverse reaction or disease progression. }\end{array}$ \\
\hline Outcomes & $\begin{array}{l}\text { Median survival. } \\
\text { Response rate. } \\
\text { Clinical effects (performance status improvement, body weight improvement). }\end{array}$ \\
\hline Notes & $\begin{array}{l}\text { Study enrolled patients with pancreatic, gallbladder and bile duct cancer. Data available for pancreatic } \\
\text { subgroup. } \\
\text { Survivals from Kaplan Meier survival curves. } \\
\text { Envelope method of randomisation. }\end{array}$ \\
\hline
\end{tabular}

\begin{tabular}{|c|c|}
\hline Study & Topham 1991 \\
\hline Methods & $\begin{array}{l}\text { Randomised trial, multicentred study. } \\
\text { Funding source not stated. } \\
\text { Planned enrolment: not stated. }\end{array}$ \\
\hline Participants & $\begin{array}{l}\text { Inclusion criteria: locally advanced or metastatic pancreatic carcinoma;cytological or histopathological diag- } \\
\text { nosis; no prior chemotherapy or radiotherapy. } \\
\text { Total patients randomised: } 69 \text { ( } 4 \text { ineligible in arm A). } \\
\text { Number assessable: } 65 \text { ( A:31, B: } 34) \text {. } \\
\text { Metastatic: A: } 12, \text { B: } 14 .\end{array}$ \\
\hline Interventions & $\begin{array}{l}\text { A. FEM chemotherapy (5FU } 1 \mathrm{~g} \text { IV d } 1 \text { and } 28 \text {, epirubicin } 60 \mathrm{mg} / \mathrm{sqm} \mathrm{d} 1 \text { and } 28 \text {, mitomycin C } 10 \mathrm{mg} \text { ) d } 1 \\
\text { every } 8 \text { weeks. } \\
\text { B. Epirubicin } 100 \mathrm{mg} / \mathrm{sqm} \mathrm{IV} \mathrm{d} 14 \text { weekly. } \\
\text { Treatment for } 3 \text { months, if response then treatment for } 4 \text { further cycles. }\end{array}$ \\
\hline Outcomes & $\begin{array}{l}1 \text { year survival. } \\
\text { Response rate. } \\
\text { Toxicity. }\end{array}$ \\
\hline Notes & $\begin{array}{l}\text { Survivals obtained from intention to treat survival curve. } \\
\text { Dropouts: A: } 3 \text { refused treatment after randomisation (A:1, B: 2). } \\
\text { Probable final publication of Topham } 1993 \text { but unable to confirm with authors. Note slight variation in the } \\
\text { chemotherapy doses between two publications. }\end{array}$ \\
\hline llocatio & $D-1$ \\
\hline
\end{tabular}

\begin{tabular}{ll} 
Study & Topham 1993 \\
\hline Methods & $\begin{array}{l}\text { Randomised controlled study, multicentred trial (3 centres). } \\
\text { Funding source not stated. }\end{array}$
\end{tabular}

Chemotherapy and radiotherapy for inoperable advanced pancreatic cancer (Review)

Copyright $\odot 2007$ The Cochrane Collaboration. Published by John Wiley \& Sons, Ltd 
Participants Inclusion criteria: histologically confirmed advanced local and/or metastatic adenocarcinoma of the pancreas;previously untreated with chemotherapy or radiotherapy; no concomitant psychiatric or uncontrolled cardiovascular disorders; no prior malignancy; WBC count $>3.0$; platelets $>100$ and serum creatinine $<150$. Total patients enrolled: 60 .

Number evaluable for toxicity and survival: 47 (A: 25, B: 22).

Mean age: A 62 y (42-78 y), B: 64 y (39-80 y).

M: F ratio: A: 15:10, B: 11:11.

Liver metastases in 9 patients on each arm.

\begin{tabular}{|c|c|}
\hline Interventions & $\begin{array}{l}\text { A: Epirubicin } 100 \mathrm{mg} / \mathrm{sqm} \text { IV every } 28 \text { days until progression. } \\
\text { B: FEM ( } 5 \mathrm{FU} 600 \mathrm{mg} / \mathrm{sqm}(\max 1 \mathrm{~g}) \text {, epirubicin } 50 \mathrm{mg} / \mathrm{sqm} \text {, mitomycin } 6 \mathrm{mg} / \mathrm{sqm}(\mathrm{max} 10 \mathrm{mg})) \mathrm{IV} \text { every } \\
28 \text { days until progression. }\end{array}$ \\
\hline Outcomes & $\begin{array}{l}\text { Median survival. } \\
\text { Toxicity. }\end{array}$ \\
\hline$\overline{\text { Notes }}$ & $\begin{array}{l}\text { Stratification on basis of presence or absence of liver metastases. } \\
\text { Patients excluded on basis of following: } 1 \text { died prior to treatment, data for } 3 \text { not available for analysis, } 3 \text { had } \\
\text { incorrect histology, previous chemotherapy and refusal of informed consent. } \\
\text { Preliminary results of ongoing study. } \\
\text { See notes from Topham } 1991 .\end{array}$ \\
\hline Allocation concealment & B - Unclear \\
\hline Study & Wang 2002 \\
\hline Methods & $\begin{array}{l}\text { Randomised controlled trial, multicentred study. } \\
\text { Funding not stated. } \\
\text { Recruitment period: July 2000-May } 2001 . \\
\text { Planned recruitment: not stated. }\end{array}$ \\
\hline Participants & $\begin{array}{l}\text { Inclusion criteria: cytologically and pathologically proven locally advanced or metastatic pancreatic carci- } \\
\text { noma; KPS 60-80; age 18-75; adequate haematological; renal and liver function; measurable disease and } \\
\text { controllable pain. } \\
\text { Number randomised: } 42\end{array}$ \\
\hline Interventions & $\begin{array}{l}\text { A. Gemcitabine } 1 \mathrm{~g} / \mathrm{sqm} / \mathrm{wk} \text { x } 7,1 \text { week of rest for the first cycle then gemcitabine } 1 \mathrm{~g} / \mathrm{sqm} / \mathrm{wk} 3 \text { out of } 4 \\
\text { weeks for subsequent cycles. } \\
\text { B. Gemcitabine } 1 \mathrm{~g} / \mathrm{sqm} / \mathrm{wk} \text { x } 3+\text { cisplatin } 60 \mathrm{mg} / \mathrm{sqm} \text { on day } 15 \text { (after gemcitabine) for } 3 \text { cycles } 4 \text { weekly. } \\
\text { Regimens given for maximum of } 8 \text { cycles }\end{array}$ \\
\hline$\overline{\text { Outcomes }}$ & $\begin{array}{l}\text { Survival at } 3,6 \text { and } 12 \text { months. } \\
\text { Median survival. } \\
\text { Time to disease progression. } \\
\text { Objective response. } \\
\text { Clinical benefit response. } \\
\text { Toxicity. }\end{array}$ \\
\hline$\overline{\text { Notes }}$ & $\begin{array}{l}\text { Abstract presented at American Society of Clinical Oncology Annual Scientific meeting 2002. Extra infor- } \\
\text { mation obtained from poster. }\end{array}$ \\
\hline Allocation concealment & B - Unclear \\
\hline
\end{tabular}

\section{Characteristics of excluded studies}

\begin{tabular}{l} 
Study $\quad$ Reason for exclusion \\
\hline Aigner $1998 \quad$ Regional coeliac axis chemotherapy with starch microembolisation versus systemic chemotherapy \\
\hline $\begin{array}{l}\text { Chemotherapy and radiotherapy for inoperable advanced pancreatic cancer (Review) } \\
\text { Copyright } \odot 2007 \text { The Cochrane Collaboration. Published by John Wiley \& Sons, Ltd }\end{array}$
\end{tabular}




\begin{tabular}{|c|c|}
\hline Alberts 2004 & andomised phase II study of a biological agent PS-341(proteosome inhibitor) versus PS-341+ gemcitabine. \\
\hline Asbury 1994 & Randomised phase II three-armed trial with no defined control arm. \\
\hline Auerbach 1997 & Phase II trial. \\
\hline Bramhall 2001 & Randomised study of gemcitabine versus a biological agent marimastat (matrix metalloproteinase inhibitor). \\
\hline Bramhall 2002 & Gemcitabine compared to gemcitabine plus marimastat, (matrix metalloproteinase inhibitor) a biological agent. \\
\hline Bukowski 1993 & Sequential randomised phase II studies with crossovers at treatment failure. \\
\hline Cascinu 1995 & Biological agent (octreotide) versus best supportive care \\
\hline Chau 2003 & $\begin{array}{l}\text { Two randomised trials: gastrazole (CCK/gastrin receptor antagonist) a biological agent versus protracted infu- } \\
\text { sional placebo and gastrazole versus protracted venous } 5 \mathrm{FU} \text {. }\end{array}$ \\
\hline Chen 2006 & Randomised study of gemcitabine versus imatinib mesylate (tyrosine kinase inhibitor), a biological agent. \\
\hline Colucci 1999 & $\begin{array}{l}\text { Preliminary report of randomised phase II study with no survival endpoints listed. Final publication in } 2002 \\
\text { does have survival data. }\end{array}$ \\
\hline Ebert 2004 & $\begin{array}{l}\text { Randomised study of imatinib mesylate (tyrosine kinase inhibitor), a biological agent in combination with } \\
\text { gemcitabine. }\end{array}$ \\
\hline GITSG 1985a & Randomised phase II study of maytansin and two dose levels of chlorozotocin. \\
\hline Gilliam 2004 & G17DT a biological agent versus best supportive care. \\
\hline Heinemann 2004 & Survival data not available yet. \\
\hline Jacobs 2004 & $\begin{array}{l}\text { Randomised phase III study of rubitecan versus best supportive care in patients with refractory pancreatic cancer. } \\
\text { Second-line study. }\end{array}$ \\
\hline Johnson 2001 & Dose-finding study of oral or intravenous lithium gamolenate \\
\hline Jones 1987 & Non-randomised retrospective study \\
\hline Klapdor 1982 & Survival endpoints not stated. \\
\hline Klein 2000 & Non-randomised retrospective study. \\
\hline Kojima 1983 & $\begin{array}{l}\text { Randomised trial of three chemotherapy regimens in hepatic,biliary and pancreatic cancer patients. No separate } \\
\text { data available for pancreatic cancer patients. }\end{array}$ \\
\hline Lersch 2001 & $\begin{array}{l}\text { Randomised phase II study of gemcitabine in combination with SCH } 66336 \text { (lonafanib) a farnesyl transferase } \\
\text { inhibitor a biological agent. }\end{array}$ \\
\hline Lokich 1974 & Non-randomised study. \\
\hline Lygidakis 1995 & $\begin{array}{l}\text { Randomised trial of palliative bypass (gastric or biliary) versus palliative bypass with locoregional immunostim- } \\
\text { ulation (with IL2, interferon) and regional intra-arterial chemotherapy (mitomycin C, carboplatin, epirubicin, } \\
\text { 5FU, leucovorin and interferon) i.e. biological and regional therapy. }\end{array}$ \\
\hline McCracken 1980 & $\begin{array}{l}\text { Randomised trial of chemoradiation (using methyl CCNU and 5FU) with or without testolactone a hormonal } \\
\text { agent. }\end{array}$ \\
\hline Moore 2003 & Randomised trial of gemcitabine versus BAY 12-9566 (matrix metalloproteinase inhibitor), a biological agent. \\
\hline Moore 2005 & Randomised trial of gemcitabine with or without erlotinib (tyrosine kinase inhibitor) a biological agent. \\
\hline Oettle 2005a & $\begin{array}{l}\text { Randomised trial of oxaliplatin/5FU and folinic acid versus best supportive care in gemcitabine refractory } \\
\text { pancreatic cancer. }\end{array}$ \\
\hline Pancreatic Soc 1989 & $\begin{array}{l}\text { British randomised trial of } 5 \mathrm{FU} \text { and epirubicin versus best supportive care. Study terminated early due to poor } \\
\text { accrual. Never published. Original data now lost. }\end{array}$ \\
\hline Richards 2002 & $\begin{array}{l}\text { Placebo controlled trial of gemcitabine in combination with histone deacetylase inhibitor C1-994, a biological } \\
\text { agent. No survival data in abstract. }\end{array}$ \\
\hline Schein 1978 & Randomised phase II trial with no defined control arm. \\
\hline Shapiro 2005 & Randomised phase III trial of gemcitabine with or without G17DT immunogen, a biological agent. \\
\hline
\end{tabular}




\section{Characteristics of excluded studies (Continued)}

\begin{tabular}{|c|c|}
\hline & \\
\hline Stolinsky 1975 & Comparison of oral and intravenous 5FU \\
\hline Sunamura 2004 & $\begin{array}{l}\text { Comparison of intraoperative radiotherapy for locally advanced pancreatic carcinoma with or without use of an } \\
\text { hypoxic cell radiosensitizer PR-350, not a cytotoxic. }\end{array}$ \\
\hline Takada 1994 & $\begin{array}{l}\text { Final publication of expanded } 1992 \text { series included pancreatic and biliary-tract cancers and combined results } \\
\text { Authors have stated that source data for } 5 \text { of pancreatic patients lost. }\end{array}$ \\
\hline Tempero 2003 & Comparison of gemcitabine given in two different dosing schedules. \\
\hline Ulrich-Pur 2003 & $\begin{array}{l}\text { Raltitrexed plus irinotecan versus irinotecan in gemcitabine pretreated pancreatic cancer. } \\
\text { Second-line study }\end{array}$ \\
\hline Van Cutsem 2004 & Randomised study of gemcitabine with or without tipifarnib (R115777) a biological agent. \\
\hline Wagener 2002 & Comparison of cisplatin-5FU with cisplatin-5FU and alfa interferon, a biological agent. \\
\hline 000 & mised trial of high dose vitamin C versus high dose vitamin C plus NSC-631570. \\
\hline
\end{tabular}

\section{Characteristics of ongoing studies}

\begin{tabular}{|c|c|}
\hline Study & CALGB 80303 \\
\hline Trial name or title & $\begin{array}{l}\text { Randomized phase III trial of gemcitabine plus bevacizumab vs. gemcitabine plus placebo in patients with } \\
\text { advanced pancreatic cancer }\end{array}$ \\
\hline Participants & Locally advanced or metastatic pancreatic carcinoma. \\
\hline Interventions & $\begin{array}{l}\text { A.Gemcitabine+placebo } \\
\text { vs } \\
\text { B.Gemcitabine+bevacizumab }\end{array}$ \\
\hline Outcomes & $\begin{array}{l}\text { Survival. } \\
\text { Response rate. } \\
\text { Duration of response. } \\
\text { Toxicity. } \\
\text { Resource utilization. } \\
\text { Marginal cost. }\end{array}$ \\
\hline \multicolumn{2}{|l|}{ Starting date } \\
\hline Contact information & Hedy Kindler, MD, Protocol chair.Ph+1773-702-0360; \\
\hline Notes & Planned accrual 528 patients \\
\hline Study & CALGB-89904 \\
\hline Trial name or title & $\begin{array}{l}\text { Phase II randomised study of gemcitabine alone vs gemcitabine with cisplatin vs gemcitabine with Docetaxel } \\
\text { vs gemcitabine with irinotecan in patients With metastatic pancreatic cancer }\end{array}$ \\
\hline Participants & $\begin{array}{l}\text { Histologically-confirmed adenocarcinoma of the pancreas. } \\
\text { Metastatic disease by CT scan. }\end{array}$ \\
\hline Interventions & $\begin{array}{l}\text { A: Gemcitabine IV over } 30 \text { minutes on d } 1,8 \text {, and } 15 \text { followed by cisplatin IV over } 30 \text { minutes on d } 1 \text { and } 15 \text {. } \\
\text { Treatment repeats every } 28 \mathrm{~d} \text { for at least } 2 \text { courses in the absence of disease progression or unacceptable toxicity. } \\
\text { vs } \\
\text { B: Gemcitabine IV over } 150 \text { minutes on d } 1,8 \text {, and } 15 \text {. Treatment repeats every } 28 \mathrm{~d} \text { for at least } 2 \text { courses in } \\
\text { the absence of disease progression or unacceptable toxicity. } \\
\text { vs } \\
\text { C: Gemcitabine IV over } 30 \text { minutes followed by docetaxel IV over } 60 \text { minutes on d } 1 \text { and } 8 \text {. Treatment repeats } \\
\text { every } 21 \mathrm{~d} \text { for at least } 3 \text { courses in the absence of disease progression or unacceptable toxicity. }\end{array}$ \\
\hline
\end{tabular}




\section{Characteristics of ongoing studies (Continued)}

vs

D: Gemcitabine IV over 30 minutes followed by irinotecan IV over 90 minutes on $\mathrm{d} 1$ and 8 . Treatment repeats every $21 \mathrm{~d}$ for at least 3 courses in the absence of disease progression or unacceptable toxicity.

Patients are followed 3 monthly for $1 \mathrm{y}$ and then every 6 months for $3 \mathrm{y}$.

\begin{tabular}{|c|c|}
\hline Outcomes & $\begin{array}{l}\text { Overall survival. } \\
\text { Time to disease progression. } \\
\text { CA19.9 biomarker response. } \\
\text { Toxicity. } \\
\text { Response rate. }\end{array}$ \\
\hline \multicolumn{2}{|l|}{ Starting date } \\
\hline Contact information & Matthew Kulke, MD, Study Chair, Dana-Farber/Harvard Cancer Center. \\
\hline Notes & $\begin{array}{l}\text { Planned accrual: } 240 \text { patients } \\
\text { (study closed). }\end{array}$ \\
\hline Study & ECOG-4201 \\
\hline Trial name or title & $\begin{array}{l}\text { Phase III randomised study of gemcitabine with or without radiotherapy in patients with locally advanced, } \\
\text { unresectable pancreatic cancer }\end{array}$ \\
\hline Participants & Locally-advanced unresectable adenocarcinoma and adenosquamous carcinoma of the pancreas. \\
\hline Interventions & $\begin{array}{l}\text { A: Gemcitabine } \\
\text { vs } \\
\text { B:Gemcitabine+concurrent radiotherapy }\end{array}$ \\
\hline Outcomes & $\begin{array}{l}\text { Overall survival. } \\
\text { Progression-free survival. } \\
\text { Toxicity. } \\
\text { Quality of life. }\end{array}$ \\
\hline Starting date & $03 / 2003$ \\
\hline Contact information & $\begin{array}{l}\text { ECOG } \\
\text { Patrick Loehrer } \\
\text { Tel: }+13172787418 \\
\end{array}$ \\
\hline Notes & $\begin{array}{l}\text { Planned accrual: } 332 \text { patients } \\
\text { (study closed) }\end{array}$ \\
\hline
\end{tabular}

Study

ECOG-6201

Trial name or title Phase III randomised study of standard infusion gemcitabine vs prolonged infusion gemcitabine with or without oxaliplatin patients with locally advanced or metastatic pancreatic cancer.

\begin{tabular}{ll}
\hline Participants & Locally advanced or metastatic pancreatic adenocarcinoma or poorly differentiated carcinoma. \\
\hline Interventions & A: Gemcitabine standard infusion \\
& vs \\
& B. Gemcitabine prolonged infusion \\
& vs \\
& C.Gemcitabine prolonged infusion+oxaliplatin \\
\hline Outcomes & Survival. \\
& Toxicity. \\
& Response rate. \\
& Patterns of failure. \\
& Progression free survival. \\
& Frequency of thromboembolism. \\
\hline
\end{tabular}

Chemotherapy and radiotherapy for inoperable advanced pancreatic cancer (Review)

Copyright $($ C 2007 The Cochrane Collaboration. Published by John Wiley \& Sons, Ltd 
Characteristics of ongoing studies (Continued)

Quality of life.

\begin{tabular}{|c|c|}
\hline Starting date & $03 / 2003$ \\
\hline Contact information & $\begin{array}{l}\text { ECOG } \\
\text { Elizabeth Poplin } \\
\text { Tel:+1 } 732235677\end{array}$ \\
\hline Notes & Planned accrual: 666 patients \\
\hline Study & ECOG-E8200 \\
\hline Trial name or title & $\begin{array}{l}\text { Phase II randomised study of irinotecan and docetaxel with or without cetuximab in patients with metastatic } \\
\text { adenocarcinoma of the pancreas. }\end{array}$ \\
\hline Participants & $\begin{array}{l}\text { Histologically-confirmed metastatic adenocarcinoma of the pancreas. } \\
\text { Core or open-biopsy material available for epidermal growth factor receptor testing. }\end{array}$ \\
\hline Interventions & $\begin{array}{l}\text { A:Docetaxel+irinotecan } \\
\text { vs } \\
\text { B:Docetaxel+irinotecan+cetuximab }\end{array}$ \\
\hline Outcomes & $\begin{array}{l}\text { Overall response rate. } \\
\text { Time to progression. } \\
\text { Overall survival. }\end{array}$ \\
\hline \multicolumn{2}{|l|}{ Starting date } \\
\hline Contact information & Barbara A. Burtness, MD, Study Chair, Yale Cancer Center \\
\hline Notes & Planned accrual: 92 patients \\
\hline Study & EORTC 40033 \\
\hline Trial name or title & Phase III trial of docetaxel/gemcitabine vs gemcitabine in advanced pancreatic cancer. \\
\hline \multicolumn{2}{|l|}{ Participants } \\
\hline Interventions & $\begin{array}{l}\text { A: Gemcitabine } \\
\text { vs } \\
\text { B: Gemcitabine/docetaxel }\end{array}$ \\
\hline \multicolumn{2}{|l|}{ Outcomes } \\
\hline \multicolumn{2}{|l|}{ Starting date } \\
\hline Contact information & M.Lutz \\
\hline Notes & \\
\hline
\end{tabular}

Study

EORTC-05962

Trial name or title Phase III randomised multicentre trial of infusional fluorouracil with or without cisplatin and with or without chronomodulation against locally advanced or metastatic pancreatic cancer.

\begin{tabular}{ll}
\hline Participants & Locally-advanced or metastatic adenocarcinoma of the exocrine pancreas. \\
\hline Interventions & A: Chronomodulated $5 \mathrm{FU}$ \\
& vs \\
& B. Chronomodulated $5 \mathrm{FU}+$ cisplatin \\
& vs \\
C: $5 \mathrm{FU}$ flat infusion \\
vs \\
D: Cisplatin flat infusion \\
\hline
\end{tabular}

Outcomes Survival

Chemotherapy and radiotherapy for inoperable advanced pancreatic cancer (Review)

Copyright @ 2007 The Cochrane Collaboration. Published by John Wiley \& Sons, Ltd 
Characteristics of ongoing studies (Continued)

Starting date

\begin{tabular}{ll}
\hline Contact information & EORTC Chronotherapy Group \\
& Francis Levi \\
& Tel:+33 145583855 \\
\hline Notes & Planned accrual: 200 patients \\
& (Trial now closed)
\end{tabular}

Study

FRE-GERCOR-GEM-GEMOX

Trial name or title Phase III randomised study of gemcitabine with or without oxaliplatin in patients with locally or advanced or metastatic unresectable pancreatic cancer.

\begin{tabular}{ll}
\hline Participants & Locally-advanced or metastatic unresectable pancreatic adenocarcinoma. \\
\hline Interventions & A: Gemcitabine \\
& vs \\
& B: Gemcitabine fixed dose rate+oxaliplatin \\
\hline
\end{tabular}

Outcomes Overall survival.

Time of response.

Clinical benefit.

QOL.

Progression free survival.

Starting date

Contact information Christophe Louvet:

Tel:+33 149282343

Notes $\quad$ Planned accrual 230

\begin{tabular}{|c|c|}
\hline Study & Heinemann 2005 \\
\hline Trial name or title & $\begin{array}{l}\text { Randomised phase II trial of capecitabine plus oxaliplatin (CapOx) vs capecitabine plus gemcitabine (CapGem) } \\
\text { versus gemcitabine plus oxaliplatin (GemOx) }\end{array}$ \\
\hline Participants & Locally advanced and metastatic pancreatic cancer. \\
\hline Interventions & $\begin{array}{l}\text { A: Capecitabine+oxaliplatin } \\
\text { vs } \\
\text { B: Capecitabine+gemcitabine } \\
\text { vs } \\
\text { C: Gemcitabine+oxaliplatin }\end{array}$ \\
\hline$\overline{\text { Outcomes }}$ & $\begin{array}{l}\text { Response rate. } \\
\text { Progression free survival. } \\
\text { Overall survival. } \\
\text { Toxicity. }\end{array}$ \\
\hline Starting date & 07/2002 \\
\hline \multicolumn{2}{|l|}{ Contact information } \\
\hline Notes & $\begin{array}{l}\text { Planned accrual: } 190 \\
\text { (study closed). }\end{array}$ \\
\hline
\end{tabular}

Study

\section{LORUS-LOR-VIR-PO3-00}

Trial name or title

Phase III randomised study of gemcitabine with or without virulizin followed by optional secondline therapy with virulizin or placebo with or without fluorouracil in patients with chemotherapy-naive locally-advanced or metastatic pancreatic cancer.

Chemotherapy and radiotherapy for inoperable advanced pancreatic cancer (Review)

Copyright $(2007$ The Cochrane Collaboration. Published by John Wiley \& Sons, Ltd 


\section{Characteristics of ongoing studies (Continued)}

\begin{tabular}{ll} 
Participants & Locally-advanced or metastatic pancreatic adenocarcinoma. \\
\hline Interventions & A:Gemcitabine+placebo \\
& vs \\
& B:Gemcitabine+virulizin \\
\hline Outcomes & Overall survival. \\
& Time to progression. \\
& Pharmacokinetics and pharmacodynamics. \\
& Safety. \\
\hline Starting date & 09/2002 \\
\hline Contact information & $\begin{array}{l}\text { Lorus Therapeutics } \\
\text { Suzanne Cadden } \\
\text { Tel: }+14167981200\end{array}$ \\
\hline Notes & Planned accrual: 400 patients \\
\hline
\end{tabular}

\begin{tabular}{ll} 
Study & MEYER-AIT-PAN-201 \\
\hline Trial name or title & $\begin{array}{l}\text { Phase II randomised study of gemcitabine vs immunotherapy with CYTOIMPLANT as first line therapy in } \\
\text { patients with unresectable, locally advanced or metastatic pancreatic cancer. }\end{array}$ \\
\hline Participants & $\begin{array}{l}\text { Histologically-proven stage II, III, or IV pancreatic cancer that is unresectable } \\
\text { No symptomatic third-space fluid collection (e.g., ascites, pleural effusion). }\end{array}$ \\
\hline Interventions & A:Gemcitabine \\
& vs. \\
& B: Endoscopic implanation of patient lymphocytes admixed with donor lymphocytes into tumour. \\
\hline Outcomes & Overall survival. \\
& $\begin{array}{l}\text { Progression free survival. } \\
\text { Response rate. } \\
\text { QOL. } \\
\text { Safety and toxicity. }\end{array}$ \\
\hline Starting date & 12/1998 \\
\hline Contact information & Meyer Pharmaceuticals, LLC, Irvine, California, 92614, United States \\
\hline Notes & $\begin{array}{l}\text { Planned accrual: } 150 \text { patients } \\
\text { (study closed). }\end{array}$ \\
\hline
\end{tabular}

\begin{tabular}{ll} 
Study & MRC PANRAD \\
\hline Trial name or title & $\begin{array}{l}\text { A randomised trial of CF (Infusional 5-Fluorouracil and Cisplatin) alone versus CF plus concurrent radiotherapy } \\
\text { in patients with locally advanced pancreatic carcinoma }\end{array}$ \\
\hline Participants & Histological evidence of locally-advanced or unresectable pancreatic adenocarcinoma. \\
& Patients evaluable for response must have bidmensionally measurable disease as assessed by Computed Tomog- \\
& raphy (CT) scans. \\
& No prior chemotherapy or radiotherapy. \\
& Life expectancy of $>3$ months. \\
& Adequate bone marrow and renal function. \\
& World Health Organisation (WHO) performance status 0-2 at randomisation. \\
& No medical contraindications to treatment protocols. \\
\hline A: 5-fluorouracil, continuous infusion for 18 weeks, plus cisplatin repeated every 3 weeks for 6 cycles. \\
vs \\
B: Cisplatin repeated every 3 weeks for 4 cycles plus 5-fluorouracil, continuous infusion for 12 weeks followed \\
by continuous infusion for a further 6 weeks at a reduced dose. Radiotherapy 50 Gy in twenty-five fractions \\
given over 5 weeks. Radiotherapy to commence on week 13 of chemotherapy.
\end{tabular}




\section{Characteristics of ongoing studies (Continued)}

\begin{tabular}{|c|c|}
\hline \multicolumn{2}{|l|}{ Outcomes } \\
\hline \multicolumn{2}{|l|}{ Starting date } \\
\hline Contact information & Royal Marsden Hospital, London, UK \\
\hline Notes & Study closed due to poor accrual \\
\hline Study & NCCTG-N014C \\
\hline Trial name or title & $\begin{array}{l}\text { Phase II randomized study of bortezomib with or without gemcitabine in patients with metastatic pancreatic } \\
\text { adenocarcinoma }\end{array}$ \\
\hline Participants & $\begin{array}{l}\text { Histologically-confirmed metastatic ductal or undifferentiated adenocarcinoma consistent with a pancreatic } \\
\text { primary for which no standard curative measures exist } \\
\text { No participants with locally-advanced disease only. }\end{array}$ \\
\hline Interventions & $\begin{array}{l}\text { A:Bortezomib } \\
\text { vs } \\
\text { B:Bortezomib+gemcitabine }\end{array}$ \\
\hline$\overline{\text { Outcomes }}$ & $\begin{array}{l}\text { Response rate. } \\
\text { Progression-free survival. } \\
\text { Overall survival. } \\
\text { QOL. }\end{array}$ \\
\hline Starting date & Study closed \\
\hline Contact information & Steven R. Alberts, MD, Study Chair, Mayo Clinic Cancer Center \\
\hline Notes & Planned accrual: 88 \\
\hline Study & NCI-6580 \\
\hline Trial name or title & $\begin{array}{l}\text { Phase II randomised study of bevacizumab and gemcitabine with either cetuximab or erlotinib in patients with } \\
\text { advanced adenocarcinoma of the pancreas. }\end{array}$ \\
\hline Participants & $\begin{array}{l}\text { Histologically or cytologically confirmed adenocarcinoma of the pancreas. } \\
\text { Patients with locally-advanced disease must have disease that extends outside the boundaries of a standard } \\
\text { radiation port. }\end{array}$ \\
\hline Interventions & $\begin{array}{l}\text { A:Bevacizumab+gemcitabine+cetuximab } \\
\text { vs } \\
\text { B:Bevacizumab+gemcitabine+erlotinib }\end{array}$ \\
\hline Outcomes & $\begin{array}{l}\text { Response rate. } \\
\text { Progression free survival. } \\
\text { Overall survival. }\end{array}$ \\
\hline Starting date & \\
\hline Contact information & University of Chicago Cancer Research Center \\
\hline Notes & Planned accrual: 54-126 patients \\
\hline Study & NCT00051467 \\
\hline Trial name or title & $\begin{array}{l}\text { A randomised, phase II, study of TNFerade }{ }^{\mathrm{TM}} \text { biologic with 5-FU and radiation therapy for first-line treatment } \\
\text { of unresectable locally advanced pancreatic cancer }\end{array}$ \\
\hline Participants & $\begin{array}{l}\text { Participants with biopsy proven locally advanced adenocarcinoma of the pancreas assessed to be unresectable, } \\
\text { who have not received previous treatment for pancreatic cancer }\end{array}$ \\
\hline Interventions & $\begin{array}{l}\text { A:Chemoradiation }+5 \mathrm{FU} \\
\text { vs }\end{array}$ \\
\hline
\end{tabular}

Chemotherapy and radiotherapy for inoperable advanced pancreatic cancer (Review)

Copyright $($ C 2007 The Cochrane Collaboration. Published by John Wiley \& Sons, Ltd 


\section{Characteristics of ongoing studies (Continued)}

B: Chemoradiation $+5 \mathrm{FU}+$ intratumoural injection of TNFerade

Outcomes

Starting date

Contact information Joel Randolph Hecht, MD, Principal Investigator, Jonsson Comprehensive Cancer Center

Notes $\quad$ TNFerade ${ }^{\mathrm{TM}}$ is a replication deficient (E1, E3 and E4 deleted) adenovirus vector containing the gene for TNFalpha controlled by a radiation inducible promoter.

\section{Study $\quad$ RTOG-PA-0020}

Trial name or title Randomised phase II trial to compare the effectiveness of gemcitabine, paclitaxel, and radiation therapy with or without tipifarnib in treating patients who have locally-advanced pancreatic cancer.

Participants Histologically confirmed unresectable, locally advanced adenocarcinoma of the pancreas Residual disease after resection (R1 or R2, microscopic or macroscopic) allowed

Interventions A: Patients receive radiotherapy once daily, $5 \mathrm{~d}$ a week, for 5.5 weeks, beginning on $\mathrm{d} 1$. Patients also receive paclitaxel IV over 1 hour and gemcitabine IV over 30 minutes on days 1, 8, 15, 22, 29, and 36.

vs

B: Patients receive chemoradiotherapy as in arm I. Within 3-8 weeks after completion of chemoradiotherapy, patients without disease progression receive oral tipifarnib twice daily for 21 days. Treatment continues every 28 days in the absence of disease progression or unacceptable toxicity. Patients are followed-up every 3 months for $2 \mathrm{y}$, every 6 months for $3 \mathrm{y}$, and then annually thereafter.

Outcomes One year survival

Toxicity

Determine the feasibility and toxicity of prolonged administration of tipifarnib after chemoradiotherapy in these patients.

Effect of

Starting date

Contact information Tyvin Andrew Rich, MD, Study Chair, University of Virginia, Health Sciences Center Cancer Center

Notes Planned accrual:154 patients

Study closed

\begin{tabular}{|c|c|}
\hline Study & SWOG S0205 \\
\hline Trial name or title & $\begin{array}{l}\text { Phase III randomised open label study comparing gemcitabine with cetuximab vs gemcitabine as first line } \\
\text { therapy of patients with advanced pancreatic carcinoma. }\end{array}$ \\
\hline Participants & Locally-advanced or metastatic pancreatic carcinoma. \\
\hline Interventions & $\begin{array}{l}\text { A:Gemcitabine } \\
\text { vs } \\
\text { B:Gemcitabine+cetuximab }\end{array}$ \\
\hline$\overline{\text { Outcomes }}$ & $\begin{array}{l}\text { Survival. } \\
\text { Time to treatment failure. } \\
\text { Response rate. } \\
\text { Self assessed pain. } \\
\text { QOL. }\end{array}$ \\
\hline \multicolumn{2}{|l|}{ Starting date } \\
\hline Contact information & $\begin{array}{l}\text { Dr Philip Philip } \\
\text { Wayne State University } \\
\text { philipp@karmanos.org }\end{array}$ \\
\hline Notes & Planned accrual \\
\hline
\end{tabular}


Characteristics of ongoing studies (Continued)

613 patients

Study

Trial name or title

TBC-PAN-003

Phase III randomised controlled study to evaluate the safety and efficacy of PANVAC-VF in combination with GM-CSF vs best supportive care or palliative chemotherapy in patients with metastatic adenocarcinoma of the pancreas who have failed a gemcitabine containing chemotherapy regimen.

\begin{tabular}{ll}
\hline Participants & $\begin{array}{l}\text { Metastatic adenocarcinoma of pancreas. } \\
\text { Vaccinated against smallpox }\end{array}$ \\
\hline Interventions & A:Best supportive care \\
& vs \\
& vs:PANVAC-VF+GM CSF \\
& C.Palliative chemotherapy \\
\hline Outcomes & 06/2004 \\
\hline Starting date & Therion Biologics Corporation \\
\hline Contact information & Planned accrual: 250 \\
\hline Notes
\end{tabular}

\begin{tabular}{|c|c|}
\hline Study & TC-CR-302 \\
\hline Trial name or title & Study of efficacy and safety of glufosfamide compared with best supportive care in metastatic pancreatic cancer \\
\hline Participants & Metastatic pancreatic adenocarcinoma \\
\hline Interventions & $\begin{array}{l}\text { A:Best supportive care } \\
\text { vs } \\
\text { B:Glufosfamide }\end{array}$ \\
\hline Outcomes & $\begin{array}{l}\text { Survival. } \\
\text { Tumour response. } \\
\text { Duration of response. } \\
\text { Progression-free survival. } \\
\text { 6-and 12-month survival. } \\
\text { Pain intensity. } \\
\text { Performance status. }\end{array}$ \\
\hline Starting date & $09 / 2004$ \\
\hline Contact information & www.thresholdpharm.com \\
\hline Notes & $\begin{array}{l}\text { Planned accrual: } 300 \text { patients } \\
\text { Second line study }\end{array}$ \\
\hline Study & WELLSTAT-401.00.0012 \\
\hline Trial name or title & $\begin{array}{l}\text { Phase III randomised study of triacetyleluridine and high dose fluorouracil versus gemcitabine in patients with } \\
\text { unresectable locally-advanced or metastatic pancreatic cancer. }\end{array}$ \\
\hline Participants & Unresectable locally-advanced or metastatic pancreatic adenocarcinoma. \\
\hline Interventions & $\begin{array}{l}\text { A.Gemcitabine } \\
\text { vs } \\
\text { B.High Dose } 5 \mathrm{FU}+\text { oral triacetyluridine }\end{array}$ \\
\hline Outcomes & $\begin{array}{l}\text { Survival. } \\
\text { Time to progression } \\
\text { Response rate }\end{array}$ \\
\hline
\end{tabular}


Characteristics of ongoing studies (Continued)

\begin{tabular}{ll} 
& $\begin{array}{l}\text { Response duration } \\
\text { Safety }\end{array}$ \\
\hline Starting date & $09 / 01$ \\
\hline Contact information & $\begin{array}{l}\text { Wellstat Therapeutics } \\
\text { Lenny Smith } \\
\text { Tel: }+1 \text { 240 6312500 }\end{array}$ \\
\hline Notes & Planned accrual: 260 patients \\
\hline
\end{tabular}

ADDITIONAL TABLES

Table 01. Best supportive care versus chemotherapy trials for advanced pancreatic cancer

$\begin{array}{lll}\text { Study ID } & \text { No. participants } & \begin{array}{l}\text { Treatment arms } \\ \text { Best supportive } \\ \text { care vs } \\ \text { cyclophosphamide/ } \\ 5 \text { FU/vincristine/ } \\ \text { methotrexate }\end{array} \\ & 26 & \begin{array}{l}\text { Best supportive care } \\ \text { vs 5FU/BCNU }\end{array} \\ \text { Andersen (1981) } & 40 & \\ & & \\ \text { Andren-Sandberg } & 47 & \\ \text { (1983) } & & \begin{array}{l}\text { Best supportive } \\ \text { care vs 5FU/ } \\ \text { vincristine/CCNU }\end{array} \\ \text { Frey (1981) } & 46 & \begin{array}{l}\text { Best supportive care } \\ \text { vs 5FU/CCNU }\end{array} \\ \text { Palmer (1994) } & 46 & \begin{array}{l}\text { Best supportive care } \\ \text { vs 5FU/adriamycin/ } \\ \text { mitomycin C }\end{array} \\ & & \end{array}$

Glimelius (1996) $53 \quad$ Best supportive care vs $5 \mathrm{FU} /$ leucovorin

Takada (1998)

Hugier (2001)
52

45 vs 5FU/mitomycin $\mathrm{C}$ and doxorubicin

\section{Clinical}

benefit/QOL

QOL(number of hospital days,. need for analgesics, rate of weight loss) : no significant difference

$10 \%$ vs $10 \%$

$3.2 \mathrm{mo}$ vs $3.0 \mathrm{mo}$ $(\mathrm{P}=0.8)$

\section{$5 \%$ vs $48 \%$}

$1.6 \mathrm{mo}$ vs $7.1 \mathrm{mo}$ $(\mathrm{P}=0.006)$

$4 \mathrm{mo}(1-20)$ vs $5 \mathrm{mo}$ (1-17)

$8 \%$ vs $12 \%$

3.9 vs $3.0 \mathrm{mo}(\mathrm{P}=$ 0.17 )

HADS:significantly less depression but not anxiety in treated group

EORTC QLQ

C30: improved or prolonged high quality life $10 \%$ vs $36 \%(\mathrm{p}<0.01)$.

Clinical effects: improvement in performance status (8\% vs $14 \%$ ), improvement in body weight ( $4 \%$ vs $14 \%)$
$3.5 \mathrm{mo}$ vs $7.6 \mathrm{mo}$ $(\mathrm{P}<0.002)$

$12.5 \%$ vs $20.7 \%$ $2.5 \mathrm{mo}$ vs $6 \mathrm{mo}(\mathrm{P}=$ 0.05 )

\section{$4.2 \%$ vs $7.1 \%$}

$4.8 \mathrm{mo}$ vs $4.9 \mathrm{mo}$ $(\mathrm{P}=0.39)$
$18.4 \%$ vs $12.6 \%$

$7.0 \mathrm{mo}$ vs $8.6 \mathrm{mo}$ $(\mathrm{P}=0.33)$ 
Table 01. Best supportive care versus chemotherapy trials for advanced pancreatic cancer (Continued)

$\begin{array}{llll}\text { Study ID No. participants } & \text { Treatment arms } & \begin{array}{l}\text { Clinical } \\ \text { benefit/QOL }\end{array} \\ \text { cisplatin } & 12 \text { month survival Median survival }\end{array}$

Table 02. 5FU versus 5FU combination chemotherapy regimens

\begin{tabular}{|c|c|c|c|c|c|c|}
\hline Study ID & No. participants & Treatment arms & $\begin{array}{l}\text { Tumour } \\
\text { response rate }\end{array}$ & $\begin{array}{l}12 \text { month } \\
\text { survival }\end{array}$ & Median survival & $\begin{array}{l}\text { QOL/Clinical } \\
\text { benefit }\end{array}$ \\
\hline Kovach 1974 & 82 & $\begin{array}{l}5 \mathrm{FU} \text { vs BCNU } \\
\text { vs } 5 \mathrm{FU} / \mathrm{BCNU}\end{array}$ & $\begin{array}{l}16 \% \text { vs } \\
33.3 \%\end{array}$ & $\begin{array}{l}23 \% \text { vs } \\
21 \%\end{array}$ & $\begin{array}{l}23 \% \text { vs } 10 \% \text { vs } \\
21 \%\end{array}$ & $\begin{array}{l}5.4 \mathrm{mo} \text { vs } 5.1 \mathrm{vs} \\
7.5 \mathrm{mo}\end{array}$ \\
\hline Cullinan 1985 & 144 & $\begin{array}{l}5 \mathrm{FU} \text { vs 5FU/ } \\
\text { adriamycin } \\
\text { vs 5FU/ } \\
\text { adriamycin/ } \\
\text { mitomycin C }\end{array}$ & $\begin{array}{l}30 \% \text { vs } 30 \% \text { vs } \\
7.6 \%\end{array}$ & $\begin{array}{l}12 \% \text { vs } 16 \% \text { vs } \\
12 \%\end{array}$ & $\begin{array}{l}22 \text { wk vs } 22 \text { wk } \\
\text { vs } 18 \text { wk }(P=n s)\end{array}$ & \\
\hline Cullinan 1990 & 187 & $\begin{array}{l}5 \mathrm{FU} \text { vs } \\
\text { Mallinson } \\
\text { regimen vs 5FU/ } \\
\text { adriamycin/ } \\
\text { cisplatin }\end{array}$ & $\begin{array}{l}7 \% \text { vs } 21 \% \text { vs } \\
15 \%\end{array}$ & $\begin{array}{l}17 \% \text { vs } 9 \% \text { vs } \\
13.5 \%\end{array}$ & $\begin{array}{l}3.5 \mathrm{mo} \text { vs } 4.5 \mathrm{~m} \\
\text { vs } 3.5 \mathrm{mo}\end{array}$ & \\
\hline Ducreux 2002 & 190 & $\begin{array}{l}5 \mathrm{FU} \text { vs } 5 \mathrm{FU}+ \\
\text { cisplatin }\end{array}$ & $\begin{array}{l}0 \% \text { vs } 12 \% \\
(\mathrm{P}<0.01)\end{array}$ & $8 \%$ vs $15 \%$ & & $\begin{array}{l}\text { Spitzer index: } \\
\text { significant } \\
\text { treatment effect } \\
\text { in favour of } \\
\text { combination } \\
\text { arm }(\mathrm{P}=0.03)\end{array}$ \\
\hline Maisey 2002 & 209 & $\begin{array}{l}5 \mathrm{FU} \text { vs } 5 \mathrm{FU}+ \\
\text { mitomycin } \mathrm{C}\end{array}$ & $\begin{array}{l}8.4 \% \text { vs } 17.6 \% \\
(\mathrm{P}=0.04)\end{array}$ & $23.5 \%$ vs $26.2 \%$ & $\begin{array}{l}5.1 \mathrm{mo} \text { vs } 6.5 \mathrm{mo} \\
(\mathrm{P}=0.34)\end{array}$ & $\begin{array}{l}\text { EORTC } \\
\text { QLQ C30: } \\
\text { No difference } \\
\text { between } \\
\text { groups during } \\
\text { treatment. }\end{array}$ \\
\hline Ducreux 2004 & 63 & $\begin{array}{l}5 \mathrm{FU} \text { vs } \\
\text { oxaliplatin vs } \\
\text { oxaliplatin 5FU }\end{array}$ & $\begin{array}{l}0 \% \text { vs } 0 \% \text { vs } \\
10 \%\end{array}$ & $\begin{array}{l}6 \% \text { vs } 6 \% \text { vs } \\
23 \%\end{array}$ & $\begin{array}{l}2.4 \text { mo vs } 3.4 \\
\text { mo vs } 9.0 \text { mo }\end{array}$ & $\begin{array}{l}\text { Clinical benefit } \\
\text { response: } 0 \% \text { vs } \\
14 \% \text { vs } 21 \%\end{array}$ \\
\hline Levi 2004 & 107 & $\begin{array}{l}5 \mathrm{FU} \text { vs } 5 \mathrm{FU}+ \\
\text { cisplatin } \\
\text { (constant rate vs } \\
\text { chronomodu- } \\
\text { lated infusion) }\end{array}$ & Not stated & Not stated & $\begin{array}{l}5.4 \text { mo vs } 8.3 \\
\text { mo }(\mathrm{P}=0.26)\end{array}$ & \\
\hline
\end{tabular}


Table 03. Gemcitabine versus gemcitabine combination chemotherapy regimens

\begin{tabular}{|c|c|c|c|c|c|c|c|}
\hline Study ID & $\begin{array}{l}\text { No. } \\
\text { participants }\end{array}$ & $\begin{array}{l}\text { Treatment } \\
\text { arms }\end{array}$ & $\begin{array}{l}\text { Tumour } \\
\text { Response } \\
\text { rate }\end{array}$ & $\begin{array}{l}\text { Clinical } \\
\text { benefit QOL }\end{array}$ & $\begin{array}{l}12 \text { month } \\
\text { survival }\end{array}$ & Median PFS & $\begin{array}{l}\text { Median } \\
\text { survival }\end{array}$ \\
\hline Berlin (2002) & 322 & $\begin{array}{l}\text { Gemcitabine } \\
\text { vs } \\
\text { gemcitabine+ } \\
5 \mathrm{FU}\end{array}$ & $5.6 \%$ vs $6.9 \%$ & & $\begin{array}{l}20 \% \text { vs } 20 \% \\
(\mathrm{P}=\mathrm{ns})\end{array}$ & $\begin{array}{l}2.2 \text { vs } 3.4 \mathrm{mo} \\
(\mathrm{P}=0.022)\end{array}$ & $\begin{array}{l}7.1 \text { vs } 9.0 \mathrm{mo} \\
(\mathrm{P}=0.09)\end{array}$ \\
\hline Wang (2002) & 42 & $\begin{array}{l}\text { Gemcitabine } \\
\text { vs } \\
\text { gemcitabine+ } \\
\text { cisplatin }\end{array}$ & $6.3 \%$ vs $11 \%$ & $\begin{array}{l}\text { Clinical } \\
\text { benefit } \\
\text { response: } \\
87.5 \% \text { vs } \\
70 \%\end{array}$ & $31 \%$ vs $11 \%$ & & 9.0 vs $7.1 \mathrm{mo}$ \\
\hline $\begin{array}{l}\text { Collucci } \\
(2002)\end{array}$ & 107 & $\begin{array}{l}\text { Gemcitabine } \\
\text { vs } \\
\text { gemcitabine+ } \\
\text { cisplatin }\end{array}$ & $\begin{array}{l}9.2 \% \text { vs } \\
24.4 \%(P= \\
0.02)\end{array}$ & $\begin{array}{l}\text { Clinical } \\
\text { benefit } \\
\text { response: } \\
49 \% \text { vs } \\
52.6 \%\end{array}$ & $\begin{array}{l}11 \% \text { vs } \\
11.3 \%\end{array}$ & $\begin{array}{l}2.0 \text { vs } 5.0 \mathrm{mo} \\
(\mathrm{P}=0.048)\end{array}$ & $\begin{array}{l}5.0 \text { vs } 6.0(\mathrm{P}= \\
0.43)\end{array}$ \\
\hline $\begin{array}{l}\text { Heineman } \\
(2003)\end{array}$ & 198 & $\begin{array}{l}\text { Gemcitabine } \\
\text { vs } \\
\text { gemcitabine+ } \\
\text { cisplatin }\end{array}$ & $\begin{array}{l}8.0 \% \text { vs } \\
10.2 \%(\mathrm{P}=\mathrm{ns})\end{array}$ & & $22 \%$ vs $26 \%$ & $\begin{array}{l}2.8 \text { vs } 5.4 \mathrm{mo} \\
(\mathrm{P}<0.01)\end{array}$ & $\begin{array}{l}6.0 \text { vs } 7.6 \mathrm{mo} \\
(\mathrm{P}=\mathrm{ns})\end{array}$ \\
\hline $\mathrm{Li}(2004)$ & 46 & $\begin{array}{l}\text { Gemcitabine } \\
\text { vs } \\
\text { gemcitabine+ } \\
\text { cisplatin }\end{array}$ & $\begin{array}{l}12 \% \text { vs } 10 \% \\
(\mathrm{P}=\mathrm{ns})\end{array}$ & $\begin{array}{l}\text { Clinical } \\
\text { benefit } \\
\text { response: } \\
36 \% \text { vs } 29 \% \\
(P>0.05) . \\
\text { Quality } \\
\text { adjusted } \\
\text { life months } \\
5.6 \text { vs } 3.8 \\
(\mathrm{p}<0.001)\end{array}$ & $\begin{array}{l}6.3 \% \text { vs } \\
13.6 \%\end{array}$ & $\begin{array}{l}2.8 \text { vs } 2.8 \mathrm{mo} \\
(\mathrm{P}=0.9)\end{array}$ & $\begin{array}{l}4.6 \text { vs } 5.6 \mathrm{mo} \\
(\mathrm{P}=0.75)\end{array}$ \\
\hline Louvet (2005) & 313 & $\begin{array}{l}\text { Gemcitabine } \\
\text { vs } \\
\text { gemcitabine+ } \\
\text { oxaliplatin }\end{array}$ & $\begin{array}{l}17.3 \% \text { vs } \\
26.8 \%(P= \\
0.04)\end{array}$ & $\begin{array}{l}\text { Clinical } \\
\text { benefit } \\
\text { response: } \\
26.9 \% \text { vs } \\
38.2 \%(\mathrm{P}= \\
0.03)\end{array}$ & 27.8 vs $34.5 \%$ & $\begin{array}{l}3.7 \text { vs } 5.8 \mathrm{mo} \\
(\mathrm{P}=0.04)\end{array}$ & $\begin{array}{l}7.1 \text { vs } 9.0(\mathrm{P}= \\
0.13)\end{array}$ \\
\hline $\begin{array}{l}\text { O'Reilly } \\
(2004)\end{array}$ & 349 & $\begin{array}{l}\text { Gemcitabine } \\
\text { vs } \\
\text { gemcitabine+ } \\
\text { exetecan }\end{array}$ & $7.1 \%$ vs $8.2 \%$ & $\begin{array}{l}\text { No difference } \\
\text { in clinical } \\
\text { benefit } \\
\text { response. } \\
\text { Improvement } \\
\text { in time to } \\
\text { deterioration } \\
\text { of analgesic } \\
\text { consumption } \\
\text { and }\end{array}$ & $21 \%$ vs $23 \%$ & $\begin{array}{l}3.8 \text { vs } 3.7 \mathrm{mo} \\
(\mathrm{P}=0.22)\end{array}$ & $\begin{array}{l}6.2 \text { vs } 6.7 \mathrm{mo} \\
(\mathrm{P}=0.52)\end{array}$ \\
\hline
\end{tabular}

Chemotherapy and radiotherapy for inoperable advanced pancreatic cancer (Review) 
Table 03. Gemcitabine versus gemcitabine combination chemotherapy regimens (Continued)

\begin{tabular}{|c|c|c|c|c|c|c|c|}
\hline Study ID & $\begin{array}{l}\text { No. } \\
\text { participants }\end{array}$ & $\begin{array}{l}\text { Treatment } \\
\text { arms }\end{array}$ & $\begin{array}{l}\text { Tumour } \\
\text { Response } \\
\text { rate }\end{array}$ & $\begin{array}{l}\text { Clinical } \\
\text { benefit QOL } \\
\text { performance } \\
\text { score with } \\
\text { combination. }\end{array}$ & $\begin{array}{l}12 \text { month } \\
\text { survival }\end{array}$ & Median PFS & $\begin{array}{l}\text { Median } \\
\text { survival }\end{array}$ \\
\hline Oettle (2002) & 565 & $\begin{array}{l}\text { Gemcitabine } \\
\text { vs } \\
\text { gemcitabine+ } \\
\text { pemetrexed }\end{array}$ & $\begin{array}{l}7.1 \% \text { vs } \\
14.8 \%(\mathrm{P}= \\
0.004)\end{array}$ & $\begin{array}{l}\text { EORTC } \\
\text { QLQ C30: } \\
\text { well preserved } \\
\text { in both arms }\end{array}$ & $20 \%$ vs $21 \%$ & $\begin{array}{l}3.3 \text { vs } 3.9 \text { mo } \\
(\mathrm{P}=0.11)\end{array}$ & $\begin{array}{l}6.3 \text { vs } 6.2 \mathrm{mo} \\
(\mathrm{P}=0.08)\end{array}$ \\
\hline Reni (2005) & 104 & $\begin{array}{l}\text { Gemcitabine } \\
\text { vs cisplatin, } \\
\text { epirubicin, } \\
\text { gemcitabine } \\
\text { and 5FU }\end{array}$ & $\begin{array}{l}8.5 \% \text { vs } \\
38.5 \%(\mathrm{P}= \\
0.0008)\end{array}$ & $\begin{array}{l}\text { Clinical } \\
\text { benefit } \\
\text { response: } \\
25 \% \text { vs 65\% } \\
\text { (P=0.0139). } \\
\text { EORTC } \\
\text { QLQ C30 } \\
\text { and PAN26 } \\
\text { suggested no } \\
\text { worsening in } \\
\text { QOL with } \\
\text { combination } \\
\text { regimen. }\end{array}$ & $\begin{array}{l}21.3 \% \text { vs } \\
38.5 \%(\mathrm{P}= \\
0.1119)\end{array}$ & $\begin{array}{l}3.3 \text { vs } 5.4 \mathrm{mo} \\
(\mathrm{P}=0.0033)\end{array}$ & 9.0 vs $9.0 \mathrm{mo}$ \\
\hline $\begin{array}{l}\text { Ohkawa } \\
(2004)\end{array}$ & 19 & $\begin{array}{l}\text { Gemcitabine } \\
\text { vs } \\
\text { gemcitabine+ } \\
\text { UFT }\end{array}$ & $33 \%$ vs $0 \%$ & $\begin{array}{l}\text { Clinical } \\
\text { benefit: } 33 \% \\
\text { vs } 25 \%\end{array}$ & & $\begin{array}{l}5.0 \text { vs } 1.9 \mathrm{mo} \\
(\mathrm{P}=0.04)\end{array}$ & $\begin{array}{l}7.6 \text { vs } 5.0(\mathrm{P}= \\
\text { ns })\end{array}$ \\
\hline $\begin{array}{l}\text { Rocha Lima } \\
(2004)\end{array}$ & 360 & $\begin{array}{l}\text { Gemcitabine } \\
\text { vs } \\
\text { gemcitabine+ } \\
\text { irinotecan }\end{array}$ & $\begin{array}{l}4.4 \% \text { vs } \\
16.1 \% \\
(P<0.001)\end{array}$ & $\begin{array}{l}\text { FACT-Hep: } \\
\text { no significant } \\
\text { difference }\end{array}$ & $22 \%$ vs $21 \%$ & $\begin{array}{l}3.0 \text { vs } 3.5 \mathrm{mo} \\
(\mathrm{P}=0.352)\end{array}$ & $\begin{array}{l}6.6 \text { vs } 6.3 \mathrm{mo} \\
(\mathrm{P}=0.79)\end{array}$ \\
\hline $\begin{array}{l}\text { Scheithauer } \\
(2003)\end{array}$ & 83 & $\begin{array}{l}\text { Gemcitabine } \\
\text { vs } \\
\text { gemcitabine+ } \\
\text { capecitabine }\end{array}$ & $\begin{array}{l}14.3 \% \text { vs } \\
17.1 \%\end{array}$ & $\begin{array}{l}\text { Clinical } \\
\text { benefit } \\
\text { response } \\
: 33 \% \text { vs } \\
48.2 \%\end{array}$ & $38 \%$ vs $32 \%$ & 4.0 vs $5.1 \mathrm{mo}$ & $\begin{array}{l}8.2 \text { vs } 9.5 \mathrm{mo} \\
(\mathrm{P}=\mathrm{ns})\end{array}$ \\
\hline $\begin{array}{l}\text { Gansauge } \\
(2002)\end{array}$ & 90 & $\begin{array}{l}\text { Gemcitabine } \\
\text { vs } \\
\text { gemcitabine+ } \\
\text { NSC- } 631570\end{array}$ & $\begin{array}{l}3.6 \% \text { vs } \\
21.4 \%\end{array}$ & $\begin{array}{l}\text { Significant } \\
\text { improvement } \\
\text { in self assessed } \\
\text { QOL in both } \\
\text { arms. }\end{array}$ & $13 \%$ vs $32 \%$ & & $\begin{array}{l}5.2 \text { vs } 10.4 \\
\text { mo }(\mathrm{P}<0.01)\end{array}$ \\
\hline $\begin{array}{l}\text { Herrmann } \\
(2005)\end{array}$ & 319 & $\begin{array}{l}\text { Gemcitabine } \\
\text { vs } \\
\text { gemcitabine+ } \\
\text { capecitabine }\end{array}$ & $\begin{array}{l}7.9 \% \text { vs } \\
10.1 \%\end{array}$ & $\begin{array}{l}\text { Clinical } \\
\text { benefit } \\
\text { response: } \\
20 \% \text { vs } 18 \% \text {. }\end{array}$ & $27 \%$ vs $27 \%$ & $\begin{array}{l}4.0 \text { vs } 4.8 \mathrm{mo} \\
(\mathrm{P}=0.207)\end{array}$ & $\begin{array}{l}7.3 \text { vs } 8.4 \mathrm{mo} \\
(\mathrm{P}=0.314)\end{array}$ \\
\hline Reiss (2005) & 466 & Gemcitabine & $7.2 \%$ vs $4.8 \%$ & & $22 \%$ vs $21 \%$ & $3.5 \mathrm{vs} 3.5 \mathrm{mo}$ & 6.2 vs 5.85 \\
\hline
\end{tabular}


Table 03. Gemcitabine versus gemcitabine combination chemotherapy regimens (Continued)

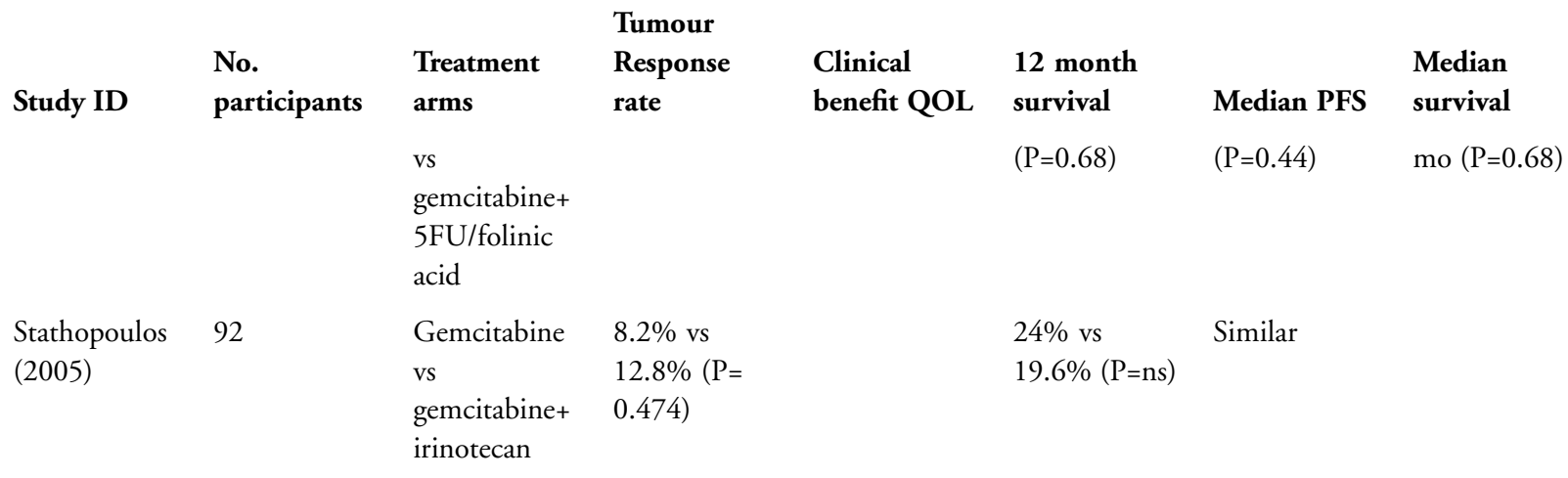

Table 04. Miscellaneous chemotherapy versus chemotherapy trials for pancreatic cancer

\begin{tabular}{|c|c|c|c|c|}
\hline Study ID & No. participants & Study arms & Overall response & Median survival \\
\hline Buroker 1979 & 140 & $5 \mathrm{FU} /$ mitomycin $\mathrm{C}$ vs $5 \mathrm{FU} / \mathrm{CCNU}$ & $22 \%$ vs $5 \%$ & 19 wk vs 17 wk $(\mathrm{P}=\mathrm{ns})$ \\
\hline Bukowski 1983 & 181 & $\begin{array}{l}\text { 5FU mitomycin } \mathrm{C} \text { vs } 5 \mathrm{FU} / \\
\text { mitomycin } \mathrm{C} / \text { streptozotocin }\end{array}$ & Not stated & $\begin{array}{l}17 \text { wk vs } 18 \text { wk (measurable) } \& 18 \\
\text { wk vs } 21 \text { wk (non measurable) }\end{array}$ \\
\hline Horton 1981 & 127 & $\begin{array}{l}\text { Melphalan vs 5FU/CCNU vs } \\
\text { 5FU/CCNU/streptozocin }\end{array}$ & $2 \%$ vs $10 \%$ vs $7 \%$ & 8 wk vs 14 wk vs 12 wk $(P=n s)$ \\
\hline Oster 1984 & 184 & $\begin{array}{l}\text { 5FU/streptozocin/mitomycin C vs } \\
5 \mathrm{FU} / \text { adriamycin/mitomycin }\end{array}$ & $4 \%$ vs $14 \%$ & 18.3 wk vs 26.4 wk $(\mathrm{P}=0.21)$ \\
\hline Kelsen 1991 & 28 & $\begin{array}{l}\text { 5FU streptozotocin/mitomycin C } \\
\text { vs cisplatin/AraC/caffeine }\end{array}$ & $10.2 \%$ vs $5.5 \%$ & 40 wk vs 20 wk ( $\mathrm{P}=0.008)$ \\
\hline Topham 1991 & 69 & $\begin{array}{l}\text { Epirubicin vs 5FU/epirubicin/ } \\
\text { mitomycin C }\end{array}$ & $4 \%$ vs $11 \%$ & 22 wk vs 18 wk $(\mathrm{P}=0.55)$ \\
\hline
\end{tabular}

Table 05. Chemoradiotherapy trials in locally advanced pancreatic cancer

\begin{tabular}{|c|c|c|c|c|}
\hline Study ID & No. participants & Study arms & Median survival & One year survival \\
\hline Childs 1964 & 25 & $\begin{array}{l}\text { RT } 35-40 \mathrm{~Gy}+\text { saline vs RT } \\
35-40 \mathrm{~Gy}+5 \mathrm{FU}\end{array}$ & 5.4 vs $7.0 \mathrm{mo}$ & $11.6 \%$ vs $30.8 \%(\mathrm{P}=\mathrm{ns})$ \\
\hline Moertel 1969 & 64 & $\begin{array}{l}\text { RT } 35-40 \text { Gy vs RT } 35-40 \\
\text { Gy+5FU }\end{array}$ & 6.3 vs $10.4 \mathrm{mo}(\mathrm{P}<0.05)$ & $5 \%$ vs $25 \%$ \\
\hline Moertel 1981 & 194 & $\begin{array}{l}\text { RT 40Gy split + 5FU vs60 Gy } \\
\text { split+5FU vs } 60 \text { Gy split }\end{array}$ & 9.6 vs 9.2 vs $5.2 \mathrm{mo}(\mathrm{P}<0.01)$ & $\begin{array}{l}40 \% \text { vs } 40 \% \text { vs } 12 \%(\mathrm{P}< \\
0.01)\end{array}$ \\
\hline Hazel 1981 & 30 & $\begin{array}{l}5 \mathrm{FU}+\mathrm{CCNU} \text { vs RT } 46 \mathrm{Gy+} \\
5 \mathrm{FU}+\mathrm{CCNU}\end{array}$ & $7.8 \mathrm{mo} v \mathrm{vs} 7.8 \mathrm{mo}(\mathrm{P}=\mathrm{ns})$ & \\
\hline Klaassen 1985 & 91 & $5 \mathrm{FU}$ vs $\mathrm{RT} 40 \mathrm{~Gy}+5 \mathrm{FU}$ & 8.2 vs $8.3 \mathrm{mo}(\mathrm{P}=\mathrm{ns})$ & $28 \%$ vs $30 \%$ \\
\hline GITSG 1985b & 157 & $\begin{array}{l}\text { RT 60Gy split + 5FU vs 60Gy } \\
\text { split +adriamycin }\end{array}$ & $8.4 \mathrm{mo}$ vs $7.5 \mathrm{mo}(\mathrm{P}>0.8)$ & \\
\hline GITSG 1988 & 42 & SMF + RT 54 Gy vs SMF & $10.5 \mathrm{mo}$ vs $8.0 \mathrm{mo}$ & $19 \%$ vs $41 \%(\mathrm{P}<0.05)$ \\
\hline Earle 1994 & 87 & $\begin{array}{l}\text { RT 40-60 Gy split + 5FU } \\
\text { vs RT 40-60 Gy split+ } \\
\text { hycanthone }\end{array}$ & 7.8 vs $7.8 \mathrm{mo}(\mathrm{P}=0.82)$ & $35 \%$ vs $28 \%$ \\
\hline
\end{tabular}

Chemotherapy and radiotherapy for inoperable advanced pancreatic cancer (Review)

Copyright @ 2007 The Cochrane Collaboration. Published by John Wiley \& Sons, Ltd 


\section{A N A L Y S E S}

Comparison 01. Chemotherapy versus best supportive care for advanced pancreatic cancer

\begin{tabular}{lcccc} 
Outcome title & $\begin{array}{c}\text { No. of } \\
\text { studies }\end{array}$ & $\begin{array}{c}\text { No. of } \\
\text { participants }\end{array}$ & Statistical method & Effect size \\
\hline 01 Mortality at 6 months & 7 & 425 & Odds Ratio (Fixed) 95\% CI & $0.37[0.25,0.57]$ \\
02 Mortality at 12 months & 7 & 425 & Odds Ratio (Fixed) 95\% CI & $0.46[0.25,0.84]$ \\
\hline
\end{tabular}

Comparison 02. 5FU alone versus another chemotherapy agent

\begin{tabular}{lcclc} 
Outcome title & $\begin{array}{c}\text { No. of } \\
\text { studies }\end{array}$ & $\begin{array}{c}\text { No. of } \\
\text { participants }\end{array}$ & Statistical method & Effect size \\
\hline 01 Mortality at 6 months & 4 & 312 & Odds Ratio (Fixed) 95\% CI & $0.58[0.37,0.92]$ \\
02 Mortality at 12 months & 4 & 312 & Odds Ratio (Fixed) 95\% CI & $0.67[0.34,1.31]$ \\
\hline
\end{tabular}

Comparison 03. 5FU alone versus $5 \mathrm{FU}$ chemotherapy combinations

\begin{tabular}{lcclc} 
Outcome title & $\begin{array}{c}\text { No. of } \\
\text { studies }\end{array}$ & $\begin{array}{c}\text { No. of } \\
\text { participants }\end{array}$ & Statistical method & Effect size \\
\hline 01 Mortality at 6 months & 8 & 842 & Odds Ratio (Fixed) 95\% CI & $0.79[0.59,1.05]$ \\
02 Mortality at 12 months & 8 & 842 & Odds Ratio (Fixed) 95\% CI & $0.90[0.62,1.30]$ \\
\hline
\end{tabular}

\section{Comparison 04. Gemcitabine versus another chemotherapy agent}

\begin{tabular}{lcccc} 
Outcome title & $\begin{array}{c}\text { No. of } \\
\text { studies }\end{array}$ & $\begin{array}{c}\text { No. of } \\
\text { participants }\end{array}$ & Statistical method & Effect size \\
\hline 01 Mortality at 6 months & 4 & 627 & Odds Ratio (Fixed) 95\% CI & $1.10[0.80,1.51]$ \\
02 Mortality at 12 months & 4 & 627 & Odds Ratio (Fixed) 95\% CI & $1.34[0.88,2.02]$ \\
\hline
\end{tabular}

Comparison 05. Gemcitabine versus gemcitabine chemotherapy combinations

\begin{tabular}{lcccc} 
Outcome title & $\begin{array}{c}\text { No. of } \\
\text { studies }\end{array}$ & $\begin{array}{c}\text { No. of } \\
\text { participants }\end{array}$ & Statistical method & Effect size \\
\hline 01 Mortality at 6 months & 14 & 3298 & Odds Ratio (Fixed) 95\% CI & $0.88[0.77,1.02]$ \\
02 Mortality at 12 months & 15 & 3390 & Odds Ratio (Fixed) 95\% CI & $0.89[0.76,1.05]$ \\
\hline
\end{tabular}

\section{N D X T ERMS}

\section{Medical Subject Headings (MeSH)}

Antineoplastic Agents [therapeutic use]; Combined Modality Therapy [methods]; Deoxycytidine [analogs \& derivatives; therapeutic use]; Fluorouracil [therapeutic use]; Pancreatic Neoplasms [*drug therapy; mortality; * radiotherapy]; Quality of Life; Randomized Controlled Trials 
MeSH check words

Humans

Title

Authors

Contribution of author(s)

Issue protocol first published

Review first published

Date of most recent amendment

Date of most recent

SUBSTANTIVE amendment

What's New

Date new studies sought but none found

Date new studies found but not yet included/excluded

Date new studies found and included/excluded

Date authors' conclusions section amended

Contact address

DOI

Cochrane Library number

Editorial group

Editorial group code

\section{COVER SHEET}

Chemotherapy and radiotherapy for inoperable advanced pancreatic cancer

Yip D, Karapetis C, Strickland A, Steer CB, Goldstein D

All reviewers were involved in the design of the protocol and in assessing the studies identified. Desmond Yip performed data entry and analysis. Desmond Yip and David Goldstein drafted the review manuscript and contributions were made to this by the other reviewers. All reviewers approved the final document.

$2000 / 1$

$2006 / 3$

24 May 2006

25 March 2006

Information not supplied by author

Information not supplied by author

01 December 2005

19 May 2005

02 December 2005

Dr Desmond Yip

Staff Specialist in Medical Oncology

Medical Oncology Unit

The Canberra Hospital

Yamba Drive

Garran

ACT

2605

AUSTRALIA

E-mail: dyip@med.usyd.edu.au

Tel: +61262442220

Fax: +61262444266

10.1002/14651858.CD002093.pub2

CD002093

Cochrane Upper Gastrointestinal and Pancreatic Diseases Group

HM-UPPERGI 
GRAPHS AND OTHER TABLES

Figure 0I. Funnel plot of chemotherapy versus best supportive care one year mortality

Review: Chemotherapy and radiotherapy for pancreatic cancer

Comparison: 01 Chemotherapy versus best supportive care for advanced pancreatic cancer

Outcome: $\quad 01$ Mortality at 6 months

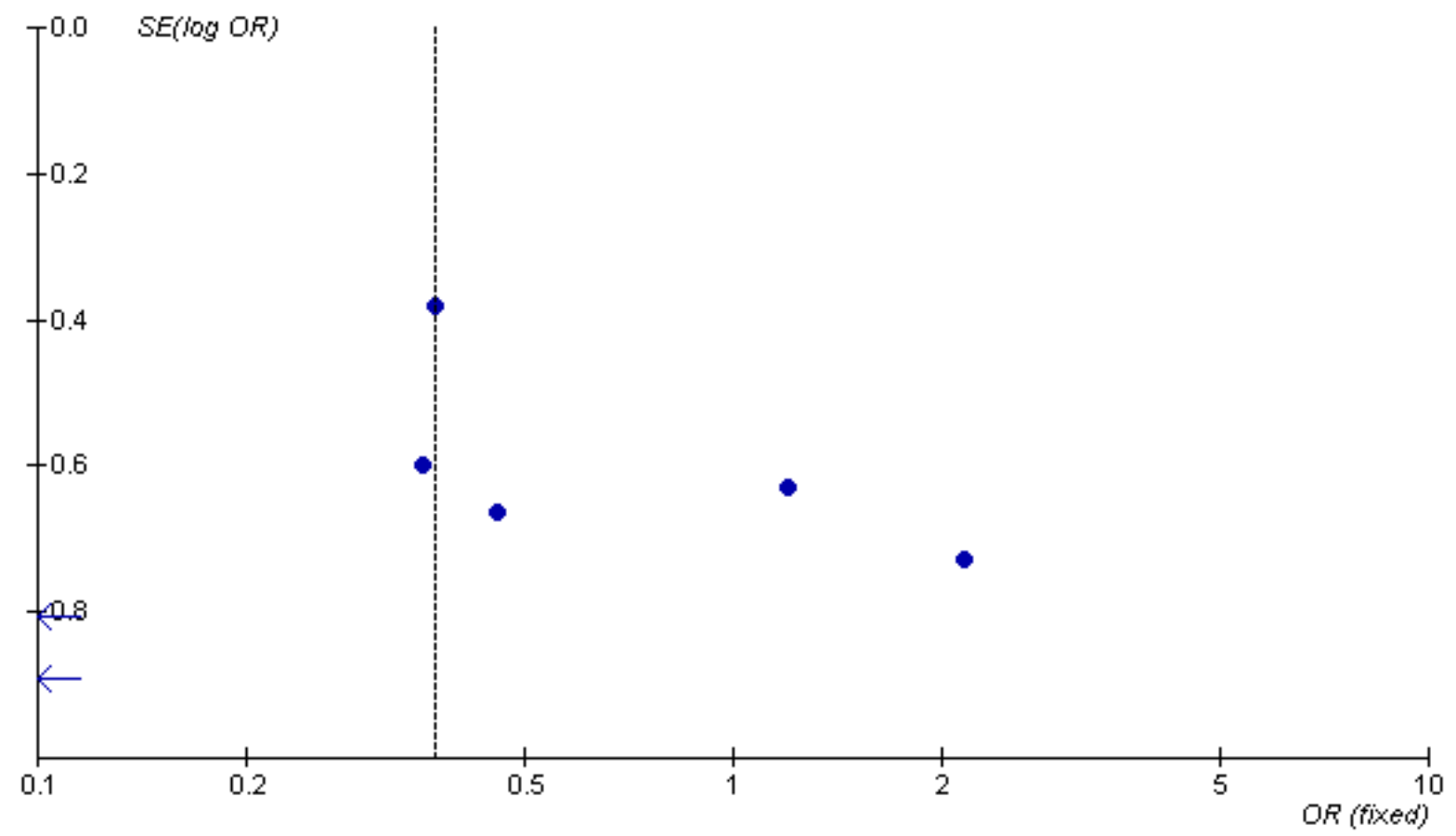


Figure 02. Funnel plot of six-month mortality in gemcitabine versus gemcitabine combination studies.

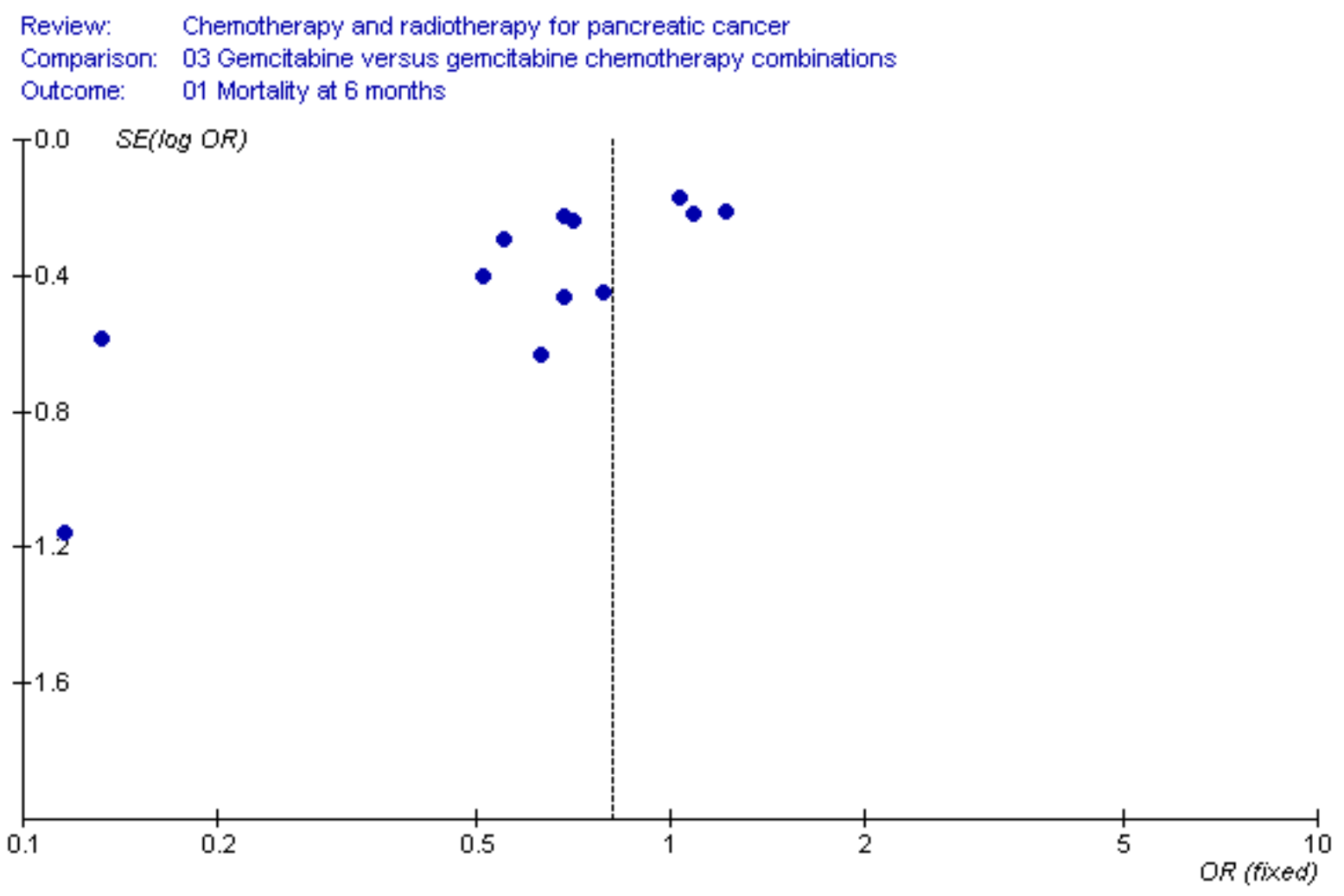


Analysis 01.0I. Comparison $0 \mathrm{I}$ Chemotherapy versus best supportive care for advanced pancreatic cancer, Outcome 01 Mortality at 6 months

Review: Chemotherapy and radiotherapy for inoperable advanced pancreatic cancer

Comparison: 0 I Chemotherapy versus best supportive care for advanced pancreatic cancer

Outcome: 01 Mortality at 6 months

\begin{tabular}{|c|c|c|c|c|c|}
\hline Study & $\begin{array}{c}\text { Chemotherapy } \\
n / N\end{array}$ & $\begin{array}{l}\text { Best supportive care } \\
n / N\end{array}$ & $\begin{array}{l}\text { Odds Ratio (Fixed) } \\
\qquad 95 \% \mathrm{Cl}\end{array}$ & $\begin{array}{c}\text { Weight } \\
(\%)\end{array}$ & $\begin{array}{c}\text { Odds Ratio (Fixed) } \\
95 \% \mathrm{Cl}\end{array}$ \\
\hline Glimelius 1996 & $15 / 29$ & $18 / 24$ & - & 12.8 & $0.36[0.11,1.16]$ \\
\hline Frey 1981 & $13 / 65$ & $35 / 87$ & & 32.2 & $0.37[0.18,0.78]$ \\
\hline Mallinson 1980 & $6 / 21$ & $17 / 19$ & - & 17.1 & $0.05[0.01,0.27]$ \\
\hline Andersen 1981 & $16 / 20$ & $13 / 20$ & & 3.5 & $2.15[0.52,9.00]$ \\
\hline Palmer 1994 & $5 / 23$ & $17 / 20$ & & 19.1 & $0.05[0.01,0.24]$ \\
\hline Takada 1998 & $8 / 28$ & $6 / 24$ & & 6.2 & $1.20[0.35,4.13]$ \\
\hline Huguier 200I & $5 / 22$ & $9 / 23$ & & 9.1 & $0.46[0.12,1.68]$ \\
\hline Total $(95 \% \mathrm{Cl})$ & 208 & 217 & & 100.0 & $0.37[0.25,0.57]$ \\
\hline \multicolumn{6}{|c|}{ Total events: 68 (Chemotherapy), I I 5 (Best supportive care) } \\
\hline \multicolumn{6}{|c|}{ Test for heterogeneity chi-square $=21.08 \mathrm{df}=6 \mathrm{p}=0.002 \mathrm{l}^{2}=71.5 \%$} \\
\hline Test for overall effe & $p<0.0000$ । & & & & \\
\hline
\end{tabular}

$\begin{array}{ccccc}0.1 & 0.2 & 0.5 & 1 & 2 \\ \text { Favours chemotherapy } & \text { Favours BSC }\end{array}$

Analysis 01.02. Comparison 01 Chemotherapy versus best supportive care for advanced pancreatic cancer, Outcome 02 Mortality at 12 months

Review: Chemotherapy and radiotherapy for inoperable advanced pancreatic cancer

Comparison: 0 I Chemotherapy versus best supportive care for advanced pancreatic cancer

Outcome: 02 Mortality at 12 months

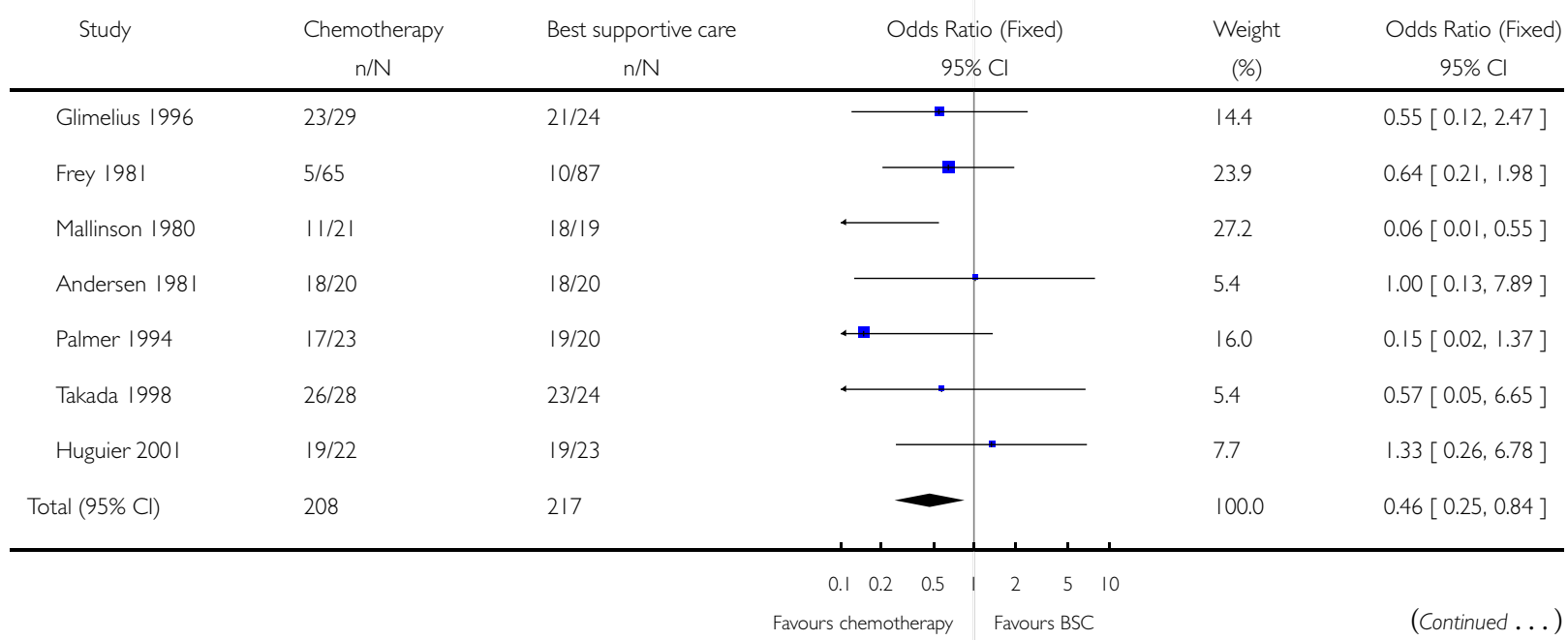

Chemotherapy and radiotherapy for inoperable advanced pancreatic cancer (Review) 


\begin{tabular}{ccccc} 
Chemotherapy & Best supportive care & Odds Ratio (Fixed) & Weight & Odds Ratio (Fixed) \\
$\mathrm{n} / \mathrm{N}$ & $\mathrm{n} / \mathrm{N}$ & $95 \% \mathrm{Cl}$ & $(\%)$ & $95 \% \mathrm{Cl}$ \\
\hline
\end{tabular}

Total events: 119 (Chemotherapy), 128 (Best supportive care)

Test for heterogeneity chi-square $=6.87 \mathrm{df}=6 \mathrm{p}=0.33 \mathrm{I}^{2}=12.6 \%$

Test for overall effect $z=2.53 \quad p=0.01$

$\begin{array}{lllllll}0.1 & 0.2 & 0.5 & 1 & 2 & 5 & 10\end{array}$

Favours chemotherapy Favours BSC

Analysis 02.01. Comparison 02 5FU alone versus another chemotherapy agent, Outcome 0 I Mortality at 6 months

Review: Chemotherapy and radiotherapy for inoperable advanced pancreatic cancer

Comparison: $025 \mathrm{FU}$ alone versus another chemotherapy agent

Outcome: 01 Mortality at 6 months

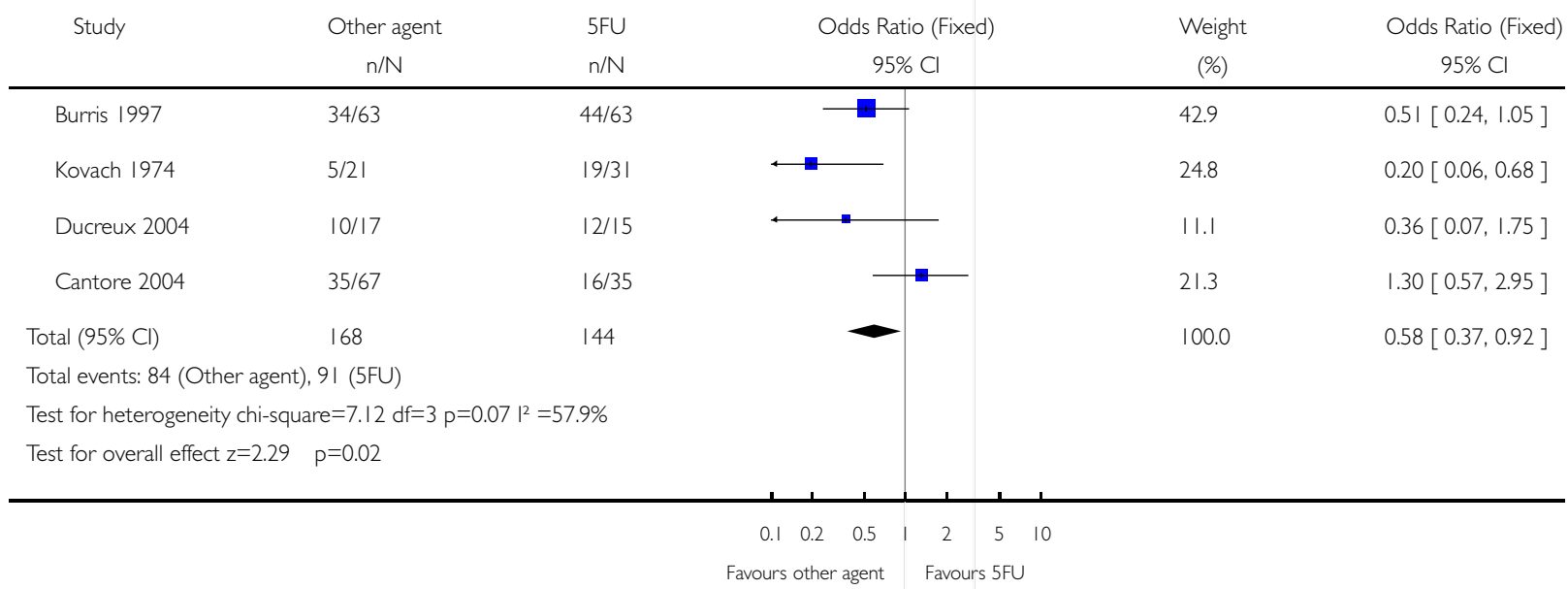


Analysis 02.02. Comparison 02 5FU alone versus another chemotherapy agent, Outcome 02 Mortality at 12 months

Review: Chemotherapy and radiotherapy for inoperable advanced pancreatic cancer

Comparison: 02 5FU alone versus another chemotherapy agent

Outcome: 02 Mortality at 12 months

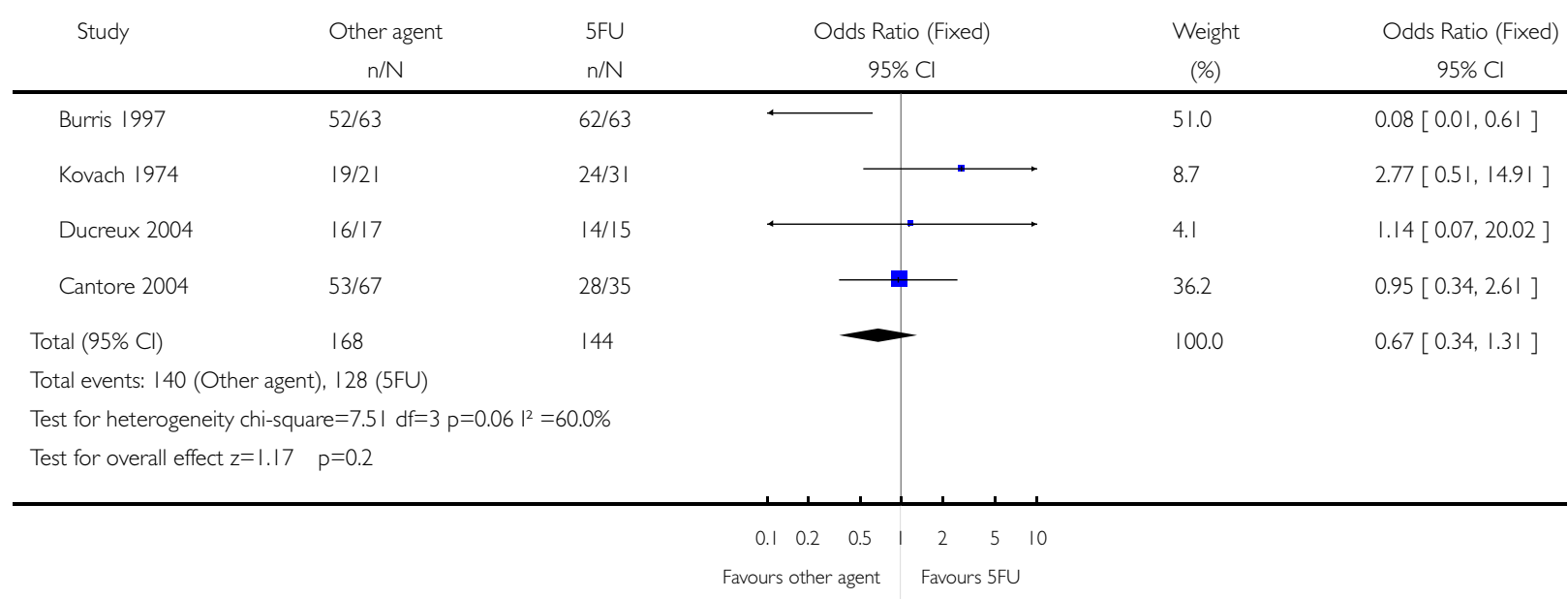

Analysis 03.01. Comparison 03 5FU alone versus 5FU chemotherapy combinations, Outcome 0I Mortality at 6 months

Review: Chemotherapy and radiotherapy for inoperable advanced pancreatic cancer

Comparison: $035 \mathrm{FU}$ alone versus 5FU chemotherapy combinations

Outcome: 01 Mortality at 6 months

\begin{tabular}{|c|c|c|c|c|c|}
\hline Study & $\begin{array}{l}\text { 5FU combinations } \\
\qquad \mathrm{n} / \mathrm{N}\end{array}$ & $\begin{array}{c}\text { 5FU alone } \\
n / N\end{array}$ & $\begin{array}{l}\text { Odds Ratio (Fixed) } \\
\qquad 95 \% \mathrm{Cl}\end{array}$ & $\begin{array}{c}\text { Weight } \\
(\%)\end{array}$ & $\begin{array}{c}\text { Odds Ratio (Fixed) } \\
95 \% \mathrm{Cl}\end{array}$ \\
\hline Ducreux 2002 & $73 / 99$ & $72 / 99$ & $\longrightarrow$ & 17.6 & $1.05[0.56,1.98]$ \\
\hline Maisey 2002 & $48 / 102$ & $59 / 107$ & $\longrightarrow$ & 28.4 & $0.72[0.42,1.25]$ \\
\hline Cullinan 1990a & $36 / 61$ & $18 / 32$ & - & 9.0 & $1.12[0.47,2.66]$ \\
\hline Cullinan 1990b & $38 / 59$ & $19 / 32$ & - & 8.2 & $1.24[0.51,3.00]$ \\
\hline Kovach 1974 & $11 / 30$ & 19/3| & 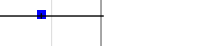 & 11.0 & $0.37[0.13,1.03]$ \\
\hline Ducreux 2004 & $8 / 31$ & $12 / 15$ & & 11.2 & $0.09[0.02,0.39]$ \\
\hline Cullinan 1985a & $27 / 44$ & $15 / 25$ & & 6.9 & $1.06[0.39,2.89]$ \\
\hline Cullinan 1985b & $31 / 50$ & $16 / 25$ & & 7.6 & $0.92[0.34,2.49]$ \\
\hline Total $(95 \% \mathrm{Cl})$ & 476 & 366 & & 100.0 & $0.79[0.59,1.05]$ \\
\hline \multicolumn{6}{|c|}{ Total events: 272 (5FU combinations), 230 (5FU alone) } \\
\hline \multicolumn{6}{|c|}{ Test for heterogeneity chi-square $=13.39 \mathrm{df}=7 \mathrm{p}=0.06 \mathrm{I}^{2}=47.7 \%$} \\
\hline Test for overall effe & $p=0.1$ & & & & \\
\hline
\end{tabular}

$\begin{array}{lllllll}0.1 & 0.2 & 0.5 & 1 & 2 & 5 & 10\end{array}$

Favours 5FU comb Favours $5 \mathrm{FU}$ alone

Chemotherapy and radiotherapy for inoperable advanced pancreatic cancer (Review) 
Analysis 03.02. Comparison 03 5FU alone versus 5FU chemotherapy combinations, Outcome 02 Mortality at 12 months

Review: Chemotherapy and radiotherapy for inoperable advanced pancreatic cancer

Comparison: 03 5FU alone versus 5FU chemotherapy combinations

Outcome: 02 Mortality at 12 months

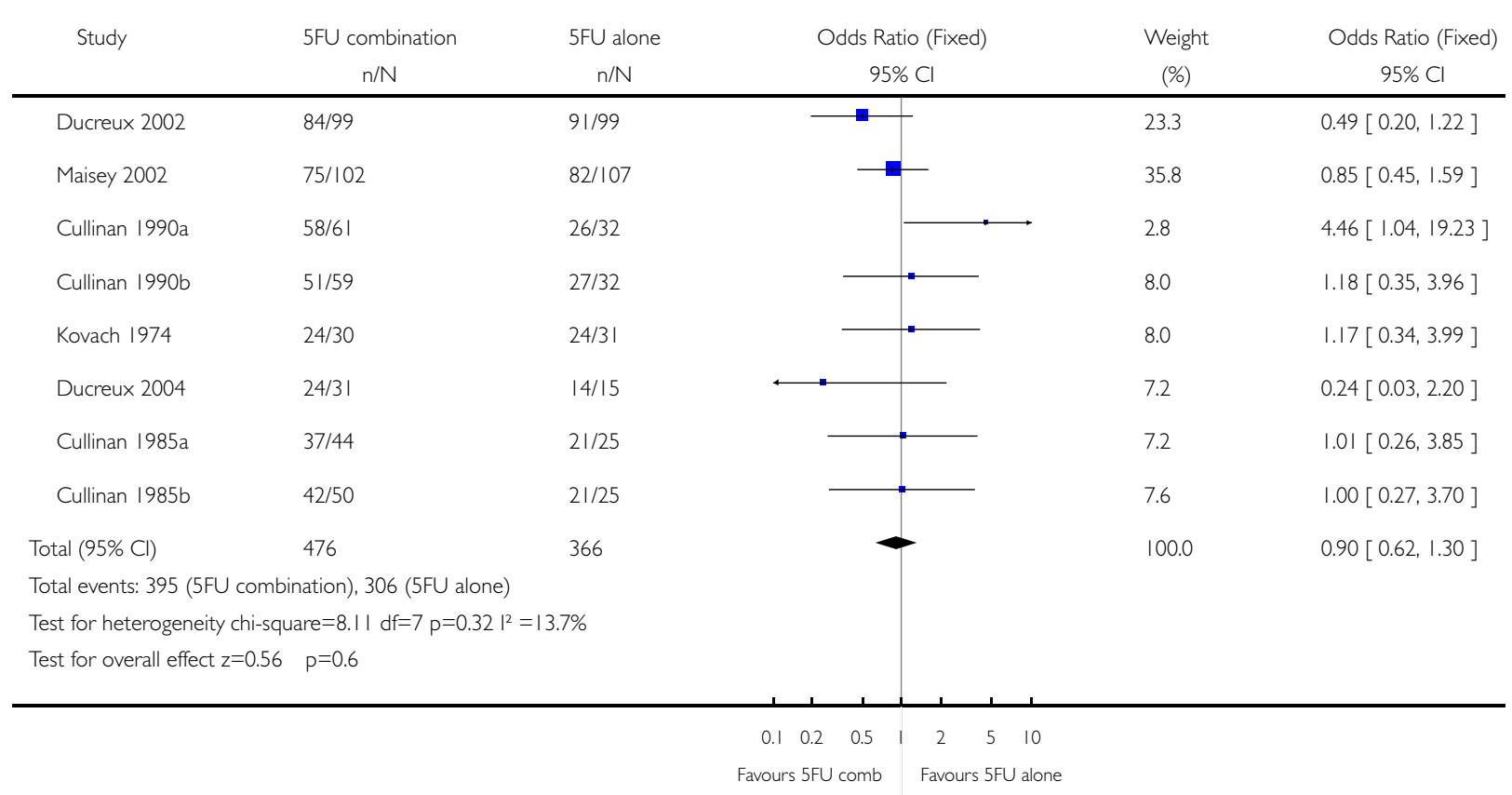

Chemotherapy and radiotherapy for inoperable advanced pancreatic cancer (Review) 
Analysis 04.01. Comparison 04 Gemcitabine versus another chemotherapy agent, Outcome 01 Mortality at 6 months

Review: Chemotherapy and radiotherapy for inoperable advanced pancreatic cancer

Comparison: 04 Gemcitabine versus another chemotherapy agent

Outcome: 01 Mortality at 6 months

Study Other agent

$\mathrm{n} / \mathrm{N}$

Odds Ratio (Fixed)

Weight

Odds Ratio (Fixed)

0I Gemcitabine versus fluorouracil

Burris 1997

$44 / 63$

Cantore 2004

$16 / 35$

Subtotal $(95 \% \mathrm{Cl})$

98

Total events: 60 (Other agent), 69 (Gemcitabine)

Test for heterogeneity chi-square $=2.83 \mathrm{df}=\mid \mathrm{p}=0.09 \mathrm{I}^{2}=64.6 \%$

Test for overall effect $z=0.96 \quad p=0.3$

02 Gemcitabine versus other agents

$\begin{array}{ccc}\text { Cheverton 2004 } & 94 / 169 & 83 / 170 \\ \text { Gansauge 2002 } & 11 / 30 & 22 / 30 \\ & 199 & 200\end{array}$

Total events: 105 (Other agent), 105 (Gemcitabine)

Test for heterogeneity chi-square $=9.29 \mathrm{df}=\mid \mathrm{p}=0.002 \mathrm{I}^{2}=89.2 \%$

Test for overall effect $z=0.05 \quad p=1$

Total $(95 \% \mathrm{Cl})$

$297 \quad 330$

Total events: 165 (Other agent), 174 (Gemcitabine)

Test for heterogeneity chi-square $=12.56 \mathrm{df}=3 \mathrm{p}=0.006 \mathrm{I}^{2}=76.1 \%$

Test for overall effect $z=0.60 \quad p=0.5$

$\mathrm{n} / \mathrm{N}$

$34 / 63$

$35 / 67$

130

00

n

95\% Cl

13.9

17.6

31.5

$1.98[0.95,4.10]$

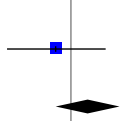

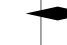

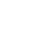

$0.77[0.34,1.75]$

$1.30[0.76,2.23]$

$\begin{array}{lllllll}0.1 & 0.2 & 0.5 & 1 & 2 & 5 & 10\end{array}$

Favours gemcitabine Favours 5FU 
Analysis 04.02. Comparison 04 Gemcitabine versus another chemotherapy agent, Outcome 02 Mortality at 12 months

Review: Chemotherapy and radiotherapy for inoperable advanced pancreatic cancer

Comparison: 04 Gemcitabine versus another chemotherapy agent

Outcome: 02 Mortality at 12 months

Study $\quad$ Other agent

Gemcitabine

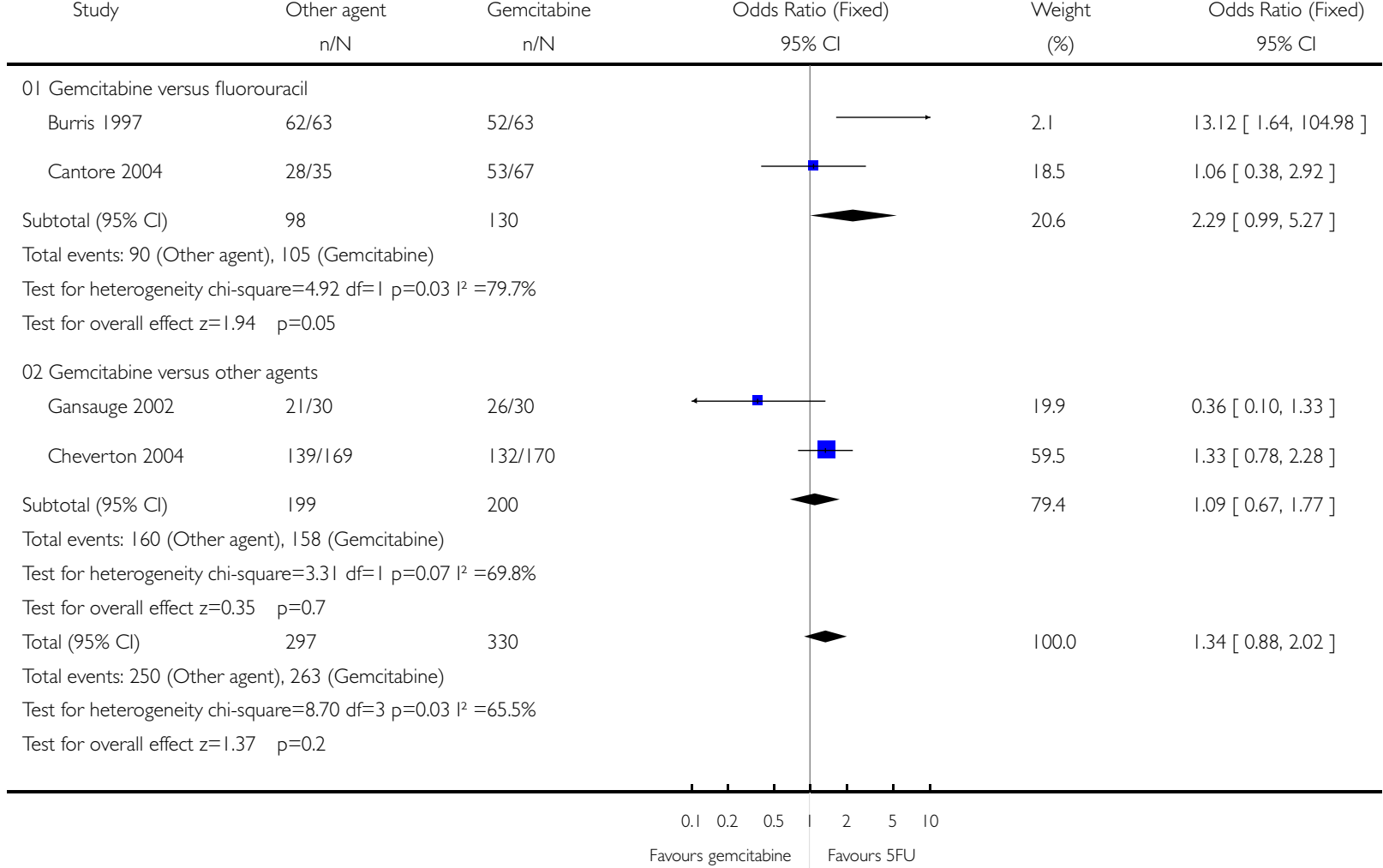


Analysis 05.0 I. Comparison 05 Gemcitabine versus gemcitabine chemotherapy combinations, Outcome 0 I Mortality at 6 months

Review: Chemotherapy and radiotherapy for inoperable advanced pancreatic cancer

Comparison: 05 Gemcitabine versus gemcitabine chemotherapy combinations

Outcome: 01 Mortality at 6 months

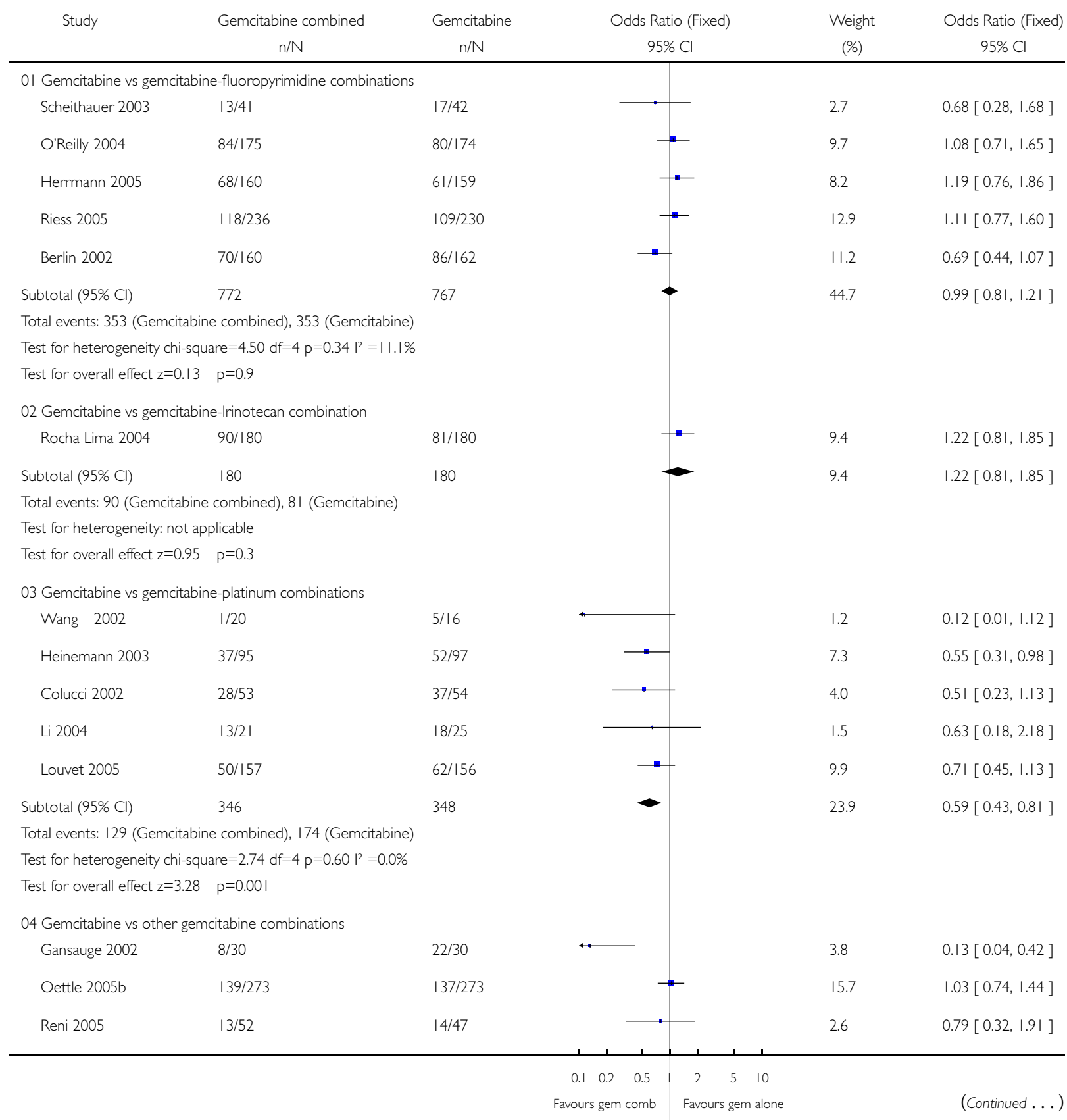

Chemotherapy and radiotherapy for inoperable advanced pancreatic cancer (Review) 


\begin{tabular}{|c|c|c|c|c|c|}
\hline Study & $\begin{array}{c}\text { Gemcitabine combined } \\
n / N\end{array}$ & $\begin{array}{c}\text { Gemcitabine } \\
n / N\end{array}$ & $\begin{array}{c}\text { Odds Ratio (Fixed) } \\
\qquad 95 \% \mathrm{Cl}\end{array}$ & $\begin{array}{l}\text { Weight } \\
(\%)\end{array}$ & $\begin{array}{c}\text { Odds Ratio (Fixed) } \\
95 \% \mathrm{Cl}\end{array}$ \\
\hline Subtotal $(95 \% \mathrm{Cl})$ & 355 & 350 & - & 22.0 & $0.85[0.63,1.14]$ \\
\hline \multicolumn{6}{|c|}{ Total events: I60 (Gemcitabine combined), 173 (Gemcitabine) } \\
\hline \multicolumn{6}{|c|}{ Test for heterogeneity chi-square $=11.45 \mathrm{df}=2 \mathrm{p}=0.003 \mathrm{I}^{2}=82.5 \%$} \\
\hline Test for overall effect $z=1.09$ & $p=0.3$ & & & & \\
\hline Total $(95 \% \mathrm{Cl})$ & 1653 & 1645 & $\bullet$ & 100.0 & $0.88[0.77,1.02]$ \\
\hline \multicolumn{6}{|c|}{ Total events: 732 (Gemcitabine combined), 78I (Gemcitabine) } \\
\hline \multicolumn{6}{|c|}{ Test for heterogeneity chi-square $=28.09 \mathrm{df}=13 \mathrm{p}=0.009 \mathrm{l}^{2}=53.7 \%$} \\
\hline Test for overall effect $z=1.75$ & $p=0.08$ & & & & \\
\hline
\end{tabular}

\section{Analysis 05.02. Comparison 05 Gemcitabine versus gemcitabine chemotherapy combinations, Outcome 02} Mortality at 12 months

Review: Chemotherapy and radiotherapy for inoperable advanced pancreatic cancer

Comparison: 05 Gemcitabine versus gemcitabine chemotherapy combinations

Outcome: 02 Mortality at 12 months

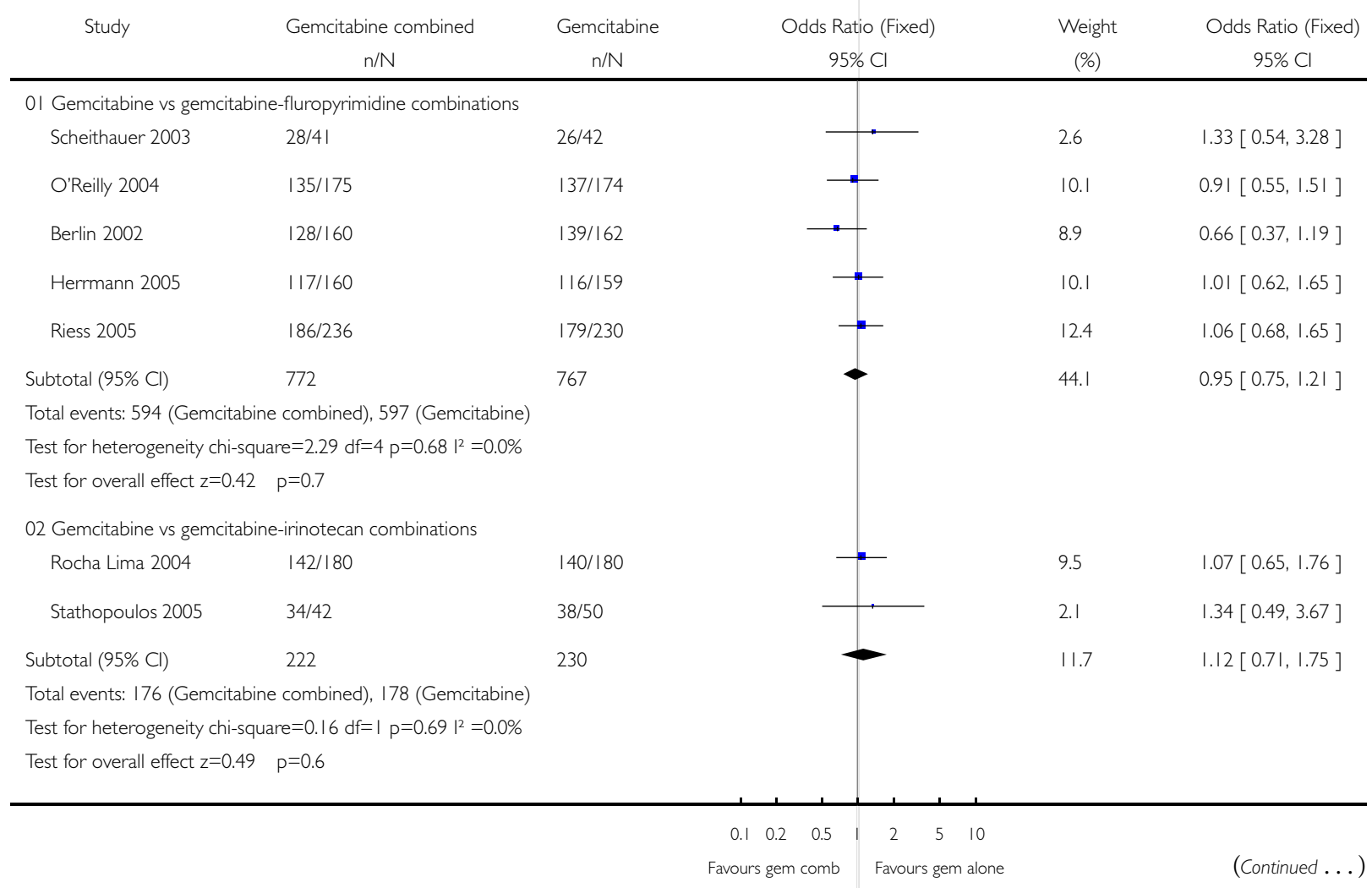


(... Continued)

\begin{tabular}{|c|c|c|c|c|c|}
\hline Study & $\begin{array}{c}\text { Gemcitabine combined } \\
n / N\end{array}$ & $\begin{array}{c}\text { Gemcitabine } \\
\mathrm{n} / \mathrm{N}\end{array}$ & $\begin{array}{c}\text { Odds Ratio (Fixed) } \\
\qquad 95 \% \mathrm{Cl}\end{array}$ & $\begin{array}{l}\text { Weight } \\
(\%)\end{array}$ & $\begin{array}{c}\text { Odds Ratio (Fixed) } \\
95 \% \mathrm{Cl}\end{array}$ \\
\hline \multicolumn{6}{|c|}{03 Gemcitabine vs gemcitabine-platinum combinations } \\
\hline Wang 2002 & $17 / 20$ & $11 / 16$ & - & 0.6 & $2.58[0.51,13.01]$ \\
\hline Colucci 2002 & $47 / 53$ & $48 / 54$ & & 1.7 & $0.98[0.29,3.25]$ \\
\hline Heinemann 2003 & $73 / 95$ & $78 / 97$ & - & 5.8 & $0.81[0.40,1.61]$ \\
\hline Li 2004 & $18 / 21$ & $23 / 25$ & & 1.0 & $0.52[0.08,3.46]$ \\
\hline Louvet 2005 & $103 / 157$ & $113 / 156$ & & 12.6 & $0.73[0.45,1.17]$ \\
\hline Subtotal $(95 \% \mathrm{Cl})$ & 346 & 348 & 4 & 21.6 & $0.81[0.57,1.16]$ \\
\hline \multicolumn{6}{|c|}{ Total events: 258 (Gemcitabine combined), 273 (Gemcitabine) } \\
\hline \multicolumn{6}{|c|}{ Test for heterogeneity chi-square $=2.46 \mathrm{df}=4 \mathrm{p}=0.65 \mathrm{I}^{2}=0.0 \%$} \\
\hline \multicolumn{6}{|c|}{ Test for overall effect $z=1.16 \quad p=0.2$} \\
\hline \multicolumn{6}{|c|}{04 Gemcitabine vs other gemcitabine combinations } \\
\hline Gansauge 2002 & 20/30 & $26 / 30$ & & 2.8 & $0.31[0.08,1.13]$ \\
\hline Oettle 2005b & $215 / 273$ & $218 / 273$ & & 14.9 & $0.94[0.62,1.42]$ \\
\hline Reni 2005 & $32 / 52$ & $37 / 47$ & 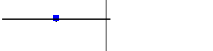 & 4.8 & $0.43[0.18,1.06]$ \\
\hline Subtotal $(95 \% \mathrm{Cl})$ & 355 & 350 & 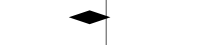 & 22.6 & $0.75[0.52,1.07]$ \\
\hline \multicolumn{6}{|c|}{ Total events: 267 (Gemcitabine combined), 28I (Gemcitabine) } \\
\hline \multicolumn{6}{|c|}{ Test for heterogeneity chi-square $=4.36 \mathrm{df}=2 \mathrm{p}=0.1 \mathrm{I} \mathrm{I}^{2}=54.1 \%$} \\
\hline \multicolumn{6}{|c|}{ Test for overall effect $z=1.58 \quad p=0.1$} \\
\hline Total $(95 \% \mathrm{Cl})$ & 1695 & 1695 & $\bullet$ & 100.0 & $0.89[0.76,1.05]$ \\
\hline \multicolumn{6}{|c|}{ Total events: 1295 (Gemcitabine combined), 1329 (Gemcitabine) } \\
\hline \multicolumn{6}{|c|}{ Test for heterogeneity chi-square $=1|.59 \mathrm{df}=| 4 \mathrm{p}=0.64 \mathrm{I}^{2}=0.0 \%$} \\
\hline Test for overall effect & $p=0.2$ & & & & \\
\hline
\end{tabular}

$\begin{array}{lllllll}0.1 & 0.2 & 0.5 & 1 & 2 & 5 & 10\end{array}$

Favours gem comb Favours gem alone 